Wright State University

CORE Scholar

2008

\title{
Analytic-Holistic Thinking, Information Use, and Sensemaking during Unfolding Events
}

Mei-Hua Lin

Wright State University

Follow this and additional works at: https://corescholar.libraries.wright.edu/etd_all

Part of the Industrial and Organizational Psychology Commons

\section{Repository Citation}

Lin, Mei-Hua, "Analytic-Holistic Thinking, Information Use, and Sensemaking during Unfolding Events" (2008). Browse all Theses and Dissertations. 869.

https://corescholar.libraries.wright.edu/etd_all/869

This Dissertation is brought to you for free and open access by the Theses and Dissertations at CORE Scholar. It has been accepted for inclusion in Browse all Theses and Dissertations by an authorized administrator of CORE Scholar. For more information, please contact library-corescholar@wright.edu. 


\title{
ANALYTIC-HOLISTIC THINKING, INFORMATION USE, AND SENSEMAKING DURING UNFOLDING EVENTS
}

\author{
A dissertation submitted in partial fulfillment of the \\ requirements for the degree of \\ Doctor of Philosophy
}

By

\section{MEI-HUA LIN}

M.S., Wright State University, 2004

B.S., The University of Iowa, 2000

2008

Wright State University 
I HEREBY RECOMMEND THAT THE DISSERTATION PREPARED UNDER MY SUPERVISION BY Mei-Hua Lin ENTITLED Analytic-Holistic Thinking, Information Use, and Sensemaking During Unfolding Events BE ACCEPTED IN PARTIAL FULFILLMENT OF THE REQUIREMENTS FOR THE DEGREE OF Doctor of Philosophy.

Helen Altman Klein, Ph.D. Dissertation Director

John M. Flach, Ph.D.

Chair, Department of Psychology

Joseph F. Thomas, Jr., Ph.D.

Dean, School of Graduate Studies

Committee on

Final Examination

Helen Altman Klein, Ph.D.

David M. LaHuis, Ph.D.

Herbert A. Colle, Ph.D.

Nathan A. Bowling, Ph.D. 


\begin{abstract}
Lin, Mei-Hua. Ph.D., Human Factors and Industrial/Organizational Psychology Program, Department of Psychology, Wright State University, 2008.

Analytic-Holistic Thinking, Information Use, and Sensemaking During Unfolding Events.
\end{abstract}

In complex domains such as commerce, military operations, transportation, and humanitarian efforts, practitioners are sometimes overwhelmed by uncertain, contradictory, and dynamic information. They must obtain, organize, interpret, and use this information often under time pressure and high stakes during sensemaking. While sensemaking is a gateway to information management, sensemaking also depends on information management; the gathering and use of information provides the raw material for sensemaking. These processes work together to help people understand complex situations but are vulnerable to cultural as well as individual variation in cognition. This study investigated individual cognitive and personality differences that may affect information management and sensemaking. Analytic-Holistic (AH) thinking was expected to influence information use and sensemaking (Lin \& Klein, 2008).

I investigated sensemaking using two scenarios in which dispositional and situational information was introduced sequentially. Each time new information, either dispositional or situational, was presented, participants identified problems and made decisions. I expected that analytic thinkers would make dispositional attribution and holistic thinkers would make situational attribution. Participants also selected and rated the relevance of the information presented. In addition, participants recalled information from an earlier scenario. I used moderated multiple regression analyses and correlation 
analyses to understand the relationships between individual differences, information use, and sensemaking.

Five important research findings emerged:

- Analytic-Holistic thinking was related to initial sensemaking judgments particularly with limited information. This suggests that when faced with a sensemaking opportunity, people are not a blank slate. They bring with them cognitive patterns, past experiences, and beliefs that both set a framework for sensemaking, and determine how information is selected, judged, interpreted, and remembered. This can interfere in situations when a common understanding is needed to deal with complex problems.

- Analytic and holistic thinkers used information differently during sensemaking. Holistic thinkers changed their sensemaking based on new information and were more influenced by the types of information presented. This relationship was weaker for analytic thinkers. The effect of $\mathrm{AH}$ thinking on information presented disappeared when new contradictory information was presented. While characteristic of a person was important in initial sensemaking, information content influenced sensemaking in the long run.

- In contrast to AH thinking, two personality variables, the Need for Cognitive Closure and the Need for Cognition, were more related to information recall than to information use and sensemaking. While people high in need for cognition recalled more information, people high in need for cognitive closure recalled less. The complex influences of individual variation in cognition and personality on sensemaking suggest the need for additional research. 
- Attribution, a component of AH thinking, was related to information use. It explained situational information use while overall AH thinking did not. This suggests the usefulness of $\mathrm{AH}$ thinking components for specific information use.

- The sensemaking context provided an opportunity to investigate information use and how people remember information. People who selected and rated dispositional information to be relevant remembered primarily this information. People who selected and rated situational information as more relevant recalled both situational and dispositional information. This suggests distinctive individual information management strategies. Some people considered the breadth of information during sensemaking while others focus on specific information.

This is a new research area that investigates the individual cognitive and personality differences in information use during sensemaking. The findings suggest the importance of understanding sensemaking over time, information management, and additional contextual and cultural factors. While this study has generated an initial understanding of this complex issue, more research is needed to describe the interplay of cognition, personality, and contextual constraints on the complexity of sensemaking and information management.

Organizations face many challenges. Like individuals, organizations need to make sense of their environment through effective information management. People in organizations must make sense of dynamic information that can fluctuate overtime. Organizations have people with different expertise, cognitive patterns, personalities, and cultural roots. Research in this area provides guidance for communication patterns, conflict resolutions, decision making, and information management. 


\section{TABLE OF CONTENTS}

I. INTRODUCTION.

Page

Challenges in Organizations...........................................

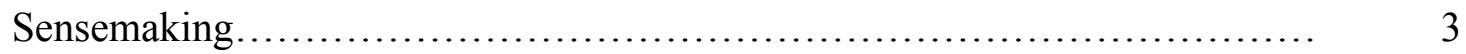

Weick's Approach................................................... 3

Klein et al.'s Data Frame Approach.................................... 4

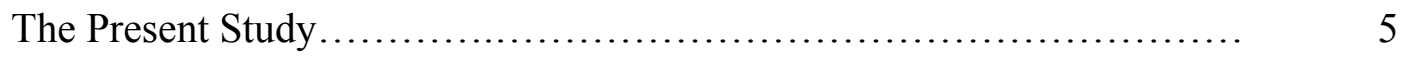

Problem Identification........................................

Decision.................................................... 8

Information Management............................................. 8

Information Properties............................................ 9

Type: Attributional information................................ 9

Amount (Quantity) ........................................... 11

Cultural Cognitive Dimension: Analytic-Holistic Thinking.................. 12

Globalization and Complexities..................................... 12

Analytic-Holistic Thinking........................................ 13

Analytic-Holistic Thinking, Information Management, and

Sensemaking.

Components of Analytic-Holistic Thinking ........................... 17

Attention: Field vs. Parts...................................... 17

Importance of context: Perceptual......................... 18

Importance of context: Information......................... 19

Relation to sensemaking.................................. 21 
Causal Attribution: Dispositional vs. Situational................. 22

Differences in causal explanation...................... 22

Information use in causal explanation...................... 24

Relation to sensemaking................................ 25

Contradiction: Differentiation vs. Dialectical.................. 26

Relation to sensemaking............................. 28

Personality Differences And Information Use.......................... 29

Need for Cognitive Closure.................................... 30

Need for Cognition........................................... 32

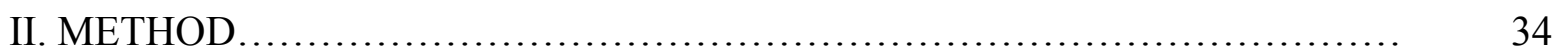

Research Design................................................. 34

Materials........................................................ 35

Sensemaking Assessment Package: Sensemaking Scenarios............. 35

Scenarios Assessment Development........................... 35

Final Sensemaking Assessment Scenarios...................... 36

Sensemaking Assessment Outcomes in Each Scenario............. 37

Problem identification ................................. 37

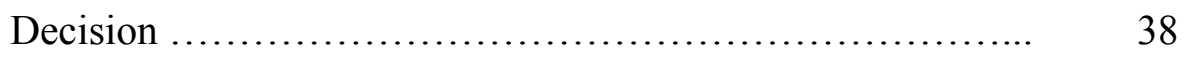

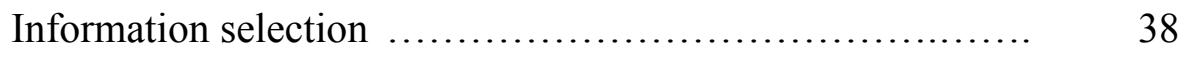

Categories of information selection $\ldots \ldots \ldots \ldots \ldots \ldots \ldots \ldots \ldots \ldots . . . \ldots$

Information Relevance .............................. 39

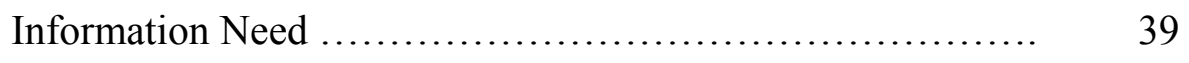

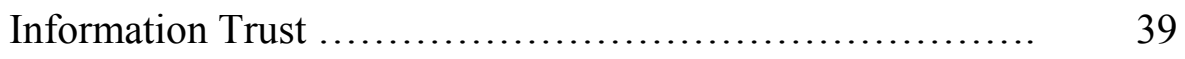


Sensemaking Assessment Package: Memory Recall Task................ 41

Coding.

Analytic-Holistic Scale (AHS) ................................. 43

The Need for Cognition Scale (NfCog) .......................... 44

The Need for Cognitive Closure (NFCC) ........................ 45

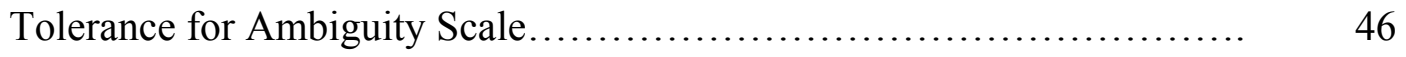

Demographics.............................................. 46

Procedure.......................................................... 46

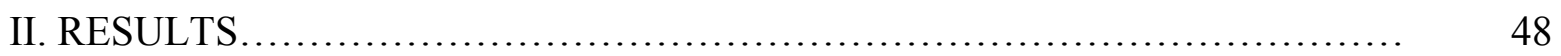

Sample and Scenario Characteristics................................. 48

Sample Characteristics......................................... 48

Scenario Differences.......................................... 48

Hypotheses Testing............................................. 50

Analytic-Holistic Thinking..................................... 50

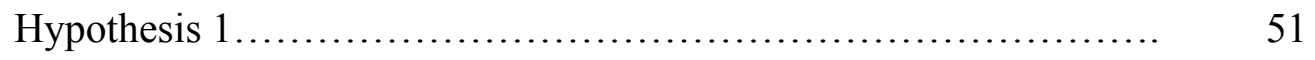

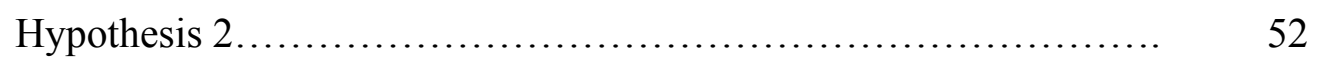

Situational PI judgment .............................. 52

Dispositional PI judgment ............................ 53

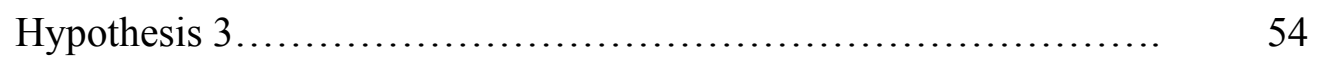

Situational PI judgment .............................. 55

Dispositional PI judgment ............................. 55

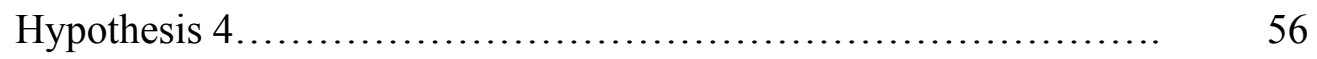




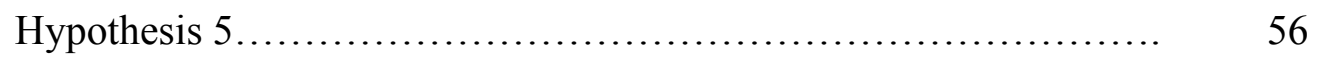

Situational decision judgment ............................. 56

Dispositional decision judgment .......................... $\quad 57$

Dispositional decision judgment: Analysis by scenario........ 58

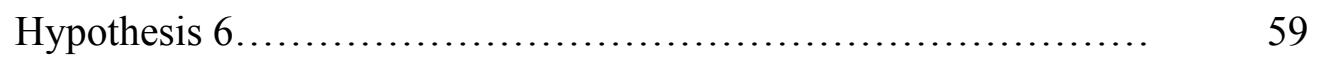

Situational decision judgment ........................... $\quad 59$

Dispositional decision judgment ......................... $\quad 60$

Dispositional decision judgment: Analysis by scenario ...... $\quad 60$

Components of AH Thinking ...................................... 62

Attention....................................................... 62

Causal Attribution.............................................. 63

Tolerance for Contradiction................................... $\quad 65$

Individual Personality Differences..................................... 67

The Need for Cognitive Closure................................... 67

The Need for Cognition............................................. 69

Additional Analysis.................................................... 71

Relationships Among Individual Differences Scales.................... $\quad 71$

Memory Recall................................................. 73

Memory Recall and Individual Differences...................... $\quad 74$

Memory Recall and Information Selection....................... $\quad 75$

Memory Recall and Information Relevance...................... $\quad 76$

Memory Recall and Problem Identification and Decision............. $\quad 77$

Qualitative Sensemaking.......................................... 77 
IV. DISCUSSION ........................................................... 80

Summary of Findings................................................. 81

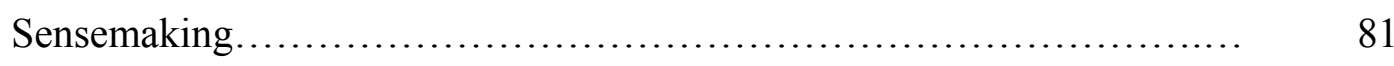

How is AH thinking related to sensemaking? ..................... 81

Does the joint effect of AH thinking and information presentation influence sensemaking? ...................................... 82

Do the components of AH thinking affect sensemaking? .............. 83

Does the joint effect of cognitive and personality differences influence sensemaking?

How do final PI and decision judgments relate to types of memory recall?

Qualitative Sensemaking...................................... 85

Information Management/Use..................................... 87

How do the components of AH thinking relate to information use?.... 87

How do personality differences relate to information use? ............ 88

Is memory recall related to information use? ...................... $\quad 89$

Do individual differences affect types of items recalled? ............. $\quad 90$

Limitations.............................................................. 91

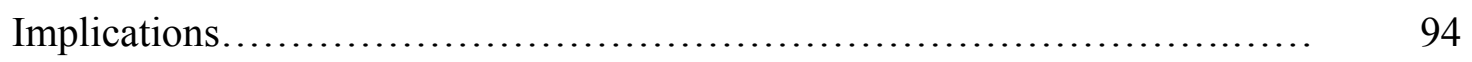

Theoretical Implications.......................................... 94

Practical Implications............................................. 95

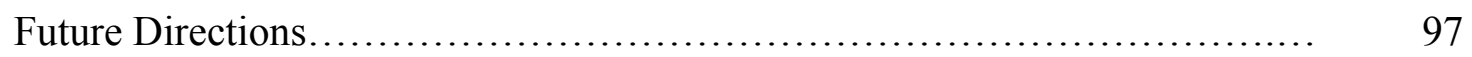

Analytic Holistic Thinking Construct................................ 97

Additional Information Characteristics.............................. $\quad 98$ 
Additional Cultural Dimensions ................................ 98

Contextual Factors................................................ 100

Naturalistic Investigation..................................... 101

V. CONCLUSION ....................................................... 102

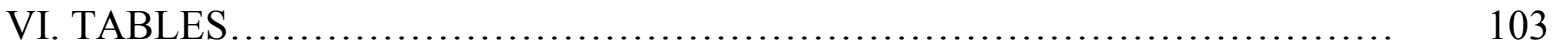

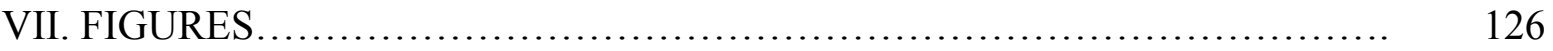

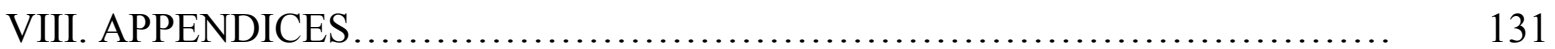

IX. REFERENCES ...................................................... 167 


\section{LIST OF TABLES}

Table

Page

1. Differences between Analytic and Holistic Thinking............................ 103

2. Design of Scenarios.................................................. 104

3. Overview of Measures.................................................. 105

4. Reliabilities of Outcome Measures..........................................106

5. Participant's Demographics.......................................... 107

6. Scenarios Comparison on Outcome Scores................................. 108

7. Individual Differences, Problem Identification, and

Decision Judgments for Combined Scenarios................................109

8. Hypotheses 2 and 3: Predicting Problem Identification (PI) Judgment

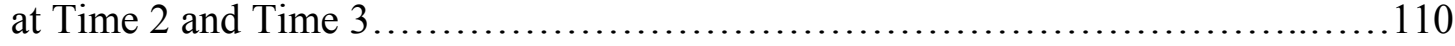

9. Hypotheses 5 and 6: Predicting Decision (PI) Judgment at Time 2 and Time 3.....111

10. Hypotheses 5 and 6: Predicting Decision (PI) Judgment at Time 2 and Time 3 for

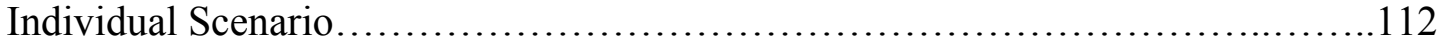

11. Individual Differences, Problem Identification, and Decision Judgments for Production Dilemma................................................... 113

12. Individual Differences, Problem Identification, and Decision Judgments for Westerly Foundation.............................................. 114

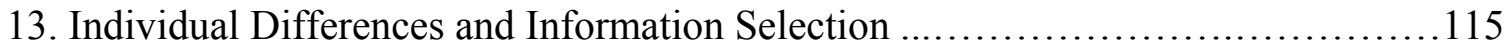

14. Individual Differences and Information Relevance ............................116

15. Individual Differences and Difference in Final Problem Identification

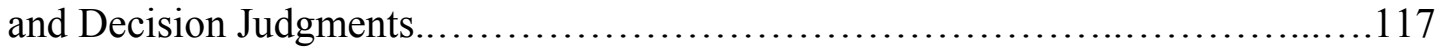

16. Hypotheses 16 and 17: Predicting Fundamental Attribution Error.................118

17. Individual Differences and Situational-Dispositional/Confirming-Disconfirming

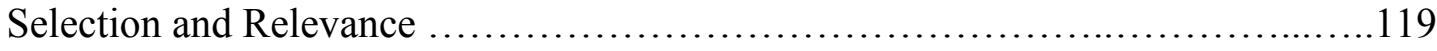

18. Individual Differences and Information Recall ................................ 120 
19. Information Recall, Information Selection, Information Relevance, Problem Identification, and Decision Judgments..........................................121

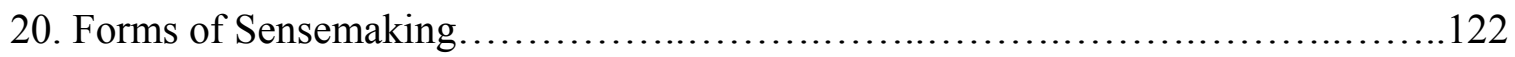

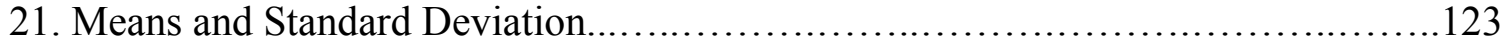




\section{LIST OF FIGURES}

Figure

1. A Framework of Individual's Sensemaking Process.............................126

2. Weick's General Model of Sensemaking.................................. 126

3. Sensemaking Activities represented in the Data Frame Model.........................127

4. Sections in Each Sensemaking Scenarios..........................................127

5. Simple slopes for high and low AH thinkers on Situational PI Judgment.................128

6. Simple slopes for high and low AH thinkers on Dispositional PI Judgment..............128

7. Simple slopes for high and low AH thinkers on Situational Decision Judgment.......129

8. Simple slopes for high and low AH thinkers on Dispositional Decision Judgment...129

9. Simple slopes for high and low AH thinkers on Dispositional Decision Judgment (WF) .................................................. 130

10. Simple slopes for high and low AH thinkers on Dispositional Decision Judgment (PD) 


\section{Acknowledgement}

I would like to extend special thanks to Dr. Helen Altman Klein for her invaluable guidance and time throughout this dissertation process. Thanks are also extended to Dr. David LaHuis, Dr. Herbert Colle, and Dr. Nathan Bowling for their helpful insight and support.

Next, I must thank my lab members, Katherine, Ashley, and Mel, were always there when I needed help. I am also grateful to Katy, my research assistant, for the time and effort she has devoted to my research.

To my dearest friends from my days in Iowa, Serina, Chin, Fabian, Jiun Ee, Alex, Gin Yee, Ricky, Zakia, and Moon, we are indeed the Perfect 10. Thank you for all these years of friendship and laughter.

To my very treasured friends I met in graduate school, Kyle, Anu, Markus, Charlene, Dan, Satomi, Pam, and Kevin. Thank you for the insight, encouragement, and the emotional support throughout the years. You understand the journey, taking it with you made life more interesting, exciting, and memorable; never ever a dull moment.

Finally, to my family, your heartfelt patience, understanding, and support are very much appreciated. You have shaped me while letting me define myself. Now, I can finally answer, "Yes, I’ve finished." 


\section{INTRODUCTION}

\section{Challenges in Organizations}

The advancement of technology has facilitated globalization and created a global flow of information. Globalization created opportunities as well as new challenges. People from distant lands are reachable, economies are becoming more interdependent, and problems around the world require and receive international involvement. Information is key to understanding and it is not static but rather dynamic and complex over time. Individuals in domains including national security, discoveries, and global business, use information to make sense of their dynamic environment and what changes mean for their organization.

The challenge of dynamic information flow has implications for how people manage information and how they make sense of it. Through sensemaking, they need to recognize and detect changes, anomalies, and problems. Sensemaking depends on the availability and interpretation of information from the information environment (Choo, 1998a). Information management is crucial for sensemaking as it provides the needed raw material. Both individual factors such as absorptive ability (Cohen \& Levinthal, 1990), attribution biases (Fiske \& Taylor, 1993), personality (Tetlock, 1992), cognitive style, and cognitive complexity (Hayes \& Allinson, 1998, 1994), and contextual factors such as social networks (Anderson, 2002), power, goals, and incentives and control systems (O’Reilly, 1983) may affect the information management process. They add to the complexity of information management and sensemaking. 
In a volatile environment, it is important for an organization to make sense of its internal and external environment to ensure survival. This means that organizations must interpret information in a way that will affect decision making and lead to productive actions. When sensemaking fails, businesses may fail, when it is successful, organizations can be adaptive. Similar to an organization, an individual decision maker needs to interpret information from his or her internal environment through sensemaking. Research is needed to examine variations in how and where decision makers obtain the information they use in decision making (Jones \& MacLeod, 1986).

This dissertation addresses how individual cognition affects information processes and sensemaking. Figure 1 represents the framework for this study. This framework is consistent with the notion that behavior is a function of an individual and his or her environment (Heider, 1958; Lewin, 1935). Here the behavior is the sensemaking outcome. The environment is defined as the internal and external information environment including contextual constraints (Anderson, 2002; O'Reilly, 1983). Individuals are described by their cognition and personality differences. In a complex environment individuals have to identify the problem and make decisions but are bounded by the context as well as by the information that is available. Individuals bring with them cognitive and personal tools that influence the judgment of the available information to affect their sensemaking.

In the following sections, I will first describe the general process of sensemaking, its importance, and its variations identified in the research literature. I will discuss two sensemaking outcomes: problem identification and decisions. Second, I present the complexities of information management. Here, I will explore the information 
manipulations used in this study. Third, I will describe how a cognitive dimension, Analytic-Holistic (AH) thinking and its four components, influence individual process information and sensemaking. Finally, I will describe how personality differences can influence information use. Two potentially important personality factors are presented. In the section following these, I will present the method, results, and discussion.

\section{Sensemaking}

Sensemaking refers to the placement of information into frameworks, the identification of surprises and anomalies, redressing problems as a situation changes, and constructing meaning, interacting in pursuit of understanding, and patterning (Weick, 1995). Individuals attend to the information from the external environment that is relevant to form possible explanations. As part of sensemaking, they identify and solve problems.

In dynamic environments, we face an unpredictable stream of changing events and information. While much of the available information may be ignored, some of it demands explanation, interpretation, and action. "Why did that happen?" "What does this mean?" "What should we do now?" We must organize, interpret, and use the information to make sense of continual changes but identifying what is relevant and what is just noise can be difficult (Choo, 1998b). People use their past experiences to reinterpret situations and to form possible explanations as new information becomes available.

\section{Weick's Approach}

Weick's general model of sensemaking suggests five key steps in the sensemaking process (see Figure 2) (Daft \& Weick, 1984; Huber, 1991; Milliken, 1990; Thomas, 
Clarke, \& Gioia, 1993). Sensemaking begins when a person notices or identifies a change, anomaly, surprise, problem, chaos or important issue in the stream of information (Milliken, 1990; Koppes \& Billings, 1988; Weick, Sutcliffe, \& Obstfeld, 2005). The recognition of any of these conditions can initiate the gathering of additional information (i.e. Hambrick, 1981, 1982; Thomas, Gioia, \& Ketchen, 1997). Categorizing information allows us to verify findings by comparing similar cases, past and present. This may suggest plausible explanations or propose effective actions. Information is interpreted as it is gathered (Thomas et al., 1997). Interpretation leads to actions or decisions (Daft \& Weick, 1984). Actions can produce changes in the environment or other performance outcome (Thomas, Shankster, \& Mathieu, 1994) that reflect the effectiveness of one's sensemaking. This in turn can lead to closure, propel additional actions, or suggest reinterpretations (Thomas et al., 1994). In this way, sensemaking is a dynamic and ongoing process.

\section{Klein et al. 's Data Frame Approach}

Klein, Phillips, Rall and Peluso (2007) suggested a data/frame model of sensemaking to describe the deliberate effort undertaken to understand events (see Figure 3). They proposed that incoming information suggests frames - mental models for organizing and understanding. These frames are similar to Minsky's (1975) notion of frames as structures for representing known situations. They may include information about dynamic relationships among components, expectations for the future, and appropriate actions. These frames, in turn, delineate what counts as data and guide the search for additional information. Contradictions and inconsistencies may provide cues for elaborating the frame or reconsidering previously discarded data (re-framing). If 
people cannot explain events by elaborating on their initial accounts, they may question their frame, perhaps reject it, and shift to another in their repertoire. People differ in how hard they work to preserve their original frame. They may, for example, be lured down a 'garden path' to explain away inconsistent data by deciding that the data is unreliable. They may also rebuild a new frame based on available data. Some people may track several frames simultaneously and, as events develop, compare these frames to find which one fits best. Both Weick's and Klein et al.'s frameworks identify crucial sensemaking processes. Their formulations suggested several questions about sensemaking and the variation it exhibits.

\section{The Present Study}

These different sensemaking models and approaches posit several important processes: detecting and identifying problem, information gathering and use, making sense of information for explanation, and taking actions or making decisions. They also represent the dynamic nature of sensemaking.

Based on the models, five points are important during sensemaking. First, during sensemaking, we have to identify the problem or anomaly in order to act on it (Weick, 1995). Identifying a problem is important but what is considered a problem may differ from one person to another. Hence, varying cognition and personality can influence problem identification. This is especially true when problems are ill-defined. When problem identification differs, sensemaking will also differ.

Second, when people are faced with an opportunity for sensemaking, they are not blank slates. Past experiences, beliefs, and values provide 'frames' to guide sensemaking (Klein et al, 2007). Hence, the availability of a frame may differ from one person to 
another. People use their past experiences to suggest frame(s) for a specific situation and these frames guide further exploration. When people have had different experiences, they are likely to use different frames.

Third, people may differ in what they count as causal explanation when trying to identify a problem. When causal explanations are broad, it is likely that additional factors will be considered as potential sources of problems. With increased potential sources of problems, causal explanation of an event may become more complex. People who differ in causal beliefs will accept different causal explanations (Nisbett, 2003). This difference is important because sensemaking explain ongoing events in a way that generates and shapes future actions.

Fourth, when gathering and using information during sensemaking, what is the range and the type of information, a person will consider during sensemaking. Even when there is a common goal for understanding, people vary in the scope and the types of information to which they attend. Because attention filters the raw material available, it is a critical step for sensemaking. Information is selected based on its relevance to the current state of the situation and the explanatory frames that are being used (Klein et al., 2007). Because people use differing frames, the information they select can differ. This means they have different material accessible for sensemaking.

Lastly, even when people have a good sense of a situation, new information may be presented. In dynamic situations, people can face contradictory information and this has been exacerbated with the advent of the Internet. People differ in how individuals differ in their openness to new and to contradictory information (Peng \& Nisbett, 1999). Inconsistent information propels the questioning and changing of frames during 
sensemaking. New contradictions may change problem identification as well as decisions.

In this study, these five points provided the guidelines for developing a sensemaking assessment tool. This assessment tool uses scenarios to simulate a sensemaking situation. Information is introduced sequentially. Sensemaking and information management processes were assessed periodically. Hence, the assessment tool has the following two characteristics. First, the scenarios probe for changes as well as for an understanding of those changes. The tool measured: quantitative and qualitative changes in sensemaking. Here, quantitative sensemaking describes the changes, and qualitative sensemaking is used to understand the reason for the changes. Two quantitative sensemaking outcomes were selected: Problem Identification (PI) and Decision (see oval 3 in Figure 1). The qualitative sensemaking is exploratory in this study. Second, information was presented sequentially (see oval 2 in Figure 1) to represent the nature of information gathering, information types, and information judgments. The section below describes the two quantitative sensemaking outcomes. The second characteristic, sequential information presentation, is described in a later section. Problem identification

Problem identification is a part of both making sense of an event and solving problems. To do this, individuals must attend to relevant information, form possible explanations from past experiences, and reinterpret situations with the new information. This study focused on two types of PI: dispositional and situational (oval 3 in Figure 1). Dispositional problems would suggest that factors affecting a problem are dispositions or internal characteristics of a person (e.g. abilities, motivations, personality, beliefs, 
intentions, etc.). Situational problems would suggest that factors other than the person affected a problem. These include situational forces that facilitated a problem (e.g. contextual constraints, time pressures, goals, etc.).

\section{Decision}

Decision making in complex dynamic situation is inherently biased; it is not based on comprehensive rationality where perfect information is used to maximize utility, and neither does it use information according to some specific and ordered preference. Instead, decision making involves imperfect expectations, limited and focused information search, selective perception, and information processing. This study focused on two types of decisions: dispositional and situational (oval 3 in Figure 1). A dispositional decision suggests a decision to solve the problem by taking action towards a person (e.g. firing, warning, training etc.). A situational decision suggests a decision to solve the problem by taking action towards the situation (e.g. changing company policy, changing structure, changing industry rules and regulations etc.).

Sensemaking uses available information. The effectiveness of sensemaking is as good as the available information. Thus, information management is crucial process for sensemaking. Below is a description of information management and information properties examined in this study.

\section{Information Management}

Individual information management processes are important for sensemaking and have high stakes. In organizations, managers must make important decisions by making sense of the internal and external environment (Weick et al., 2005). They have to sort through a flux of information to detect problems and make decisions based on the 
information at hand. However, a situation can change with new information, and managers may have to readdress, and redefine the problem, and make new decisions. These complex processes involve the interplay of many factors and constraints. Information provides the raw material for sensemaking, and the amount, type, and relevance of information may influence sensemaking, and vice-versa. This study simulated the challenges a person faces with sequential and varying information (oval 2 in Figure 1). It traces the changing of problem identification and decision judgments at each point when information was received.

\section{Information Properties}

Several factors influence the selection of information for processing or interpretation. First, attention influences the amount of information selected. A broader rather than focused attention provides a larger information pool. Second, information is selected or ignored depending on its perceived relevance. The more relevant it is, the more likely it would be interpreted. Perceived relevance, therefore, can influence the type of information selected for sensemaking. Third, following the theory of cognitive dissonance, individuals are more likely to use information that confirms their existing belief structures (Festinger, 1957). Hence, individuals with different belief structures or someone who is not susceptible to cognitive dissonance may select different information. Because of the implications of cognition on attention, relevance, and cognitive dissonance (Choi, Choi, \& Norenzayan, 2004; Choi \& Nisbett, 2000), I focused on two information properties: types of information and amount of information.

Type of information: Attribution

Two factors influence the types of attributional information people need. First, an 
individual's need for different types of information can be determined by his or her values, beliefs, previous experiences as well as a particular problem or a goal (O'Reilly, 1983). For example, one's initial frame or initial understanding of a situation not only influences what counts as explanation but also drives the search for particular information. Second, cognitive dissonance theory posits behavior-attitude consistency (Festinger, 1957). When faced with cognitive dissonance, a person can adopt ways to reduce the effectiveness of discrepant information from his or her current beliefs by derogating the source, excluding the source from communication, or distorting the information (O'Reilly, 1980). Hence, the use of attributional information may depend on its consistency with one's belief structures and one's susceptibility to cognitive dissonance.

In the present study, attributional information refers to information that contributed to how a person draws causal explanations. Information presented can be dispositional or situational in nature. Dispositional information is information that described personal attributes, such as personality, beliefs, feelings, and attitudes towards an event, object, or person (Bhawuk, 2001; Triandis, 1995). Situational information is information that described external cues such as information surrounding the person and how those cues influence events.

In order to simulate the challenges a person may face when incoming and varying information is received, the material designed in this study presented information at two points in time. Information presentation was manipulated based on the attributional characteristics described above. This manipulation, consistent with Figure 1, introduces the information environment or the contextual constraints available to the participant 
during sensemaking. While, the information presentation served as the manipulation, individuals might only use information that was relevant for judgments. Hence, this study also examined the extent to which each dispositional and situational information item was judged relevant for sensemaking.

\section{Amount (Quantity)}

Information management is a process for organizing information (Choo, 1998b). Information varies in amount. In this study, the amount of information is defined as the number of informational items selected by an individual during sensemaking. While the amount of information was not manipulated, it serves as a measure of information need. The dilemma for a person during a complex situation regarding information is: How much information do I need? How much can I retain? Is too little or too much information better? Shortage of information prevents the consideration of all the facts prior to making a decision. Excesses of information make it difficult to identify the most important and relevant information. In this information age, obtaining information can be quick but processing it may not be as rapid, so the concern may be overload not scarcity (Choo, 1998b; O’Reilly, 1980). Information explosion increases the difficulty of gathering and selecting the right kind of information, leading to a loss of sense (Weick, 1995). In order to manage information and avoid overloading, data from the external environment needs to be selected, organized, and interpreted with care. The important questions are: Will there be differences in how individuals with their limited capacities gather, select and integrate information from the vast amount available? How would these differences influence the sensemaking process? 
People differ in the amount of information they need. Some people might need more information before making decisions while others may avoid excess information. Because of different belief structures, they might have preferences for different kinds of information in varying amounts. Consistent with the earlier types of information, this study also examined the amount of dispositional and situational information needed for sensemaking.

In the previous sections, I explained sensemaking and information management processes, then presented and suggested ways to tap sensemaking outcomes and important information characteristics that individuals may prefer. In the next section, I explain how individuals may differ in their judgments of information and how that may affect sensemaking. As mentioned earlier, past experiences influence sensemaking. As individuals' experiences are embedded in a cultural context that influences their thinking (Berry, 1986; Hutchins, 1995; Klein, 2004), I propose cognitive patterns would affect the way they manage information and make judgments (see oval 1 in Figure 1). One purpose of this study was to examine the influence of a cultural cognitive dimension, $\mathrm{AH}$ thinking, on information processes (Choi et al., 2004) and sensemaking. While AH differences were found cross-culturally, AH thinking also varies a within group (Choi, Koo, \& Choi, 2007; Lin, 2004). Hence, the present study is the first study that examines AH difference within a national group in the context of information use and sensemaking. Cultural Cognitive Dimension: Analytic-Holistic Thinking

\section{Globalization and Complexities}

With globalization, an organization's environment becomes increasingly large and complex. Multinational interactions are important and inevitable. Teams are likely to 
be diverse and crucial to solving complex problems. As organizations span national borders, complications can arise with national differences in information management and sensemaking. Sensemaking, that is constructing meaning from what has been sensed about the environment, is problematic because information about the environment, especially in an international context, can be ambiguous and therefore subject to multiple interpretations. When people from different nations work together on complex problems; the processes underlying sensemaking can vary greatly. Each national group brings a distinct view of the world and different mental models and categories (Klein, 2004). Different causal frames for sensemaking can lead to different interpretations of situations (Bhagat, Harveston \& Triandis, 2002), different problems, and different decisions. Hence, a within group study without the variability introduced with national differences is the first step to understanding the complexities of sensemaking.

AH thinking distinguishes important differences in perception, judgment of information, and attribution. This study examined this dimension and its effect on information evaluation and sensemaking. AH thinking was treated as an individual difference in this study.

\section{Analytic-Holistic Thinking}

Analytic and holistic differences can be understood from two perspectives. First, the Ecocultural Model posits different ecological constraints facilitated field independentinterdependent and cognition (Berry, 1976). For example, groups who engaged in hunting and gathering exhibit field independent perception while those engaged in farming exhibit field dependent perception (Berry, 1986). These ecocultural constraints provided a lens through which members of a group see the world (Klein, 2004). 
A second perspective for understanding $\mathrm{AH}$ cognitive differences came from two ancient philosophic traditions: Greek Aristotelian philosophy and Chinese Confucius philosophy (Nisbett, 2003). The individual's sense of personal agency, tradition of debate, and social and political systems as well as different strategies to understand the world facilitated different cognition (see Cromer, 1993; Lloyd, 1991; Nisbett, 2003 for details). The Greeks Aristotelian philosophy facilitated analytic thinking and the Chinese Confucius philosophy cultivated holistic thinking. Analytic-Holistic Thinking, Information Management, and Sensemaking

A main difference between analytic and holistic thinkers is the inclusion of context. Holistic thinkers are more likely to include the context than analytic thinkers. This resulted in several differences (see Table 1). Analytic thinkers view the world as composed of separate elements that can be understood independently; they focus on objects and dispositions while holistic thinkers focus on the relationships among different elements and context (Nisbett, 2003; Nisbett, Choi, Peng, \& Norenzayan, 2001).

Choi, Koo, and Choi (2007) proposed four components subsumed under AH thinking. These components provided the conceptual basis for the present analysis. Attention defines the scope of information considered or needed: Analytic thinkers focus on central features in the field while holistic thinkers attend to the field as a whole. Causal Attribution directs the search for explanations to situational or dispositional causes. Analytic thinkers target dispositional causes while holistic thinkers also include situational causes. Tolerance for Contradiction describes the difference between analytic differentiation - polarizing goals and options to define the most important on one hand, and holistic naïve dialecticism - merging goals and options by synthesis on the other. 
Perception of Change describes beliefs about change, whether phenomena are viewed as linear by analytic thinkers or as cyclical, non-static patterns by holistic thinkers. These differences in cognition can influence sensemaking. These components provide a general understanding of $\mathrm{AH}$ thinking and are described later in detail (also see Lin \& Klein, 2008 for a comprehensive review). Perception of Change will not be followed through as no hypothesis was formed based on this component.

One goal of this study was to examine how Analytic-Holistic orientations in cognition influence the way people view information and use it in PI and making decisions. In the present study, a problem or an anomaly can be attributed to the dispositions of a person or the characteristics of a situation. Similarly, a person can make the decisions to take action with the person or to make changes to the situation. These PI and decision judgments were measured four times in the study. Because of differences in belief structures about causes, I expect higher holistic thinking tendencies will have higher initial situational PI and initial decisions judgments (Hypotheses 1 and 4). Because holistic people consider both situational and dispositional information in making attributions, no hypotheses on initial dispositional judgments were included. The overall score on the Analytic-Holism Scale (Choi et al., 2007) was used to define analyticholistic tendency. A higher score indicates holistic thinking. The specific hypotheses based on the contribution of $\mathrm{AH}$ thinking are as follow:

H1: Analytic-Holistic (AH) scores will be positively correlated with initial situational problem identification judgment.

Because of the differences in attention scope, belief in causal structure, and different strategies dealing with information, I expect analytic and holistic thinkers to 
vary in their information use at each introduction of new information, resulting in different PIs and decisions during sensemaking. In order to examine how analytic and holistic thinkers use information to affect judgments, consistent with the framework in Figure 1, a person's analytic-holistic tendency will affect the use of certain information to make sense of the situation. Because holistic thinkers orient to the context, they are more inclusive in their information use. Below are the hypotheses that test $\mathrm{AH}$ thinking as a moderator of information presentation (IP) and judgments. Influences will be reflected in the judgment of PI (Hypotheses 2 and 3) and decisions (Hypotheses 5 and 6) after new information is presented.

H2: The interaction between AH score and Information Presentation (IP) 1 will significantly affect both situational and dispositional problem identification (PI) judgments in Time 2, after controlling for PI judgments in Time 1, IP 1, and AH score. The slope between IP 1 and both situational and dispositional PI judgments in Time 2 will be steeper for people high in holistic thinking than people low in holistic thinking. ${ }^{1}$ See Footnote

H3: The interaction between AH score and IP 2 will significantly affect both situational and dispositional PI judgments in Time 3, after controlling for PI judgments in Time 2, IP 2, and AH score. The slope between IP 2 and both situational and dispositional PI judgments in Time 3 will be steeper for people high in holistic thinking than people low in holistic thinking.

\footnotetext{
${ }^{1}$ A visual misrepresentation of the slopes was inconsistent with the conceptual logic of the relationship between Analytic-Holistic Thinking and information use. The hypothesis on simple slopes analysis was changed to reflect the logic of the hypothesis. The subsequent Hypotheses 3, 5, and 6 also reflected this change.
} 
H4: AH score will be positively correlated with initial situational decision judgment.

H5: The interaction between AH score and IP 1 will significantly affect both situational and dispositional decision judgments in Time 2, after controlling decision judgments in Time 1, IP 1, and AH scores. The slope between IP 1 and both situational and dispositional decision judgments in Time 2 will be steeper for people high in holistic thinking than people low in holistic thinking.

H6: The interaction between AH score and IP 2 will significantly affect both situational and dispositional decision judgments in Time 3, after controlling decision judgments in Time 2, IP 2, and AH score. The slope between IP 2 and both situational and dispositional decision judgments in Time 3 will be steeper for people high in holistic thinking than people low in holistic thinking.

\section{Components of Analytic-Holistic Thinking}

The three components, Attention, Causal Attribution, and Tolerance for Contradiction, considered in this study stem from the AH distinction (i.e. Nisbett, 2003; Nisbett et al., 2001). I define each component; describe the supporting research; outline

implications to information management and sensemaking in the following sections, and present the research hypotheses.

Attention: Field vs. Parts

Attention helps define the scope of information available for consideration, and this may limit the information available for sensemaking in a complex environment. 
Consistent with early mother-child communication patterns, holistic thinkers look towards the relationship between the object and the field (Fernald \& Morikawa, 1993). This leads to attention to the whole picture and emphasizing relationships and interconnections, a more field interdependent view. Analytic thinkers look to individual objects rather than to the field as a whole (Fernald \& Morikawa, 1993). The focus is on individual parts, a more field independent view.

Importance of context: perceptual. Several studies have measured the differences in attention using field dependence, a measure of the extent to which people differentiate objects from the context (Masuda \& Nisbett, 2001; Witkin, Lewis, Hertzman, Machover, Meissner, \& Karp, 1954). Cross-cultural research in attention and cognition had shown that holistic thinkers were more field-dependent and analytic thinkers more field independent (Nisbett, 2003). Masuda and Nisbett (2001) found that Japanese participants, typically holistic thinkers, recalled more contextual information (i.e. background stimuli), and relationships among objects than were American participants, typically analytical thinkers. Japanese were also better than Americans at remembering objects with original presented backgrounds than when objects were placed with novel backgrounds. This further support the hypothesis that holistic thinkers had difficulty in separating objects from their context. In other studies, East Asians were also found to be more context or field dependent than Westerners (Kitayama, Duffy, Kawamura, \& Larsen, 2003; Masuda \& Nisbett, 2006; Miyamoto, Nisbett, \& Masuda, 2006). East Asians included contextual information while Westerners attended to focal information at the expense of contextual information. 
This attentional difference is further supported in a study of the activation of frontal and parietal brain regions associated with attentional control (Hedden, Ketay, Aron, Markus, \& Gabrieli, 2008). Activation was greater when individuals were given a culturally non-preferred judgment task than a culturally preferred judgment task, indicating a greater need for attention for the unfamiliar task. They found consistent results with between and within cultural group comparison.

Differences in attention were not limited to perception in the physical representation, but extended to emotional judgments in a social representation. Masuda and colleagues (2008) showed a sample of Americans and Japanese participants a central cartoon figure with either Happy, Neutral, or Sad facial expression together with four smaller background cartoon figures also with either Happy, Neutral, or Sad expression. East Asians modulated their judgments of the central figure by the emotions of the background figures while the Americans did not. If a neutral figure was surrounded by happy figures, the East Asians rated the figure as more happy. Their judgment of emotion reflected that they attended to the social context of the cartoon figure, not to the figure alone. Here again, holistic thinkers would have more peripheral social information available for later use. Klein and colleagues (2006) extended this finding with additional East Asian groups.

Importance of context: information. The role of attention was also seen when people made sense of a complex situation. People in individualistic cultures who see the 'self' as independent of the immediate social environment are more likely to focus on knowledge about personal attributes (Markus \& Kitayama, 1991). On the other hand, people in collectivistic cultures who see the 'self' as functioning within the immediate 
social environment are more likely to focus on external cues and how those cues influence events. In solving a complex computer simulated decision making task, Asian Indians and Germans were asked to take the role of a developmental aide worker and work to improve the conditions of a semi-nomadic tribe over time by requesting necessary information (Strohschneider \& Guss, 1999). Even though Indian participants generally asked for less information than the German participants, they asked for more background and contextual information, such as the social conditions, in their effort to accomplish the task.

In a similar study, Gelfand, Spurlock, Sniezek and Shao (2000), extended the role of attention to judgments of information usefulness. Participants were given relational or individual information about a target person across four situations. Chinese students saw relational information such as social groups, family, social class, as more useful for predicting own and target's behavior, whereas U.S. students favored individual information such as personal accomplishments. Because of this difference, it is likely that analytic and holistic thinkers would have different information available for sensemaking.

The role of attention was also seen when people were asked to establish a motive for an ambiguous situation. Choi, Dalal, Kim-Prieto, and Park (2003) found the broader attention associated with holistic thinking had implications for the amount of information one considered in a sensemaking situation. Americans, with their analytic thinking, excluded more information as irrelevant than did a sample of Koreans. The same difference was found when Americans were compared to samples of Japanese, Korean, and Taiwanese students (Klein et al., 2006). Consistent with the earlier findings, 
Westerners attended to a more focused range of information while East Asians attended to information that was more diverse.

Relation to sensemaking. Sensemaking starts with awareness of an anomaly or a problem. It continues to the selection and evaluation of a frame to provide a sense of the situation. When cultural groups differ in their attention to visual fields, to social contexts, and to problem spaces, they are likely to notice different anomalies. In addition, differences in attention and the reliance on context suggest that the relevance of information and the meaning of information may be influenced by context. When people vary in the range of information they consider relevant, they will have available different examples and counter examples for use in sensemaking. Holistic thinkers appear to use information more intuitively because they have more information available to consider. Analytic thinkers favor rule or cost-benefits analysis because they attend to a narrow set of information (Norenzayan, Smith, Kim, \& Nisbett, 2002). Taken together, attention directs PI and sets the stage for subsequent sensemaking.

Attention influences the scope of information pool for sensemaking. Analytic thinkers see each piece of information as relatively independent of its context (Markus, Kitayama, \& Heiman, 1996). In contrast, holistic thinkers looked for contextual cues in each piece of information (Kagitcibasi, 1997; Markus \& Kitayama, 1991; Triandis, 1995). In order to examine the range of information one considers during sensemaking, I hypothesized that holistic people with a wider attention scope will select more information (Hypothesis 7) and find this information to be more relevant (Hypothesis 8) during sensemaking while analytic people, with a more focused attention, will select less 
information. A higher attention score represents broader attention. Based on this reasoning, the hypotheses are:

H7: Attention scores will be positively related to the percentage of information items selected.

H8: Attention scores will be positively related to the rated relevance of available information.

\section{Causal Attribution: Dispositional vs. Situational}

Attribution describes how people assign cause (Heider, 1958) and this has implications for the selection and the use of information. Dispositional attribution identifies internal causes such as competence, personality, and values as most explanatory. Situational attribution looks also to external causal factors such as task demands, environment barriers, and surrounding people. Analytic thinkers typically attribute behavior to the actor's disposition while overlooking situational causes. Holistic thinkers use both situational and dispositional factors to identify the driving forces for behavior and events (i.e. Choi, Nisbett, \& Norenzayan, 1999; Lin, 2004; Morris \& Peng, 1994). Differences were also found in the way they use information to explain causes.

Differences in causal explanation. Research in Western settings finds that people attributed behavior to the actor's disposition, while giving less importance to situational causes of behavior (Fiske \& Taylor, 1993; Gilbert \& Malone, 1995; Gilbert, Pelham, \& Krull, 1988; Ross, Amabile, \& Steinmetz, 1977; Van Boven, Kamada, \& Gilovich, 1999). This contradicted the attribution theory that warned that one should not explain behavior with dispositions when it could be explained by the situation. The law of noncommon effects (Jones \& Davis, 1965) and discounting principal (Kelley, 1967) are 
examples that illustrate the attribution process. This tendency of attribution occurred so frequently that it was dubbed the 'fundamental attribution error' (FAE) (Ross et al., 1977) or correspondence bias (Gilbert \& Malone, 1995). In this study, dispositional attributors were expected to be more susceptible to this 'error.'

Three studies illustrate that people use different causal frames for explanation during sensemaking. First, Miller (1984) presented Americans and Hindu Indians with a scenario describing a motorcycle accident and asked "Why did the driver leave the passenger at the hospital without staying to consult about the seriousness of the passenger's injury?" Americans were more likely to attribute the behavior to the disposition of the driver, such as irresponsibility or the drive to succeed at work. The Indians, in contrast, were more likely to mention situational attributions, such as responsibilities and obligations at work. One accident, different attributions.

Next, Morris and Peng (1994) found different causal explanations for naturalistic events. They examined media treatment of two well-covered mass murders, one by a Chinese graduate student and the other by an Irish-American postal worker. The English language newspaper accounts reflected significantly more dispositional attributions such as "having a very bad temper," and "had repeatedly threatened violence." The Chinese language newspaper provided more situational explanations such as "was isolated from the Chinese community," and "followed the example of a recent mass slaying in Texas." A laboratory investigation of these probable causes was consistent with the journalistic report. American students included more dispositional causes and rated them as more important while the Chinese students included both dispositional and situational causes 
and rated both as important. Taken together, this research confirmed attribution differences.

Finally, Markus, Uchida, Omoregie, Townsend, and Kitayama (2006) showed differences in causal explanations of success. They examined Japanese and American media responses for explanations of Olympic performances. The Japanese medal winners responses to a journalist's question, "How did you succeed?" included more categories describing athletes' positive and negative personal attributes, but also more background, and social and emotional experience. American media accounts included fewer categories and emphasized positive personal characteristics and features of the competition. Result from a follow-up laboratory study found Americans chose dispositional information as relevant while the Japanese used more categories and found situational information more compelling to explain success. In all three examples, attribution guided the selection of causal frameworks, dispositional or situational, to explain events.

Information use in causal explanation. While causal frames influence the relevance of information, research also suggested the power of information to influence causal attribution differences. Choi and Nisbett (1998) manipulated situational information saliency to determine causal attribution. They found no differences between Koreans and Americans in dispositional attribution when situational information was limited, but Americans were more likely than Koreans to ignore information when situational information was salient. They stay with their dispositional frame while Koreans were likely to change frames by incorporating the situational information. In making sense of two organizational scenarios, Lin (2004) presented Malaysians and Americans with both dispositional and situational information in two scenarios. The 
study found Malaysians to be more holistic in their thinking than Americans. They remembered significantly more situational information and identified both dispositional and situational explanations while Americans rated situational causes as less likely than Malaysians. The different value placed on situational information would be expected to lead to different explanations during sensemaking.

Relation to sensemaking. Because people vary in the causal explanations they use, I expect them to begin with different causal frames, they attend to, value, and accept different information. They use information differently to explain situations and make predictions about later events (i.e. Choi et al., 1999; Choi \& Nisbett, 1998). These differences shape their sense of the problem space and direct decision making and planning.

Causal attribution influences the information selected and used for sensemaking. Dispositional attributors believe that causes are determined by the attributes of a person. The focus on dispositional information means they will consider less information and use fewer categories of information. Situational attributors believe in a causal interaction between the environment and the person. The focus on both dispositional and situational information will increase the information items selected. A higher attribution score represents a higher tendency for a situational causal explanation. The hypotheses are as follow:

H9: Causal attribution scores will be positively related to percentage of information items selected.

A consideration of the context by situational attributors increases the selection of situational information and the judgment of relevance during sensemaking. 
H10: Causal attribution scores will be positively related to the percentage of situational information items selected.

H11: Causal attribution scores will be positively related to mean of situational information rated as relevant.

To replicate Markus and colleagues (2006) study on categories of information, I hypothesized that situational attributors will use more categories during sensemaking.

H12: Causal attribution scores will be positively related to the number of categories of information selected.

\section{Contradiction: Differentiation vs. Dialectical}

Tolerance for Contradiction describes how people typically manage divergent information. The first approach, characteristic of analytic thinkers, uses differentiation and avoids contradictions whenever possible by polarizing goals and options (Peng \& Nisbett, 1999). Consistent with Western logical systems, where each statement must be true or false but not both, information, goals, and options are polarized to define the most important. The second approach uses naïve dialecticism. Holistic thinkers deal with contradiction dialectically by searching for the "Middle Way" between opposing propositions, retaining basic elements of each by synthesizing them. Holistic thinkers tolerate contradiction because they see truth in opposing views (Peng \& Nisbett, 1999).

Peng and Nisbett (1999) compared dialectical and non-dialectical proverbs from traditional Chinese and American cultural folk wisdom. Dialectical proverbs contain contradiction such as "beware of your friends not your enemy" while non-dialectical proverbs contain no contradiction such as "for example is not proof." The Chinese sources have four times as many dialectical as compared to American sources suggest 
contradiction plays a larger role in the Chinese folk wisdom. American participants preferred non-dialectical proverbs while the Chinese participants preferred dialectical proverbs. Similar results were obtained using Yiddish proverbs as a control for familiarity of proverbs.

Tolerance for contradiction influences openness to opposing positions during sensemaking. Choi and Nisbett (2000) investigated the judgment of contradiction using the Good Samaritan paradigm. Koreans and Americans reacted differently to a contradictory conclusion. Koreans, displayed more hindsight bias, showed less surprise when told a character described as religious, generous, and helpful but under time pressure and stress did not provide help to a victim. The Americans were more surprised with the conclusion which contradicted their expectation. The same finding was confirmed with a story where the target was described negatively but ended up performing a positive action.

To study this same distinction, Peng and Nisbett (1999) asked participants to judge how true pairs of contradictory statements were. The Chinese, thinking dialectically, judged two statements as non-contradictory and as parts of a whole rather than as dichotomous descriptions. They accepted the seeming contradictions as multiple perspectives of a single truth (Chu, Spires, \& Sueyoshi, 1999; Nakamura, 1985). In contrast, differentiating reasoning, typical of Westerners, seek constancy. Contradictory propositions were unacceptable by formal logic. Hence, contradictory statements cannot both be true. Propositions were considered in a restricted context rather than embedded in a broader context (Cromer, 1993). Thus, Westerners saw contradictory statements as 
opposing. They polarized contradictions, deciding which position was correct, and explaining away other positions.

Relation to sensemaking. During sensemaking, tolerance for contradiction may influence the way goals are chosen. Differentiation thinkers to seek the best goal may reduce cognitive dissonance by avoiding or quickly dismissing divergent information and options but may favor information that supports the goal. This simplification may reduce information overload (O'Reilly, 1980; Weick, 1979) but may also exclude information needed as new information emerges and existing frames are reexamined or changed. Dialectical thinkers seek to assimilate contradictory positions for an intermediate goal mean they are more comfortable with divergent information and experience less dissonance (Choi et al., 1999; Hiniker, 1969). Seeing more information as related (Choi et al., 2003), they seek to fit information to form a bigger picture of the complex situation. They may be more prone to information overload but may also be more prepared for changes and surprises. These differences between dialectical and differentiation reasoners provide conflicting paths in complex situations.

During sensemaking, information is used to reduce ambiguity (Weick, 1995). People who avoid opposing information may err in not considering alternate positions. People who are comfortable with contradiction may remain open to new information longer. They may track several frames simultaneously so that they can merge frames or modify them. Their readiness to change their sense of the situation and their decisions depending on the situation can prolong the sensemaking process. These differences can hinder collaboration when high tolerance people are more flexible in decision making and 
view the low tolerance people as rigid. Low tolerance people seek to complete work would view high tolerance people's flexibility as indecisive.

Tolerance for contradiction affects PI and decisions in sensemaking. People high in tolerance for contradiction believe that some truths exist in two opposing positions and may retain an intermediate position. They may not identify causes as conflicting and thus, may choose several approaches to solve the problem. During sensemaking, people who have a low tolerance for contradiction believe that two opposing views cannot be correct at the same time and will choose the cause that contributes most to the problem. This belief will also affect decision judgments. A higher score on tolerance for contradiction suggests a greater likelihood to synthesize opposing positions and prefer an intermediate solution. This leads to the following hypotheses:

H13: People with high tolerance for contradiction will show less absolute difference between their final dispositional and situational problem identification judgments than people with low tolerance for contradiction.

H14: People with high tolerance for contradiction will show less absolute difference between their final dispositional and situational decision judgments than people with low tolerance for contradiction.

\section{Personality Differences And Information Use}

People differ in their propensities for processing information. Several personality variables are associated with information processing (Anderson, 2002). People may handle the same information in different ways. They may prefer different forms of data and information, like different sources, and handle unreliable information in different ways. In addition, making sense out of this information can be overwhelming during time 
pressure and the changing environment. Personality differences can influence how people handle information during these situations and have implication on decision effectiveness (Anderson, 2002; Davenport \& Prusak, 1998). Hence, the need for cognitive closure and the need for cognition are included in this study to give a broader perspective on individuals' information selection and use.

\section{Need for Cognitive Closure}

Webster and Kruglanski (1994) defined the need for cognitive closure as a dispositional construct that is manifested through differences in desire for predictability, preference for order and structure, discomfort with ambiguity, decisiveness, and closemindedness. It is related to an individual's motivation with respect to information processing and judgment. Individuals motivated to attain cognitive closure were more likely to use early information in forming judgments compared with individuals motivated to avoid closure (Heaton \& Kruglanski, 1991; Kruglanski \& Freund, 1983). These individuals with high dispositional need for cognitive closure also considered less information before making judgments, yet they were more confident in their judgment and required less time to form it (Webster \& Kruglanski, 1994). They had the tendency to commit FAE (Hong, Morris, Chiu, \& Veronica, 2000) and were less susceptible to persuasion (Webster \& Kruglanski, 1994).

The need for cognitive closure has been linked to attribution. Chiu and colleagues (2000) found that dispositional attribution varies as a function of the need for closure. People with high cognitive closure were more likely to make attributions to individual dispositions whereas those with low cognitive closure made situational attributions. Consistent with this past research, I posit that cognitive closure will be related to the type 
of information considered during sensemaking. Because dispositional attribution may be an easier process (Winter, Uleman, \& Cunniff, 1985; Winter \& Uleman, 1984), those with high cognitive closure will look for dispositional information rather than for situational information (Knowles, Morris, Chiu, \& Hong, 2001) while those with low cognitive closure may equally attend to both kinds of information. A higher score represents a higher need for cognitive closure. This reasoning leads to the following hypothesis:

H15: Need for Cognitive Closure scores will be positively related to the percentage of dispositional information items selected.

As described earlier, the tendency to dispositional attribution in the presence of available situational explanation is called FAE. FAE is common in dispositional attributors (Gilbert \& Malone, 1995) and also in people with a higher need for closure (Webster, 1993). While research has shown that both individually contributed to FAE, I explore the joint effect of attribution and need for cognitive closure on FAE. Because individuals high in need for closure are motivated to achieve closure, they may be more likely to make dispositional attributions. Together with the tendency to make dispositional attribution, people high in both need for cognitive closure and dispositional attribution are more likely to be susceptible to FAE. This leads to the following hypothesis:

H16: There will be a significant interaction between Attribution scores and the Need for Cognitive Closure scores on final dispositional PI judgments. The slope between Attribution and final PI judgments will be steeper for people 
high in need for closure than people low in need for closure to reflect their dispositional tendency for PI.

\section{Need for Cognition}

The need for cognition describes the amount of thought an individual typically puts forth in daily activities (Cacioppo, Petty, Feinstein, \& Jarvis, 1996; Cacioppo \& Petty, 1982). Individuals high in intrinsic motivation to exercise their mental faculties are characterized as high in need for cognition (chronic cognizers) whereas individuals low in intrinsic motivation to engage in effortful cognitive endeavors are characterized as low in need for cognition (chronic cognitive misers) (Cacioppo et al., 1996). These individual differences were found to influence the acquisition or processing of information relevant to dilemmas or problems. High levels of cognition are found to be negatively related to the tendency to ignore, avoid, or distort new information (Venkatraman, Marlino, Kardes, \& Sklar, 1990). People high in need for cognition sought out, scrutinized, and used relevant information when making decisions and solving problems more than did people with low need for cognition (Berzonsky \& Sullivan, 1992).

Individuals with high need for cognition were more likely to seek information across domains. They were more likely to have acquired, thought about, and reflected back on information to make sense of events. In contrast, individuals with low need for cognition were more likely to rely on other people, cognitive heuristics, or social comparison processes. The need for cognition is expected to affect the amount of information gathered during sensemaking. A person with a lower need for cognition is likely to select less information items while someone with a higher need for cognition may want and select more information. Based on this research, I hypothesized: 
H17: The Need for Cognition scores will be positively related to the percentage of information items selected.

The relationship of the need for cognition and $\mathrm{AH}$ thinking might itself influence the tendency for a person to commit FAE. Because individuals high in need for cognition have the intrinsic motivation to process and consider more information, they may be less likely to make dispositional attributions. Because individuals high in holistic thinking will take the context into account when making judgments, they may also be less likely to make dispositional attributions. Together, people high on both need for cognition and holistic thinking are less likely to be susceptible to FAE. The reasoning leads to the following hypothesis:

H18: There will be a significant interaction between AH scores and Need for Cognition scores on the final dispositional PI judgments. The slope between AH scores and final PI judgments will be steeper for people low in need for cognition than people high in need for cognition to reflect their dispositional tendency for PI.

In the next section, I described the methods design to assess the changes in sensemaking and the materials used to tap individual differences described earlier in this study. 


\section{METHOD}

\section{Research Design}

This research used a mixed factorial design. There were two between subject factors and a within subject factor. The between subject factors were 2 (Scenario Order) $\mathrm{x}$ 2 (Information Presentation Order). Participants received the two scenarios in a counterbalanced order resulting in two scenario orders. In each scenario, dispositional (D) information and situational (S) information were presented sequentially to tap information use and change in judgments. The counterbalancing of information presentation order created two versions of information presentation in each scenario. One version began with information that suggested a dispositional cause followed by information that suggested a situational cause (D-S). In the other version, the order was reversed (S-D). Participants received both scenarios either in D-S order or S-D order.

The main order I am interested in is Information Presentation (D versus S). While the information presentation is different, the content in each scenario was the same. Each participant received both scenarios and the same content. Hence, all participants received the same materials, making a within subject factor.

The 2 (Scenario Order) x 2 (Information Presentation Order) design created four booklets. Participants were each given a booklet with one of the specific order shown in Table 2. For example, participants with Booklet 1 received Scenario 1 followed by Scenario 2, both with a D-S information presentation order in both scenarios. Participants also completed five questionnaires, a memory task, and a demographic sheet. 


\section{Materials}

There were two types of materials. Table 3 shows an overview of the measures used in this study. The first was the Sensemaking Assessment Package that included two unfolding scenarios, here labeled Sensemaking Scenarios, with questions inserted to assess the outcome measures, and a Memory Recall task. Different sections in each scenario presented the unfolding of the scenario. Figure 4 illustrates the five sections of a scenario where Sections A to E describe the sequences in the unfolding scenarios while the Response column in Table 3 shows what was measured in each Section.

The second type of material measured the predictor variables: Analytic-Holism Scale (AHS), Need for Cognition Scale (NfCog), Need for Cognitive Closure (NFCC), and Tolerance Ambiguity Scale (TAS). See Response column in Table 3 for the measures in each section of the questionnaires. Each of these measures is described in the section below.

\section{Sensemaking Assessment Package: Sensemaking Scenarios}

\section{Sensemaking Assessment Development}

The final sensemaking assessment was developed in six pilot studies. Pilot

Studies 1, 2, and 3 developed the sensemaking scenarios based on interviews, information development, and evaluation of scenarios and information. In Pilot Study 1, undergraduates were interviewed to find relevant scenarios and to understand the use of information. In Pilot Study 2, information for each scenario was developed from the interviews and earlier research materials (Lin, 2004). Undergraduates rated how relevant each information item was to dispositional cause and situational cause. Items were rewritten to clarify the scenarios. In Pilot Study 3, graduate students evaluated information 
items, overall scenarios for the balance and strength of information, and scenarios interest for undergraduates. Changes were made iteratively to refine scenarios.

Pilot Study 4 further developed the two scenarios into sensemaking assessments by incorporating the outcome measures: problem identification (PI) judgments, decision judgments, information selection, information relevance, information need, information trust, and qualitative sensemaking. In Pilot Study 5, the sensemaking assessments together with other measures used in the study were tested. Completion time was noted. A memory task was added. In Pilot Study 6, the sensemaking assessment package was finalized to incorporate needed improvement and changes for the final sensemaking assessment package for the study. See Appendix A for details of each pilot study.

\section{Final Sensemaking Assessment Scenarios}

Two sensemaking assessment scenarios were developed from the pilot studies, Production Dilemma (PD) and Westerly Foundation (WF). Production Dilemma involved a chaotic commercial production department and a CEO who wanted a fair report on the activities of the department. Westerly Foundation involved a non-profit organization that was facing a shortage of funds and the Board of Directors who wanted recommendation to solve the problem. See Appendix B for the two sensemaking scenarios.

As illustrated in Figure 4, there were five sections in each final scenario. Each scenario started with an initial problem presentation that suggested a dilemma between two possible causes, the particular person or the changes in the organization. Participants were asked to make the initial PI and decision judgments as to what they think happened and what they would decide to do [Section A]. They were then asked to select 
information from different categories of information to help make sense of the problem [Section B].

Each scenario then presented additional information that represented dynamic changes in the stories [Section $\mathrm{C}$ and $\mathrm{D}]$. Either information about the person is presented first, followed by changes in the situation, or vice-versa. In each scenario, there were thirteen items in each of the two information presentation manipulations with a total of 26 items. In the information presentation that suggested dispositional or person cause, there were eleven dispositional items and two situational items. In the information presentation that suggested a situational cause, there were eleven situational items and two dispositional items. In these sections, participants were asked to re-judge causes and decisions as they received the additional information, and they evaluated the relevance of the information presented at each point.

Participants were then presented all twenty six information items and they again selected information [Section E]. Here, they made the final PI and decision judgments. Ratings of information need and trust were also collected.

Sensemaking Assessment Outcomes in Each Scenario

As the sensemaking assessment generated the outcomes used to analyze the study hypotheses, it is important to describe how these outcomes were measured. See Appendix B for all items and Table 4 for combined and individual scenario reliabilities. Below are the descriptions of each outcome:

Problem identification. Two types of problems were identified: situational and dispositional. For items, three for each type of PI, participants were asked "How likely do you think that each of this is the problem? Rate from 1 (Not likely) to 7 (Most likely)." 
These were measured at four points in the scenario. Situational PI items reliabilities for the two combined scenarios from Time 1 to Time 4 were $.63, .72, .65$, and $.74(\mathrm{n}=6)$, respectively. Dispositional PI items reliabilities from Time 1 to Time 4 were $.79, .88, .83$, and $.81(\mathrm{n}=6)$, respectively.

Decision. There were two types of decisions: situational and dispositional. Six items measured the decisions, three for each type of decision. Participants were asked "How likely are you to recommend these actions? Rate from 1 (Not likely) to 7 (Most likely)." These were also measured four times. The reliabilities for the two combined scenarios from Time 1 to Time 4 were $.69, .75, .71$, and .73 for situational decision items $(\mathrm{n}=6)$ and $.71, .75, .67$, and .66 for dispositional decision items $(\mathrm{n}=6)$.

Information selection. There were two parts in the scenarios where information selection was assessed. The first information selection was before Information Presentation (IP) 1. Nine categories each with a range of 3-5 information items in each category were presented. A total of 36 items were presented. Participants were asked to "Mark ' $X$ ' for items that will best help you understand the problem." The responses were dichotomous, either an item was marked or it was not. The reliability for Information Selection 1 for the combined scenarios $(\mathrm{n}=72)$ was .92 .

The second information selection was after IP 2 but before the final judgments. It consisted of the 26 information items created for the study. Participants were asked to "Please select information that is relevant for your report by marking ' $\boldsymbol{X}$ ' in the boxes below." The responses were dichotomous, either an item was marked or it was not. The reliability for Information Selection 2 for the combined scenarios $(\mathrm{n}=52)$ was .84 .

Categories of information selection. In Information Selection 1, nine categories 
of information tested the range of categories of information used. Selection of a category was defined as having at least one item selected from that category. For example, if the item 'Group Composition' was selected, that means the category 'Work Group Information' was selected. The reliability for category selection for the combined scenarios $(\mathrm{n}=18)$ was .89 .

Information relevance. There were two types of information: dispositional and situational were used for the two information manipulation presented. There were thirteen items for dispositional items and thirteen situational items for a total of 26 information items. The relevance of these information items were assessed after each information presentation. Participants were asked "Please rate from 1 (Not at all Relevant) to 7 (Very Relevant) how relevant is each item." The reliabilities for the combined scenarios for situational items ( $\mathrm{n}=26)$ was .86 and .87 for dispositional items $(\mathrm{n}=26)$.

Information need. One item was used to assess information need. Participants were asked "Rate from 1 (Not at all) to 7 (A lot) the extent you need more information to investigate the problem." This was measured four times.

Information trust. One item was used to assess information trust. Participants were asked "How much do you trust the information that was presented to you?" They rated from 1 (Not at all) to 7 (A lot). This was measured twice, one time in each section of the information presentation.

Qualitative sensemaking. In parallel with the measures describe above, an open ended question, "What do you now think happened?", was asked four times to find what participants thought happened in the scenario (see Appendix B). These queries tap sensemaking qualitatively to chart how participants change their assessment of the 
scenarios as additional and contrary information is given. This measurement of sensemaking allows participants to justify their PI in the scenarios. Appendix C showed the sequence of coding for responses and the description of the response codes.

The open ended question, asked four times, provided four responses. In the scenario participant first responded to the initial frame with limited information [Respond 1 (R1)] (the first page of Appendix C illustrates an example). Next, participants receive the first information presentation [Information Presentation 1 (IP1)]. The first information presentation could be consistent $(=)$ or inconsistent $(\neq)$ with participants' first response. Participant could stay with $(=)$ or change $(\neq)$ their first response in the second response [R2] based on the first information presentation. They then received a second information presentation [IP2] in which the content was always contrary to content of the first information presentation. The second information presentation could be consistent $(=)$ or inconsistent $(\neq)$ with the second response. Participants could stay with $(=)$ or change $(\neq)$ their second response in the third response [R3]. Before the fourth response [R4], no new information was given but participants were presented with all previous information and they selected the information deemed important for the scenario.

Open ended responses were coded for situational, dispositional, or both types of explanations. For each open ended response, a participant's need for more information was also coded as present or absent. The four open ended responses yielded codes that depended on the consistency of a participant's initial explanation and on the first information presented as well as on subsequent response to the second information presentation. In Appendix C, combinations of qualitative sensemaking patterns based on responses over information presentation are illustrated for a person with an initial 
dispositional response. From the qualitative data collected from participants, nine sensemaking patterns were identified (see second page of Appendix $\mathrm{C}$ for Codes descriptions).

Participant responses were coded in the following way: The occurrence of the first question taps a participant's Initial Frame of the problem. Individuals who were able to give a reason(s) for the problem by identifying causal factors were those who started sensemaking with an initial frame. They stated cause(s) in the open ended question. For example, "In my experience financial problems are caused by poor planning by management."

The first and second information presentations allow for changes in the second and third responses. The responses to these information presentations tapped two other forms of sensemaking, Questioning and Preserving. In questioning a frame, a participant was ready to change their understanding of the situation. They may not trust the information they were given. For example, “It is not Andy's fault as I previously thought. I don't believe what his co-workers said about him because I think they were just using Andy." In preserving a frame, participants are establishing a base to maintain their previous understanding of the situation. They will hold to their original conclusion even if they are presented with new contradictory information and will use information consistent with the conclusion to strengthen the conclusion. For example, "It is Andy's fault as I previously thought. I know the previous supervisor may think well of him but there are so many negatives about Andy."

\section{Sensemaking Assessment Package: Memory Recall Task}

Included in the Sensemaking Assessment Package was the memory recall task. 
This task assessed the kind of information items participants remembered from the first scenario they received. To do this, they completed a memory recall task. Participants were reminded about the first scenario they were presented with in the study. For example, "Earlier in this session, you were presented with the [Scenario Name] scenario." They were then presented with the initial problem from the scenario. For example, "You are an advisor for non-profit organizations...Your job is to understand the situation and recommend action." Participants were then asked to recall as many information items as they could from the scenario. This task measured the number and type of information items a participant recalled. See Appendix D for memory recall task.

\section{Coding}

Information was coded for Dispositional-Situational information and ConfirmingDisconfirming information. Dispositional-Situational information was coded into three mutually exclusive categories: Dispositional Target (DT), Dispositional Non-Target (DNT), and Situational (S). Confirming-Disconfirming information was coded into two exclusive mutually categories: Confirming and Disconfirming.

Dispositional Target information recall was defined as recall of information that was related to internal attributes of the target person such as personality, beliefs, feelings, physical attributes, etc (i.e. Michael or Andy). Some examples are "Michael is new to non-profit organization" and "Andy is a troublemaker." Dispositional Non-Target information recall was defined as recall of information that was related to internal attributes of a non target person such as personality, beliefs, feelings, or physical attributes, etc. For example, information about other directors and employees in WF and Chris and other employees in PD are non target information. Some examples are "Mr. 
Spector set up foundation policy" and "Chris is the new supervisor." Situational information recall was defined as recall of information that was related to external factors of a person (i.e. events surrounding the person, industry and organizational information, economy, etc.). Some examples are "two other foundations were set up" and "new machines were brought in."

Confirming Information was information that was consistent and supported a current sense of a situation. This was defined as information that confirmed a cause to be the problem. For example, "Andy is a troublemaker" supported an individual to be the problem and "The economy is facing a recession" supported the situation to be the problem. Disconfirming Information was information that was inconsistent and could change the current sense of a situation. This was defined as information that refuted a cause to be the problem. For example, "Andy knows a lot about the production process" refuted an individual to be the problem and "The management met with and explained the planned changes to production workers" refuted the situation to be the problem. When information recall was neither confirming nor disconfirming, each category received an absent code. See Appendix E for Memory Coding description.

Analytic-Holism Scale (AHS)

In order to measure an individual's Analytic-Holistic (AH) thinking, I used the Analytic-Holism Scale (AHS; Choi, Koo, \& Choi, 2007). This scale is relatively new in cross cultural research but it is one of the few psychometrically valid scales available to measure AH thinking. The score on AHS was used as a moderator (H2, H3, H5, \& H6) and predictor $(\mathrm{H} 1, \mathrm{H} 4, \& \mathrm{H} 18)$ in this study. The three subscales on AHS, Attention, Causal Attribution, and Contradiction, were also used as predictor scores for hypotheses 
(H7-H8; H9-H12, H16; H13-H14, respectively). See Appendix F for the scale.

This scale consisted of 24 items measuring the four components of AH thinking on a 7-point Likert scale. Five items from Perception of Change subscale and one from Contradiction subscale were reverse coded items. A higher score signifies a higher holistic tendency. Example items include "The whole is greater than the sum of its parts," "Any phenomenon has numerous numbers of causes, although some of the causes are not known." "It is more desirable to take the middle ground than go to extremes," and "Future events are predictable based on present situations."

Choi and colleagues (2007) reported a Cronbach's alpha of .73 for the overall scale, and .67, .76, .71, and .71 for Attention, Causal Attribution, Contradiction, and Perception of Change subscales, respectively. The present study has an alpha of .60 for the overall scale, and 62, .71 .52, and .48 for Attention, Causal Attribution, Contradiction, and Perception of Change subscales, respectively. Choi et al. (2007) found that a fourfactor model $\left(\chi^{2}(246)=802.61, \chi^{2} / \mathrm{df}=3.26, \mathrm{GFI}=.88\right)$ had a better fit. As in Choi and colleagues (2007), all subscales were significantly correlated with the overarching scale (AHS). In the present study, Perception of Change subscales not related to Contradiction and Causal Attribution.

\section{The Need for Cognition Scale (NfCog)}

In order to measure the need for cognition, an individual's tendency to engage in and enjoy thinking, I used the short form of the Need for Cognition Scale (NfCog; Cacioppo, Petty, \& Kao, 1984). The score on the NfCog was used as a predictor and moderator (H17 and H18, respectively). See Appendix G for the scale. 
The original scale had 34 items and the short form has 18 items on a 5-point Likert scale. Half of the items were reverse-scored items. Example items form the short form include "I would prefer complex to simple problems," "Thinking is not my idea of fun," and "I prefer my life to be filled with puzzles that I must solve." The two forms were correlated at .95 . One factor structure accounted for $37 \%$ of the variance. It represents a single continuum of interindividual variations in the general tendency to engage in and enjoy effortful cognitive endeavors. The scale has a Cronbach alpha of .90 (Cacioppo et al., 1984). Cronbach's alpha value for the present study was .87.

\section{The Need for Cognitive Closure (NFCC)}

The need for cognitive closure describes an individual's motivation to attain a conclusion or desire for predictability, preference for order and structure, discomfort with ambiguity, decisiveness; and, close-mindedness. To measure this, I used the short form of the Need for Cognitive Closure Scale (NFCC; Pierro, \& Kruglanski, 2005). The score on NFCC was used as a predictor and moderator (H15 and H16, respectively). See Appendix $\mathrm{H}$ for the scale.

The NFCC (long form) consists of five subscales: Preference for Order, Preference for Predictability, Decisiveness, Discomfort with Ambiguity, and Closed Mindedness. It has a Cronbach's alpha of .84 and the reliability of the subscale ranges from .62 to .82 . The test-retest reliability coefficient over a 12 -week period is .86 (Webster \& Kruglanski, 1994). This scale has 42 items.

A short form of NFCC consists of 16 items on a 6-point Likert scale. Example items include "I prefer activities where it is always clear what is to be done and how it need to be done," and "I get very upset when things around me aren't in their place." 
Two items form a lie score are "I never been late for work or for an appointment," and “I have never hurt another person's feelings." Pierro and Kruglanski (2005) found attenuated correlations between shortened revised NFCC and previous version of NFCC in U.S. and Italian samples are .92 and .93 , respectively. Reliability was satisfactory at .80 in a U.S. sample and .79 in an Italian sample. Cronbach's alpha value for the present study was .73 .

\section{Tolerance for Ambiguity Scale}

MacDonald (1970)'s scale of tolerance for ambiguity measures an individual's perception of ambiguous or inconsistent situations as desirable; or tendency to perceive or interpret ambiguous environment as threatening or undesirable, was used for exploration in this study. It has 20 items. This is a dichotomous scale with true-false responses. Example items include "I don't like to work on a problem unless there is a possibility of coming out with a clear-cut and unambiguous answers," and "Sometimes I rather enjoy going against the rules and doing things I'm not supposed to do." The scale had an alpha of .78. Cronbach's alpha value for the present study was .48. See Appendix I for the scale.

\section{Demographics}

Participant's gender, age, ethnic identity, level of education, GPA, and working experience information was collected. See Appendix J for demographic sheet.

Procedure

Data was collected in groups of 10 or fewer participants. Each session took approximately 90 minutes. First, participants were provided a description of the study and were asked their consent to participate. They were then given the package of testing 
materials and instructions on how to proceed. Written instructions were included with each section of materials. Participants completed each scenario at their own pace. After participants completed both scenarios, they completed the questionnaires in the following order: Analytic-Holism Scale, the Need for Cognition Scale, the Need for Cognitive Closure Scale, Tolerance for Ambiguity Scale, and the memory recall task. Finally, they completed a demographic sheet. Participants were then debriefed and questions were answered. 


\section{RESULTS}

In the first section, I describe the sample and scenario characteristics. In the second section, I present hypotheses testing using correlation analyses and moderated multiple regressions. Lastly, I explored additional analyses: the relationships among the individual measures, memory recall, and qualitative sensemaking using two exploratory measures.

\section{Sample and Scenario Characteristics Sample Characteristics}

Three hundred and thirty six undergraduates from Introductory Psychology courses participated in this study. Twenty four participants were excluded from the sample based on exclusion criteria of foreign born, incomplete data, or misunderstanding of instructions. The final sample included 312 participants. As described in the Method section, there were four booklets. Seventy eight participants received one of the four booklets. The sample consisted of $26.6 \%$ male and $73.4 \%$ female with an average age of 19.61 years $(S D=3.66)$. Participants were primarily freshmen $(72.4 \%)$ and Caucasian American (64.7\%). A majority majored in Health Sciences (34.0\%), followed by Social/Behavioral Sciences (15.1\%). See Table 5 for detailed demographics information on schooling, childhood background, and work experience.

\section{Scenario Differences}

Because two scenarios were used, scenarios were compared for outcome differences using repeated measures and multilevel random coefficient (MRC) modeling analyses. 
Analyses were performed on outcomes related to selection of categories, the percentage of information items selected, the percentage of types of information items selected, relevance judgments of types of information, problem identification (PI) and decision judgments, and the differences for final judgments.

Using repeated measure analyses, scenarios did not differ for information selection - the number of categories selected, percentage of information items selected, percentage of situation information items selected, and percentage of dispositional information items selected. However, differences were found for ratings of situational information relevance, Pillai's trace $=.11$, Wilks's lambda $=.89, F=39.18, p<.001$; dispositional information relevance, Pillai's trace $=.01$, Wilks's lambda $=.99, F=3.91$, $p<.05$; and overall information relevance, Pillai's trace $=.02$, Wilks's lambda $=.98, F=$ $6.54, p<.05$. See Table 6 for details.

Using MRC modeling analyses as suggested in Bliese and Ployhart (2002), PI and decision judgments over four measurement times were compared between scenarios while controlling for scenario order and information presentation order. Scenarios, scenario order, and information presentation order were level-2 variables while Time was a level-1 variable. For PI judgments, scenarios were not significantly different for either dispositional PI or situational PI. For decision judgments, scenarios were significantly different only for dispositional decision, $B=0.11, d f=2179, t=2.13, p<.05$.

The difference scores between the final situational and dispositional PI judgments for the two scenarios were compared. I also compared the difference scores between the final situational and dispositional decision judgments. Scenarios were significantly 
different for the PI judgments, Pillai's trace $=.10$, Wilks's lambda $=.90, F=36.02, p<$ .001 but not for the decision judgments. See Table 6 for details.

In order to simplify analyses for hypotheses testing, I first used combined scores of both the scenarios to provide general findings. I additionally conducted hypotheses testing on individual scenarios with associated outcomes differences found in analyses of scenario differences. These include dispositional decision judgments, information relevance, and the difference between the final PIs judgments. For the additional analyses, combined scores were used.

\section{Hypotheses Testing}

I examined three sets of research hypotheses. The first set looked at $A H$ thinking with PI (H1, H2, H3) and decision judgments (H4, H5, H6). Specifically, how AH thinking influenced initial PI and decision judgments (H1, H4) and how it interacted with the two information presentations to affect subsequent PI and decision judgments $(\mathrm{H} 2$, H3, H5, H6). The second set, components of AH thinking, was hypothesized to be related to the information characteristics: Information selection $(\mathrm{H} 7, \mathrm{H} 9, \mathrm{H} 10, \mathrm{H} 12)$ and Information relevance (H8, H11). Additionally, Tolerance for Contradiction was posited to relate to the absolute difference scores between two PI and two decision judgments (H13, H14). The third set examines two individual personality differences in information selection (H15, H17) and the combination of each of these individual differences with AH thinking in affecting PI judgments (H16, H18). The hypotheses were assessed using correlation analyses or moderated multiple regressions as appropriate.

\section{Analytic-Holistic Thinking}

There were several commonalities among the hypotheses tested here. First, 
Analytic-Holistic thinking was hypothesized to influence initial situational PI and decision. Because holistic thinkers use a situational causal framework during sensemaking, they would begin with situational causes. Hypotheses 1 and 4 test this assumption using correlational analyses. Second, because analytic and holistic thinkers might seek different types of information, they might use information differently to identify problems and make decisions. This was tested using two sequential information presentations. Hypotheses 2, 3, 5 and 6 test this assumption using moderated multiple regressions.

Moderated multiple regression is a form of hierarchical multiple regression that uses a hierarchical entry of the predictor variables to determine if the relationship between one of the predictors and a criterion variable is influenced by a third moderating variable. A significant interaction indicates a moderating effect and will be followed by a simple slopes analysis. This analysis is used for hypotheses with moderators, H2, H3, H5, H6, H16, and H18. In Hypothesis 2, the moderated multiple regression is described in detail, while subsequent hypotheses following similar steps are briefly described.

H1: AH scores will be positively correlated with initial situational PI judgments. To test Hypothesis 1, the mean overall Analytic-Holistic (AH) scores and the initial situational PI judgment scores [Combined: Problem Identification Sit T1] ${ }^{2}$ were correlated. The AH scores were significantly correlated with initial situational PI judgment scores, $r=.13, p<.05$. Hypothesis 1 was supported. People higher in holistic thinking were more likely to identify problems to be situational in their initial judgment. See Table 7.

\footnotetext{
${ }^{2}$ Brackets here and in later results indicate labels in tables.
} 
H2: The interaction between AH scores and Information Presentation (IP) 1 will significantly affect both situational and dispositional PI judgments in Time 2, after controlling for PI judgments in Time 1, IP1, and AH scores. The slope between IP1 and both situational and dispositional PI judgments in Time 2 will be steeper for high holistic thinking than people low in holistic thinking.

To test Hypothesis 2, the influence of AH thinking on the relationship between IP1 and the PI judgments, moderated multiple regression analyses were used. Analyses were examined independently for situational PI and dispositional PI judgment outcomes.

Situational PI judgment. Situational PI judgment at Time 2 was selected as the outcome. I regressed this on situational PI judgment at Time 1, IP1, AH scores, and the interaction term of IP1 and AH scores in three steps. In Step 1, situational PI judgment at Time 1 was entered to predict situational PI judgment at Time 2. In Step 2, IP1 and AH scores were entered. In Step 3, the interaction term computed as a cross-product of predictors (IP1 x AH scores) was entered. See Table 8 for results.

In Step 1, situational PI judgment at Time 1 predicted situational PI judgment at Time 2. Variance accounted for by this initial model was significant, $R^{2}=.19, F(1,310)$ $=71.15, p<.001$, indicating that situational PI judgment at Time 1 predicted situational PI judgment at Time 2. In Step 2 two other predictors, IP1 and AH scores, were added. The variance accounted for by this model was $R^{2}=.32$. The incremental variance was significant, $\Delta R^{2}=.14, \Delta F(2,308)=30.73, p<.001$, revealing that the addition of information presentation and $\mathrm{AH}$ thinking increased the predictive power of the model. In Step 3, when the interaction term was added, the model was significant, $R^{2}=.33$. The incremental variance was also significant, $\Delta R^{2}=.01, \Delta F(1,307)=5.13, p<.05$. The 
interaction term was significant, $B=.45, t=2.27, p<.05$, indicating that the situational PI judgment at Time 2 depended upon the interaction of IP1 and AH scores.

A significant interaction of IP1 and AH scores on situational PI judgments suggested that $\mathrm{AH}$ thinking influenced how information was used in making situational PI judgments. This allowed for further simple slope analyses.

A simple slope analysis describes the effect of AH tendency on the relationship between IP1 and the situational PI judgments. These simple slopes are the regression of the outcome, situational PI judgments at Time 2, on the predictor, IP1 at specific values of the moderator, AH scores. Two means of AH scores, representing one standard deviation above and below the mean of AH scores, were created to indicate high and low AH thinking (Aiken \& West, 1991). These generated two simple regression lines of situational PI judgment on IP1 as a function of two levels of AH thinking. See Figure 5.

These regression lines were not parallel reflecting the interactions effects. The relationship between situational PI judgments and IP1 changed as a function of AH scores. The slope for people with higher holistic scores was steeper than that of people lower in holistic thinking, as hypothesized. This shows that higher holistic thinking used the situation information presented in a way that is reflected in their situational PI judgment. However, the effect is significant but small, as indicated by incremental variance of $1 \%$. Another interpretation is that they are more susceptible to situational information presentation. Hypothesis 2 was supported for situational PI judgment.

Dispositional PIjudgment. The moderated multiple regression analysis was repeated for dispositional PI judgment at Time 2. See Table 8 for results. Variance accounted for in Step 1 was significant, $R^{2}=.08, F(1,310)=28.02, p<.001$, indicating 
that dispositional PI judgment at Time 1 predicted dispositional PI judgment at Time 2. The variance accounted for in Step 2 was $R^{2}=.60$. The incremental variance was significant, $\Delta R^{2}=.51, \Delta F(2,308)=196.14, p<.001$. In Step 3, when the interaction term was added, the model was significant, $R^{2}=.78$. The incremental variance was also significant, $\Delta R^{2}=.01, \Delta F(1,307)=9.23, p<.01$. The interaction term was significant, $B=-.67, t=-3.04, p<.01$, indicating that the dispositional PI judgment at Time 2 depended upon the interaction of IP1 and AH scores.

The interaction of IP1 and AH score on dispositional PI judgments at Time 2 supports the interaction effect in Hypothesis 2. AH thinking influences how information was used when making judgments during sensemaking. The simple slopes analysis for dispositional PI judgment is similar to that described for situational PI judgment. Two regression lines of high and low AH scores were graphed. See Figure 6.

The non-parallel regression lines indicate that the relationship between dispositional PI judgments and IP1 changed as a function of AH scores. Again, the steeper slopes were for people with higher holistic scores than people lower in holistic scores. The slopes showed that people higher in holistic thinking seemed to be more susceptible to whatever information they are presented. When dispositional information was presented, they rated dispositional PI judgment to be higher and when situational information was presented, they judged the dispositional PI to be lower. Again, effect is significant but small. Hypothesis 2 was supported for dispositional PI judgment.

H3: The interaction between AH scores and IP2 will significantly affect both situational and dispositional PI judgments in Time 3, after controlling for PI judgments in Time 2, IP2, and AH Scores. The slope between IP2 and both 
situational and dispositional PI judgments in Time 3 will be steeper for people high in holistic thinking than people low in holistic thinking.

Hypotheses 3 followed the same analyses as Hypotheses 2 except that the outcome scores were judgments at Time 3. In Step 1, I controlled for judgments at Time 2. Step 2 and 3 followed those in Hypothesis 2 except that IP2 replaced IP1. Again situational and dispositional PI judgments were investigated independently. See Table 8 for results.

Situational PI judgment. In Step 1, the variance accounted for was significant, $R^{2}=.18, F(1,310)=66.50, p<.001$. Situational PI judgment at Time 2 predicted situational PI judgment at Time 3. In Step 2, the variance accounted for was $R^{2}=.26$ when IP 2 and AH scores was added. The incremental variance was significant, $\Delta R^{2}=$ $.09, \Delta F(2,308)=17.62, p<.001$. In Step 3, the variance accounted for was $R^{2}=.26$. The incremental variance with the added interaction term was not significant, $\Delta R^{2}=.00$, $\Delta F(1,307)=1.73, p>.05$. The interaction term was not significant, $B=.22, t=1.32, p$ $>$.05. Situational PI judgment at Time 3 did not depend on the interaction of IP2 and AH scores. Hypothesis 3 was not supported.

Dispositional PI judgment. The variance accounted for Step 1 was not significant, $R^{2}=.00, F(1,310)=.39, p>.05$. Dispositional PI judgment at Time 2 did not predict dispositional PI judgment at Time 3. See Table 8 for results. The variance accounted for in Step 2 was $R^{2}=.28$ with an incremental variance of $\Delta R^{2}=.28, \Delta F(2$, $308)=60.70, p<.001$. In Step 3 , the variance accounted for was $R^{2}=.29$. The incremental variance, $\Delta R^{2}=.01, \Delta F(1,307)=.77, p>.05$ and the interaction term, $B=$ $-.22, t=-.88, p>.05$, were not significant. Dispositional PI judgment at Time 3 did not 
depend upon the interaction of IP 2 and AH scores. Hypothesis 3 was not supported. A simple slope analysis would not be meaningful.

H4: AH scores will be positively correlated with initial situational decision judgments.

To test Hypothesis 4, the mean overall AH scores and the initial situational decision judgment scores [Combined: Decision Sit T1] were used in a correlation analysis. The AH scores were significantly correlated with the initial situational PI judgment scores, $r=.17, p<.01$. Hypothesis 4 was supported. People higher in holistic thinking were more likely to recommend a situational solution in their initial judgment. See Table 7.

H5: The interaction between AH scores and IP1 will significantly affect both situational and dispositional decision judgments in Time 2, after controlling decision judgments in Time 1, IP1, and AH scores. The slope of IP1 and both situational and dispositional decision judgments in Time 2 will be steeper for people high in holistic thinking than people low in holistic thinking.

The analyses for Hypotheses 5 and 6 were consistent to those three steps described in Hypotheses 2 and 3, respectively, using decision judgment scores rather than PI judgments at their respective measurement times. See Table 9 for results.

Situational decision judgment. In Step 1, situational decision judgment at Time 1 predicted situational decision judgment at Time 2 . The variance accounted for was $R^{2}=$ $.19, F(1,310)=74.78, p<.001$. In Step 2 , the variance accounted for was $R^{2}=.43$. The incremental variance was significant, $\Delta R^{2}=.24, \Delta F(2,308)=64.29, p<.001$. In Step 3 , when the interaction term was added, the model was significant, $R^{2}=.43$. The 
incremental variance was also significant, $\Delta R^{2}=.01, \Delta F(1,307)=4.89, p<.05$. The significant interaction term, $B=.45, t=2.21, p<.05$, indicates that the situational decision judgment at Time 2 depended upon the interaction of IP1 and AH scores.

A significant interaction of IP1 and AH scores on situational decision judgments outcome suggested that $\mathrm{AH}$ thinking influences how information was used when making decision judgments in sensemaking supporting the interaction effect in Hypothesis 5. The simple slopes analysis in Figure 7 shows the relationship between IP1 and the situational decision judgments at two levels, high and low, of AH thinking.

As in earlier analyses, the slope was steeper for people higher holistic thinking than people lower holistic thinking. Higher holistic thinkers used situational information to affect their situational decision judgments. When dispositional information was presented, they used dispositional information to be wary of adopting a situational decision showing a lower situational judgment. The incremental variance of $1 \%$ indicates the effect is small. Hypothesis 5 was supported for situational decision judgment.

Dispositional decision judgment. As reported in the scenario differences section, differences over time were found for the dispositional decision judgment. The analysis associated with this variable first used combined score then scores from each scenario. I used dispositional decision judgment at Time 2 as the outcome. Variance accounted for in Step 1 was significant, $R^{2}=.15, F(1,310)=53.06, p<.001$. See Table 9 for results. Dispositional decision judgment at Time 1 predicted dispositional decision judgment at Time 2. The variance accounted for in Step 2 was $R^{2}=.56$. The incremental variance was significant, $\Delta R^{2}=.42, \Delta F(2,308)=146.81, p<.001$. In Step 3, when the interaction term was added, the model was significant, $R^{2}=.57$. The incremental variance, $\Delta R^{2}=$ 
$.01, \Delta F(1,307)=6.20, p<.05$ and the interaction term, $B=-.52, t=-2.49, p<.05$, were significant. Dispositional decision judgment at Time 2 depended upon the interaction of IP1 and AH scores.

A significant interaction of IP1 and AH scores on dispositional decision judgments outcomes suggested that $\mathrm{AH}$ thinking influences how information was used when making dispositional decision judgments. This supported the interaction effect of Hypothesis 5.

The simple slopes analysis in Figure 8 shows the relationship between IP1 and the dispositional decision judgments at high and low $\mathrm{AH}$ thinking. As in earlier analysis, the slopes suggest that people higher in holistic thinking are more susceptible to whatever information they are presented. When dispositional information was presented, they judged dispositional decisions to be higher, when presented with situational information, they judged the dispositional decisions to be lower. Again, effect is significant but small. Hypothesis 5 was supported for dispositional decision judgment.

Dispositional decision judgment: Analysis by scenario. The same analysis was performed independently for each scenario. See Table 10 for details. The WF result showed a significant interaction as did the combined scenarios results. The PD scenario had a non-significant interaction. In PD, the variance accounted for in Step 1 was significant, $R^{2}=.11, F(1,310)=39.23, p<.001$. The variance accounted for in Step 2 was $R^{2}=.25$. The incremental variance was significant, $\Delta R^{2}=.14, \Delta F(2,308)=27.80$, $p<.001$. In Step 3, when the interaction term was added, variance accounted for was $R^{2}$ $=.25$. The incremental variance, $\Delta R^{2}=.00, \Delta F(1,307)=.30, p>.05$ and the interaction term, $B=.17, t=.55, p>.05$, was not significant. Dispositional decision 
judgment at Time 2 did not depend upon the interaction of IP1 and AH scores.

In WF, variance accounted for in Step 1 was significant, $R^{2}=.18, F(1,310)=$ 69.62, $p<.001$. The variance accounted for in Step 2 was $R^{2}=.45$. The incremental variance was significant, $\Delta R^{2}=.27, \Delta F(2,308)=74.57, p<.001$. In Step 3 , when the interaction term was added, the model was significant, $R^{2}=.46$. The incremental variance, $\Delta R^{2}=.01, \Delta F(1,307)=3.97, p<.05$ and the interaction term, $B=-.55, t=$ 1.99, $p<.05$, was significant. Dispositional decision judgment at Time 2 depended upon the interaction of IP1 and AH scores. The simple slopes analysis in Figure 9 shows similar direction as the combined scores except when situational information is presented, people higher in holistic thinking did not judge dispositional judgment to be lower.

H6: The interaction between AH scores and IP2 will significantly affect both situational and dispositional decision judgments in Time 3, after controlling decision judgments in Time 2, IP2, and AH scores. The slope of IP2 and both situational and dispositional decision judgments in Time 3 will be steeper for people high in holistic thinking than people low in holistic thinking.

Situational decision judgment. In Step 1, the variance accounted for was $R^{2}=$ $.22, F(1,310)=87.62, p<.001$. See Table 9 for results. The variance accounted for in Step 2 was $R^{2}=.33$. The incremental variance was significant, $\Delta R^{2}=.11, \Delta F(2,308)=$ 24.81, $p<.001$. In Step 3, the variance accounted for was $R^{2}=.33$. The incremental variance was not significant when the interaction term was added, $\Delta R^{2}=.01, \Delta F(1$, $307)=2.36, p>.05$. The interaction term was not significant, $B=.29, t=1.54, p>.05$, indicating that the situational decision judgment at Time 3 did not depend upon the interaction of IP2 and AH scores. 
Dispositional decision judgment. Variance accounted for in Step 1 was significant, $R^{2}=.05, F(1,310)=14.56, p<.001$. See Table 9 for results. Dispositional decision judgment at Time 2 predicted dispositional decision judgment at Time 3 . The variance accounted for in Step 2 was $R^{2}=.25$. The incremental variance was significant, $\Delta R^{2}=.20, \Delta F(2,308)=41.50, p<.001$. In Step 3, the variance accounted for was $R^{2}=$ .26. When the interaction term was added, the incremental variance was not significant $\Delta$ $R^{2}=.01, \Delta F(1,307)=3.87, p>.05$. The interaction term was not significant, $B=-.47, t$ $=-1.97, p>.05$. Dispositional decision judgment at Time 3 did not depend upon the interaction of IP 2 and AH scores. Because the interaction terms were not significant Hypothesis 6 was not supported using combined scores. No simple slopes analyses were required for the combined scores.

Dispositional decision judgment: Analysis by scenario. Because there were differences between the scenarios for disposition decision judgments, the same analysis was performed independently for each scenario. While the PD scenario had a significant interaction, the WF scenario as the combined scenarios did not show a significant interaction. In WF, variance accounted for in Step 1 was significant, $R^{2}=.13, F(1,310)$ $=44.67, p<.001$. See Table 10 for details. The variance accounted for in Step 2 was $R^{2}$ $=.24$. The incremental variance was significant, $\Delta R^{2}=.13, \Delta F(2,308)=24.95, p<$ .001 . In Step 3, variance accounted for was $R^{2}=.25$, with a non significant incremental, $\Delta R^{2}=.00, \Delta F(1,307)=.03, p>.05$. The interaction term was not significant, $B=-.05$, $t=-.16, p>.05$. Dispositional decision judgment at Time 3 did not depend upon the interaction of IP2 and AH scores. 
In PD, variance accounted for in Step 1 was significant, $R^{2}=.02, F(1,310)=$ $6.65, p<.05$. See Table 10 for details. The variance accounted for in Step 2 was $R^{2}=.14$. The incremental variance was significant, $\Delta R^{2}=.12, \Delta F(2,308)=20.70, p<.001$. In Step 3, when the interaction term was added, the model was significant, $R^{2}=.16$, with a significant incremental, $\Delta R^{2}=.02, \Delta F(1,307)=6.79, p<.05$. The interaction term was significant, $B=-.86, t=-2.61, p<.05$. Dispositional decision judgment at Time 3 depended upon the interaction of IP2 and AH scores.

The simple slopes analysis in Figure 10 shows the relationship between IP2 and the dispositional decision judgments at high and low AH thinking for PD scenario. The slope was steeper for people with higher holistic scores than for people lower in holistic thinking. People higher in holistic thinking seemed to be more susceptible to whatever information they were presented. When dispositional information was presented, they judged dispositional decisions to be higher. When presented with situational information, they judged the dispositional decisions to be lower. Hypothesis 6 was supported for the PD scenario.

In summary, the results in $\mathrm{H} 1$ and $\mathrm{H} 4$ showed that higher holistic thinking was related to higher initial situational PI and decision judgments. In all cases for significant interactions, slopes of high $\mathrm{AH}$ were steeper than low $\mathrm{AH}$, supporting all interactions hypotheses. It did not matter if judgments were dispositional or situational, people higher in $\mathrm{AH}$ thinking were more sensitive to both situational and dispositional information presented. All effects, however, were small. Specific results in $\mathrm{H} 2$ and $\mathrm{H} 5$ (except for WF) showed that $\mathrm{AH}$ thinking interacted with the first information presentation to affect both situational and dispositional PI and decision judgments at Time 2. These interaction 
effects did not carry over at Time 3 as examined in H3 and H6 (except for PD). The judgments at Time 2 accounted for much of the variance of judgments in Time 3 . AH thinking did not appear to have an effect on later judgments; it did not predict judgments while information presentation did (See Lower portion of Table 8 and 9: Step 2).

\section{Components of AH Thinking}

AH thinking components, Attention, Causal Attribution, and Tolerance for Contradiction, influence on the percentage of information items selected, information rated as relevant, the judgment differences between dispositional and situational PIs, and the differences between dispositional and situational decision judgments, were investigated.

Attention

People higher in holistic thinking, with wider attention scope, were assumed to seek more peripheral information in their sensemaking. This was expected to result in a higher percentage of information items selected and higher ratings of information relevance. Hypotheses 7 and 8 tested these outcomes, respectively, using correlation analyses.

H7: Attention scores will be positively related to the percentage of information items selected.

To test Hypothesis 7, the mean of Attention scores of the AHS [Attention] and the mean percentage of items selected from Information Selection 1 and Information Selection 2 [Combined: \% of Information Selected (1\&2)] were used. The attention scores were not significantly correlated with percentage of items selected, $r=-.04, p>$ .05 . Hypothesis 7 was not supported. A wider attention scope did not influence the 
selection of information items. Additional separate analyses of attention on Information Selection 1 and Information Selection 2, respectively, were also not significant. See Table 13.

H8: Attention scores will be positively related to the rated relevance of available information.

In order to test Hypothesis 8, the mean of Attention scores of the AHS [Attention] and the mean rating of information relevance [Combined: Overall Info Relevance] were used. The attention scores were not significantly correlated with mean information relevance, $r=.06, p>.05$. I tested the individual scenarios as the relevance scores were different for the two scenarios. The correlations were non significant, WF: $r=.03, p>$ .06 and PD: $r=.07, p>.05$. Hypothesis 8 was not supported. A wider attention scope did not influence the relevance judgments of information items. See Table 14.

\section{Causal Attribution}

Because people with holistic thinking were expected to include context in their causal attribution, it was hypothesized that they would include a variety of information in their sensemaking, resulting in a higher percentage of information items selected, a higher percentage of situational information items selected, higher rating for situational information relevance, and a more diverse use of information categories. Hypotheses 9 to 12 tested each of these outcomes, respectively, using correlation analyses.

H9: Causal attribution scores will be positively related to the percentage of information items selected.

To test Hypothesis 9, the mean of Causal Attribution scores of the AHS [Causal Attribution] and the mean percentage of items selected from Information Selection 1 and 
Information Selection 2 [Combined: \% of Information Selected (1\&2)] were used. The mean of attribution scores was not significantly correlated with the percentage of items selected, $r=.10, p>.05$. A situational perspective of causality did not increase the percentage of information items selected. Additional separate analyses of attribution on Information Selection 1 and Information Selection 2, respectively, were also not significant. See Table 13.

H10: Causal attribution scores will be positively related to the percentage of situational information items selected.

To test Hypothesis 10, the mean of Causal Attribution scores of the AHS [Causal Attribution] and the mean percentage of situational items selected in Information Selection 2 [Combined: \% of Sit Information Selected 2] were used. The mean of attribution scores were significantly correlated with the percentage of situational items selected, $r=.18, p<.01$. This indicated that people with a situational perspective on causal attribution selected more situational information. Hypothesis 10 was supported. See Table 13.

H11: Causal attribution scores will be positively related to mean of situational information rated as relevant.

To test Hypothesis 11, the mean of Causal Attribution scores of the AHS [Causal Attribution] and the mean rating of situational information relevance [Combined: Sit Info Relevance] were used in a correlation analysis. The mean of attribution scores were significantly correlated with mean of situational information relevance, $r=.18, p<.01$. Hypothesis 11 was supported. This indicated that people with a situational perspective on causal attribution rated situational information as more relevant. In the individual 
scenarios, the relationship was not significant for WF, $r=.09, p>.05$ but was significant for $\mathrm{PD}, r=.22, p<.001$. See Table 14 .

H12: Causal attribution scores will be positively related to the number of categories of information selected.

To test Hypothesis 12, the mean of Causal Attribution scores of the AHS [Causal Attribution] and the number of information categories selected [Combined: Numbers of Category Selected] were used in a correlation analysis. The mean of attribution scores were not significantly correlated with the number of information categories selected, $r=$ $.04, p>.50$. Hypothesis 12 was not supported. Attribution did not influence the use of information categories. See Table 13.

\section{Tolerance for Contradiction}

Because people with holistic thinking see truths in two seemingly opposing views, they were more likely to use dialectical reasoning when dealing with 'conflicting' situations. That is, they would synthesize two approaches instead of contrasting them. This would result in people higher in holistic thinking showing a smaller difference between dispositional and situational options of PI and if decision judgments. Hypotheses 13 to 14 tested each using correlation analysis, respectively.

H13: People with high tolerance for contradiction will show less absolute difference between their final dispositional and situational PI judgments than people with low tolerance for contradiction.

To test Hypothesis 13, the mean of Tolerance for Contradiction scores of AHS [Contradiction] and the absolute difference scores between the ratings of final dispositional and situational PI judgments [Combined: Abs Difference in PI T4] were 
correlated. A larger absolute difference score indicates that the judgments were polarized. The mean of tolerance for contradiction scores were not significantly correlated with the absolute difference between the dispositional and situational PI judgments, $r=.03, p>$ .05 . The relationship was also not supported in the individual scenarios, WF: $r=.03, p>$ .05 and PD: $r=.01, p>.05$. Hypothesis 13 was not supported. This means the tolerance for contradiction did not affect the choice between the two PI judgment options. See Table 15.

H14: People with high tolerance for contradiction will show less absolute difference between their final dispositional and situational decision judgments than people with low tolerance for contradiction.

To test Hypothesis 14, the mean of Tolerance for Contradiction scores of AHS [Contradiction] and the absolute differences between final judgments in decision judgments [Combined: Abs Difference in Decision T4] were correlated. A larger absolute difference score indicated that the judgments were polarized. The mean of tolerance for contradiction scores was not significantly correlated with the absolute difference between the dispositional and situational decision judgments, $r=.03, p>.05$. These were also not significant in the individual scenarios, WF: $r=.03, p>.05$ and PD: $r=.01, p>.05$. Hypothesis 14 was not supported. This means tolerance for contradiction did not affect the choice between the two decision judgments. See Table 15.

In summary, of the three components of AH thinking investigated, only causal attribution showed a significant relationship with information selection and information relevance. Attribution was related to situational information items selected and situational information relevance but not related to overall percentage of information items selected 
and to categories of information used. Attention seemed unrelated to information characteristics. This could be because participants read all information presented in each scenario, that is, they were forced to attend to all information, not selective attention. The tolerance for contradiction was not related to the absolute difference score between both PI and decision judgments.

\section{Individual Personality Differences}

In order to find if individual differences measures were related to sensemaking process, two personality variables associated with individual information processing characteristics were included: The Need for Cognitive Closure (NFCC) and the Need for Cognition (NfCog).

\section{The Need for Cognitive Closure}

Because people with high NFCC seek quick conclusions, they were expected to look for and use information that would support this goal. Because dispositional attribution was posited to be easier to process (Winter et al., 1985; Winter \& Uleman, 1984), Hypothesis 15 tested if the NFCC score was correlated with the percentage of dispositional items selected. Because a disposition conclusion might be easier to reach, people with high need for cognitive closure and dispositional attribution would also be more likely to attribute to dispositions when situational explanations were available or

FAE. This was tested in Hypothesis 16 using a moderated multiple regression.

H15: The Need for Cognitive Closure (NFCC) scores will be positively related to the percentage of dispositional information items selected.

To test Hypothesis 15, the mean of NFCC scores [The Need for Cognitive Closure] and the percentage of dispositional information items selected in Information 
Selection 2 [Combined: \% Dis Information Selected 2] were used in a correlation analysis. The mean of NFCC scores were significantly correlated with the percentage of dispositional information items selected, $r=-.19, p<.001$. However, these correlations were negative, opposite from the hypothesized results. This was also significantly negative for percentage of situational items selected, $r=-.17, p<.001$. Hypothesis 15 was not supported. See Table 13.

H16: There will be a significant interaction between Causal Attribution scores and the NFCC scores on final dispositional PI judgments. The slope of Causal Attribution and final PI judgments will be steeper for people high in need for closure than people low in need for closure to reflect their dispositional tendency for PI.

To test Hypothesis 16, the Causal Attribution scores on the AHS and the NFCC scores were used to predict dispositional tendency reflecting the fundamental attribution error (FAE). A significant joint effect of attribution and NFCC on final dispositional PI judgment while controlling for final situational PI judgment, Attribution scores, and NFCC scores would reflects dispositional tendency. Analysis was carried out in three steps. In Step 1, situational PI judgments were entered to predict dispositional PI judgment. In Step 2, Attribution scores and NFCC scores were entered to predict dispositional PI judgment. In Step 3, the cross-product term of Attribution scores and NFCC scores was entered to predict dispositional PI judgment.

Variance accounted for in Step 1 was significant, $R^{2}=.02, F(1,310)=7.02, p<$ .05. Situational PI judgment predicted dispositional PI judgment. In Step 2, variance and incremental variance accounted was significant, $R^{2}=.04, \Delta R^{2}=.02, \Delta F(2,308)=3.16$, $p<.05$. As a set, Attribution scores and NFCC scores predicted dispositional PI 
judgment. Individual coefficients show Attribution but not NFCC significantly predicted the outcome. In Step 3, the variance accounted for was $R^{2}=.04$. When interaction term was added, the incremental variance was not significant, $\Delta R^{2}=.00, \Delta F(1,307)=.52, p$ $>.05$. The interaction term was not significant, $B=-.02, t=-.72, p>.05$. Dispositional PI judgment did not depend upon the interaction of Attribution and the NFCC.

Hypothesis 16 was not supported. No simple slope analysis was required. See Table 16 for details.

\section{The Need for Cognition}

People high in the need for cognition, enjoy thinking, were expected to look for and use more information. Hypothesis 17 tested this assumption using correlation analysis. Because of the wider selection of information and the willingness to explore cognition, people with high need for cognition and high in AH thinking might be less likely to commit FAE. This was tested in Hypothesis 18 using moderated multiple regressions.

H17: The Need for Cognition (NfCog) scores will be positively related to the percentage of information items selected.

To test Hypothesis 17, the mean of NfCog scores [The Need for Cognition] and the mean percentage of items selected from Information Selection 1 and from Information Selection 2 [Combined: \% of Information Selected (1\&2)] were used. The mean of NfCog scores were not significantly correlated with the percentage of items selected, $r=.07, p>.05$. Hypothesis 17 was not supported. Additional separate analyses of attention on Information Selection 1,r $=.04, p>.05$, and Information Selection 2, $r=$ $.08, p>.05$, respectively, were also not significant. See Table 13 . 
H18: There will be a significant interaction between $\mathrm{AH}$ scores and the NfCog scores on the final dispositional PI judgments. The slope of AH scores and final PI judgments will be steeper for people low in need for cognition than people high in need for cognition to reflect their dispositional tendency for PI.

To test Hypothesis 18, the overall AH scores and the NfCog scores were used to predict dispositional tendency. The steps in this analysis were similar to those used in Hypothesis 16. In Step 1, situational PI judgments were entered to predict dispositional PI judgments. In Step 2, AH scores and NfCog scores were entered to predict dispositional PI judgment. In Step 3, the cross-product term of AH scores and NfCog scores was entered to predict dispositional PI judgment.

Variance accounted in Step 1 was significant, $R^{2}=.02, F(1,310)=7.02, p<.05$, indicating situational PI judgment predicted dispositional PI judgment. See Table 16 for results. In Step 2, variance and incremental variance accounted for was not significant, $R^{2}$ $=.02, \Delta R^{2}=.02, \Delta F(2,308)=.28, p>.05$. As a set, AH thinking and need for cognition did not predict dispositional PI judgment. In Step 3, when the interaction term was added, the variance and incremental variance accounted for was not significant, $R^{2}=.03, \Delta R^{2}=$ $.01, \Delta F(1,307)=.71, p>.05$. The interaction term was not significant, $B=.18, t=.63$, $p>.05$. Dispositional tendency did not depend upon the interaction of AH thinking and the need for cognition. Hypothesis 18 was not supported. No simple slope analysis was required.

In summary, hypotheses related to the need for cognitive closure and the need for cognition did not show an effect on the hypothesized information selection. Perhaps these two personality differences affect other processes in sensemaking rather than information 
characteristics. Each hypothesized moderating effect was also not significant. The need for cognitive closure did not it interact with attribution to affect dispositional tendencies. The need for cognition did not interact with AH thinking to affect dispositional tendencies.

\section{Additional Analysis}

To provide a comprehensive picture of the relationship between AH thinking, information management, and sensemaking, several post hoc analyses were undertaken. First, I explored the relationships among the individual scales used in the study. As AH thinking is a new scale, it is important to understand how it relates to other individual measures. Second, I examined the types of information recalled as a different measurement of the attention process of participants during sensemaking. This revealed what kind of information participants deemed relevant for sensemaking. Lastly, the patterns of qualitative sensemaking responses were explored.

\section{Relationships Among Individual Differences Scales}

I compared the overall AH scores and the components score with the other scales used in the study. Overall AH scores was not related to the NfCog but the Causal Attribution subscale was related, $r=.18, p<.05$. People with high need of cognition were also people with a situational approach to causal attribution. A person who includes situational aspects in causal attribution showed a higher need for cognition. See Table 7.

Overall AH scores was not related to the NFCC but the Perception of Change subscale was, $r=-.12, p<.05$. The correlation showed that people with a nonlinear perspective have a lower need for cognitive closure. A belief about the flexibility of the universe appears to be inconsistent with the need for cognitive closure. Attention was 
positively correlated with the NFCC, $r=.12, p<.05$. The correlation showed that people with wider attention scope have a higher need for cognitive closure. This could be because their wider attention requires a higher need for closure in order to prevent information overload. See Table 7.

The overall AH scores and subscales were not related to Tolerance for Ambiguity. The lack of relationships between AHS and the other scales indicated that AHS was measuring construct different from these other individual scales. See Table 7.

Table 7 also showed that the other scales in the study were moderately related to each other. The NfCog was negatively correlated with the NFCC, $r=-.49, p<.001$. People with higher need for cognition have lower need for cognitive closure. People with higher need for cognition are less of a cognitive miser show less need for cognitive closure. Whereas people with low need of cognition are cognitive misers show a higher need for cognitive closure. This supported previous research (Petty \& Jarvis, 1996; Webster \& Kruglanski, 1994).

The NfCog was positively correlated with Tolerance for Ambiguity, $r=.34, p<$ .001. People with higher need for cognition have higher tolerance for ambiguity. This relationship makes sense as people with high need for cognition enjoy thinking, they have the ability and motivation to try to disentangle information, making them less ambiguous, therefore, may have a higher tolerance for ambiguity. This supported previous research (Weary \& Edwards, 1994). See Table 7.

The NFCC was negatively correlated with Tolerance for Ambiguity, $r=-.39, p<$ .001. People with higher need for closure do not tolerate ambiguity. Whereas a lower 
need for cognitive closure may be comfortable with ambiguity. This supported previous research (Weary \& Edwards, 1994). See Table 7.

In summary, the overall $\mathrm{AH}$ scores was not related to the personality measures included in the study. This suggests AH thinking is different from these personality measures. Two components of AH thinking, perception of change and attention, were related to the need for cognitive closure. Previous research showed attribution to be related to the need for cognitive closure while this present study found perception of change and attention, but not attribution, was related to the need for cognitive closure. The personality measures were related to each other, suggesting a commonality among them as suggested by previous research (Webster \& Kruglanski, 1994).

\section{Memory Recall}

Because individuals remember what they attend to and that are relevant, a memory recall task provides a powerful tool to understanding the types of information participants seek and find relevant. Participants were given a memory recall task of their first scenario at the conclusion of the study. Information was coded into categories of information as described previously in the Method section. See Appendix I for Memory Coding description.

Ten participants' data were used to establish coding reliability. Two coders independently coded the memory recall data after reliability was obtained. Each participant recalled more than one information item. This resulted in a total of 173 cases. Inter-rater reliability was established for each code. A kappa of .89, .57, and .75 was attained for Dispositional Target (DT), Dispositional Non Target (DNT), and Situational (S) respectively. A kappa of .84, and .69 was attained for Confirming and Disconfirming, 
respectively. When all cases were coded, an inter-rater reliability was again established. A total of 2660 cases for 312 participants yielded a kappa of $.90, .43, .77, .76$ and .82 for DT, DNT, S, Confirming, and Disconfirming, respectively.

The mean information items recalled in the sample was $8.53(S D=3.75)$. The mean number of accurate items information recalled in the sample was $7.48(S D=3.57)$. The mean information recalled for DT, DNT, and S, Confirming and Disconfirming in the sample was $3.89, .54,3.05,6.16$, and 1.52 , respectively. When a memory recall item was rare or ambiguous, the coders discussed and came to a unanimous agreement on the codes.

Memory Recall and Individual Differences

The result reported here combined dispositional non target (DNT) information with situational (S) information. Dispositional non target information was information that was external to the target (Andy or Michael). Hence, it was grouped as contextual.

The 2 (Dispositional, Situational) and 2 (Confirming, Disconfirming) provided four types of information: Dispositional Confirming, Dispositional Disconfirming, Situational Confirming, and Dispositional Disconfirming. I compared the individual difference measures and the types of information recalled. See Table 18. Only the overall AH scores was related to memory recall for two types of information, dispositional disconfirming and situational confirming, $r=.11, p<.05$, and $r=.15, p<.01$, respectively. These two types of information lean toward situational attribution. People higher in need for cognition remembered more dispositional confirming, situational confirming, and disconfirming information, $r=.17, p<.001, r=.21, p<.01$, and $r=.14$, $p<.05$, respectively. A higher need for cognition may have reduced the focus to all 
information. People with high need for cognitive closure remembered less dispositional confirming, situational confirming, and disconfirming information, $r=-.17, p<.001, r=$ $-.16, p<.001$, and $r=-.14, p<.05$, respectively. A higher need for cognitive closure may have facilitated a weaker focus on all types of information.

In summary, AH thinking was only related to two types of information recall while the need for cognitive closure and the need for cognition seemed to relate more to types of information recall. While people with high need for cognitive closure remember less information, people with high need for cognition recall more information.

\section{Memory Recall and Information Selection}

I examined the types of items selected from the sensemaking scenarios, and the types of information later recalled. See Table 19. The dispositional items selected were related only to dispositional information recalls. For example, dispositional confirming items selected was related to dispositional confirming information recalled, $r=.17, p<$ .001. This was also the case for disconfirming items selected. Dispositional disconfirming and situational disconfirming items selected were only related to dispositional disconfirming and situational disconfirming information recalled respectively, $r=.11, p<.05$ and $r=.19, p<.001$. On the other hand, situational confirming items selected were related to both situational confirming and disconfirming information recalled, $r=.27, p<.001$ and $r=.19, p<.001$, respectively, and to dispositional confirming information recalled, $r=.11, p<.05$.

Situation and dispositional items selected and the types of information recalled also followed these patterns. Dispositional items selected were only related to dispositional confirming information recall, $r=.14, p<.05$, while situational items 
selected were related to all three types of information recall, $r=.12, p<.05$ for dispositional confirming items, and $r=.24, p<.001$ and $r=.22, p<.001$ for situational confirming and disconfirming items, respectively.

In summary, while dispositional and disconfirming items selected were related only to the respective memory recall, situational confirming items selected were related to more diverse information recalled.

Memory Recall and Information Relevance

I then examined the types of items rated as relevant from the sensemaking scenarios and the types of information recalled. See Table 19. The patterns showed that Dispositional items relevance were only related to the respective memory recall. For example, dispositional confirming items relevance were related to dispositional confirming information recalled, $r=.20, p<.001$ and dispositional disconfirming information recalled, $r=.13, p<.05$. Dispositional disconfirming items relevance were related to dispositional disconfirming information recalled, $r=.13, p<.05$. On the other hand, situational confirming items relevance is related to both dispositional confirming information recalled, $r=.20, p<.001$, and dispositional disconfirming information recalled, $r=.13, p<.05$. It was also related to situational confirming information recalled, $r=.17, p<.001$. Situation and dispositional items relevance and the types of information recalled also followed these patterns. Dispositional items rated as relevant were related to both dispositional confirming information recalled, $r=.13, p<.05$, and $r$ $=.11, p<.05$ for dispositional disconfirming information recalled. Situational items rated as relevant were related to dispositional confirming and disconfirming information 
recalled, $r=.17, p<.05$ and $r=.13, p<.05$, respectively, and to situational confirming information recalled, $r=.14, p<.05$.

In summary, while dispositional and disconfirming items rated as relevant were related only to the respective memory recall, situational confirming items rated as relevant were related to more diverse information recalled. These patterns are consistent with those of information selection and memory recall. Memory Recall and Problem Identification and Decision

I examined the final PI and decision judgments and the types of information recalled. See Table 19. The patterns showed that final dispositional PI was related to dispositional confirming information recalled, $r=.18, p<.05$. Final situational PI was related to situational confirming information recalled, $r=.16, p<.001$. Final decision judgments were not related to any types of information recalled. In summary, PI was consistent with the types of information recalled.

\section{Qualitative Sensemaking}

In order to tap qualitative sensemaking, an open ended question, "What do you now think happened?," was asked four times. Participants' responses were coded. See Appendix C. There were 624 responses coded from 312 participants. Due to missing and unclear responses, $41(6.6 \%)$ responses were not coded. Four other responses (.6\%) were given a special code of 'withholding'. Participants with these responses, responded to the first and second open ended question as 'not sure yet' or 'more information is needed.' They withheld from responding until all information was presented. Five hundred seventy nine responses were each given one of the nine sensemaking codes in Appendix C. Two 
trained coders coded the data independently and all coding was discussed. A rater agreement was established for every response.

The nine codes were conceptually divided into two groups. See Table 20. The first group was from people who had switched their frames to be consistent with the new information. They did this at both information presentations. Responses that received Code 4 and Code 5 were in this group. The only difference between Code 4 and Code 5 is that people assigned Code 4 had received information consistent with their initial frame in the first information presentation while people assigned Code 5 did not received inconsistent information.

The second group consisted of people who resisted change in their frames to at least one of the two information presentations. Responses that fall into this group were those assigned all other codes besides 4 and 5 .

Forty two percent (42\%) of the responses displayed Code 4 . There were $16.3 \%$, Code 5, and 14.3\%, Code 1. Code 2, 3, 6, 7, 8 and 9 had less than $10 \%$ each. See Table 20 for details. There are $58.3 \%(n=364)$ who switches with new information while $34.8 \%(n=215)$ resisted new information.

To understand sensemaking within the two scenarios, the above codes were described for each scenario. For WF, there were a total of 312 responses; 20 (6.4\%) responses that were not coded due to missing and unclear response while 3 responses (1.0\%) were 'withholding' responses. There were 51.3\% responses that displayed Code 4 and $16.7 \%$ had Code 5 . There were $10.3 \%$ with Code 1 while Code 2, 3, 6, 7, 8 and 9 had less than $5 \%$ each. When the codes were combined, $67.9 \%(n=212)$ compared to $24.7 \%$ ( $n=77)$ changes sensemaking based on the information they received. 
For PD, there were a total of 312 responses; 21 (6.7\%) responses were not coded due to missing and unclear responses while 1 response (.3\%) was a 'withholding' response. There were $32.7 \%$ responses that displayed Code 4 and $16.0 \%$ had Code 5 . There were $18.3 \%$ with Code 1 while Code $2,3,6,7,8$ and 9 had less than $10 \%$ each. When the codes were combined, $48.7 \%(n=152)$ compared to $44.2 \%(n=138)$ switches their sensemaking based on the information they received.

To investigate if participant's responses were related to AH thinking and qualitative sensemaking, those who switched based on information presentation were compared to those who did not. In WF, no differences were found for AH thinking and its components as well as quantitative sensemaking. In PD, only the Attribution component was different among the two groups of sensemakers, $F(1,289)=4.09, p<.05$. However, the participants who switched less have higher situational attribution than those who had switched with the introduction of new information, $F(1,288)=4.09, p<.05,(M=4.92$, $S D=1.03$ versus $M=4.69, S D=.93$ ). No differences were found in overall AH thinking and other components as well as quantitative sensemaking.

In summary, several patterns of sensemaking were observed. In general, a majority of participants changed their sensemaking based on the new information while others stayed with earlier problem identification. Individual differences explored in this study did not predict the patterns of sensemaking. 


\section{DISCUSSION}

Globalization and advancement in technology adds complexity to the use of information. The abundance of information available from many sources including the Internet means that people face often ambiguous and contradictory information. Individuals must sort through and interpret this overload of information while balancing conflicting goals and time constraints. In addition, individual characteristics can complicate this process. Sensemaking is a way to deal with the complexity and overload of information (Choo, 1998b; O'Reilly, 1980; Weick, 1995). This study was designed to understand how individual differences influence sensemaking and information use. The individual differences under study were Analytic-Holistic (AH) thinking as well as two personality variables, the need for cognition and the need for cognitive closure. Two scenarios set the context in which sensemaking and information use were examined.

This discussion consists of five sections. In the first two sections, understanding of sensemaking and understanding information use are discussed relative to the study hypotheses and exploratory questions. Exploratory questions include a qualitative measure of sensemaking that taps how people explain events with unfolding information and a memory recall task that assesses the types of information recalled. In the third section, limitations of the study and suggestions for improvements are outlined. Next, several theoretical and applied implications are presented. Finally, future directions are proposed. 


\section{Summary of Findings}

\section{Sensemaking}

To understand sensemaking, several questions are addressed. The first three are related to $\mathrm{AH}$ thinking, $\mathrm{AH}$ thinking and information presentation, and components of AH thinking. The last two are related to the influence of two personality measures and memory recall on sensemaking. Analytic and holistic thinkers were expected to use different information because the importance of context would influence how they make sense of situations. Similarly, components AH thinking and personality differences were hypothesized to influence sensemaking. The relationship between memory recall and sensemaking is also described.

How is AH thinking related to sensemaking?

AH thinking was positively related to initial situational problem identification (PI) (H1) and decision judgments (H4). People with higher holistic thinking were more likely to find the problem to be situational and were more likely to make decisions to change the situation (i.e. changes in the organization). This confirms previous studies that associate holistic thinking with situational attribution (i.e. Choi et al. 2003) and extended the relationship to how we identify problems and make decisions.

Unlike previous research that provided all information before judgments were made, the present study found differences even when partial information was presented. The results suggest that even with minimal information, people are able to make judgments because they bring with them past experiences and beliefs that influence their sensemaking. This is consistent with Klein and colleagues (2007)'s data/frame model in which past experiences and expertise provide an initial frame for sensemaking. Analytic 
and holistic thinkers have different frameworks and these influence their initial PI and decisions.

Does the joint effect of AH thinking and information presentation influence sensemaking?

$\mathrm{AH}$ thinking together with the manipulation of information presentation affected PI and decisions. The results showed that the change from initial judgments at Time 1 to a subsequent judgment at Time 2 was affected by the breadth of information use $(\mathrm{H} 2$, H5). People with higher holistic thinking showed broader information use. When presented with situational information, holistic thinkers made more situational judgments and when presented with dispositional information, they made more dispositional judgments. While people lower in holistic thinking also displayed this pattern of judgments, it was less pronounced. This is consistent with earlier findings that people higher in holistic thinking are more inclusive of the context (i.e. Choi et al., 2007; Masuda \& Nisbett, 2001). They were more willing to use both kinds of information to modify their sense of the scenarios. The findings suggest that the initial frame changes depend on cognitive patterns and how information was used.

The joint effect of $\mathrm{AH}$ thinking and information presentation on Time 2 to Time 3 judgments was not found when additional and contrary information was presented $(\mathrm{H} 3$, H6). The non significant interactions between $\mathrm{AH}$ thinking and information presentation on subsequent judgments showed that $\mathrm{AH}$ thinking did not influence judgments on the longer term. The focus appeared to have shifted from individual cognitive patterns to the information given. While a majority of the analyses from Time 2 to Time 3 were not significant, one interaction effect was significant for dispositional decision judgments in the PD scenario. Scenario differences will be discussed in a later section. 
While most past research measures the effect of AH thinking only once, this research presents material sequentially to assess effect. The results extend the models of sensemaking to suggest that individual differences may not have a lasting effect in the process of sensemaking. The results here suggest that $\mathrm{AH}$ thinking matters in the initial use of the information but as additional information was given, the content becomes more important. Consistent with the idea of sensemaking, when we are faced with a new situation, we first make sense with our past experiences and may be more influenced by our individual characteristics. As more information is received about the situation, information influences sensemaking more than individual characteristics.

Do the components of AH thinking affect sensemaking?

I compared AH components with PI and decision judgments. Tolerance for Contradiction did not affect sensemaking (H12 and H13). People with higher Tolerance for Contradiction were expected to be less polarized between the situational and dispositional options. Results showed no significant relationships. The use of a more analytic sample instead of cross-national samples may have influenced the outcome. Because these participants are likely to see the options as contradictory, they may be less likely to adopt both options to the same degree as would a holistic sample. The negative relationship between situational and dispositional PI judgments, $r=-.15, p<.01$, suggests that even though the response format allowed for the adoption of both situational and dispositional approaches, participants in this study saw them as opposing options. This was also true between situational and dispositional decision judgments, $r=$ $-.16, p<.01$. See Table 7 .

I also examined components of $\mathrm{AH}$ thinking in relation to fundamental attribution 
error (FAE), which refers to making dispositional judgments even when situational factors are present during sensemaking. A higher rating of disposition judgments compared to situational judgments reflects FAE. Attribution was the only component of AH thinking that was related to the difference between disposition and situational PI during sensemaking, $r=-.22, p<.05$. See Table 15 . Attribution was also negatively related to the differences in decisions, $r=-.14, p<.05$. See Table 15. The negative relationships supported the idea that people with a situational view of causal attribution were less susceptible to FAE. They adopted situational approaches and were less likely to indicate problems and solutions to be dispositional. This is consistent with previous FAE research (Gilbert \& Malone, 1995).

Does the joint effect of cognitive and personality differences influence sensemaking?

The Need for Cognitive Closure was expected to interact with Attribution (H16) to make FAE higher for people with a high need for cognitive closure and low situational attribution. While Hong and colleagues (2000) found that a high need for cognitive closure moderated the relationship between attribution and the degree of FAE, this study did not replicate this finding. Because participants worked at their own paces, their need for cognitive closure may have been lessened. Perhaps the inclusion of ambiguous information and the addition of time pressures in scenarios would elicit the need for cognitive closure.

The Need for Cognition was expected to interact with AH thinking (H18) to influence FAE. FAE was expected to be lower for people with a high need for cognition and a high AH thinking. The result did not support this expectation. Possibly, information presented in the scenarios was manageable. Perhaps the addition of information items and 
increased complexity to the scenario may distinguish the responses of people with high and low need for cognition.

\section{How do final PI and decision judgments relate to types of memory recall?}

I used a memory task to tap four types of information recall. The results showed that confirming information rather than disconfirming information is related to PI and decision judgments. Those who identified problems to be situational were more likely to remember situational confirming information. Those who identified problems to be dispositional were more likely to remember dispositional confirming information. These patterns showed that people use confirming information during sensemaking. While these patterns are interesting, we could not conclude the causal direction of a particular judgment and the confirming information recall. This needs further research.

\section{Qualitative Sensemaking}

I used qualitative methods to examine how participants respond when there is limited information for initial sensemaking and how sensemaking changes with inconsistent information. Almost all the participants appeared to have an initial frame for the event. While this could be influenced by the suggestion of causal factors in the beginning of each scenarios (i.e. director vs. external changes), participants were able to explain their initial frame even with this limited information. When inconsistent information was given, a majority of participants made changes in their sensemaking consistent with the information presented. A substantial percentage, however, ignored the inconsistent information and stay with their current frame. These patterns of sensemaking are consistent with forms suggested by Klein and colleagues (2007). Surprisingly, several responses indicate an opposite pattern of change. These participants' subsequent 
sensemaking were different from the information presented even though the information presented was consistent with their previous sensemaking. These patterns may be consistent with the models of correction for attribution discussed in Gilbert and Malone (1995) and Choi et al. (1999). Further research in this area is needed to understand the complexities of sensemaking.

I divided the participants into those who switched with new information received and those who did not. I compared these two groups on their individual differences. No significant relationships were found between individual differences and qualitative sensemaking.

In summary, AH thinking affected initial sensemaking. This means that people have past experiences, cognitive patterns, belief systems, and expertise that affect their sensemaking. The different $\mathrm{AH}$ frameworks determine how information was used during sensemaking. People interact with their information environment in a way that changes their sense to be consistent with ways they value information. The diminishing effect of AH thinking exemplifies the effect of time in understanding sensemaking. With additional information, the content of information played a more significant role during sensemaking. The qualitative data also support the use of information presented to modify sensemaking. The data revealed that people differ in the way they explain the same scenarios. While individual differences could not explain this difference, the memory recall data supports the availability of different information during sensemaking. Participants focused on confirming information that was consistent with their PIs in the scenario. The personality variables were not related to sensemaking. Lastly, there is some evidence that scenario differences might have affected results, again emphasizing the 
importance of context for sensemaking.

\section{Information Management/Use}

The second goal was to understand information use. Choo (1998b) suggested several information characteristics important for information management in organizations. Among them are amount (number of items), type, and relevance. To examine how participants use information, I presented information sequentially and asked participants to select information items from different categories. Next, they rated the usefulness of dispositional and situational information. Components of $\mathrm{AH}$ thinking and two personality variables were included to understand information selection and rated usefulness.

How do the components of AH thinking relate to information use?

Attribution was the only component of $\mathrm{AH}$ thinking related to the information management characteristics investigated. While attribution was unrelated to both the overall items (H9) and dispositional items selected, it was related to the situational items (H10). This is consistent with the notion that people with situational perspectives of causal attribution look for situational information. Yet, no difference was found for the selection of dispositional information items. This supports the earlier finding that people with both dispositional and situational perspectives focus on dispositional information. The overall AHS score was not related to the types of information selected (See Table 13). This supports the findings by Choi and colleagues (2003) that overall AH thinking is not related to dispositional or situational items selection. The present study suggests that the component of Attribution may be a better predictor of information selection than overall AH thinking. 
People who had a situational perspective rated overall information and situational information to be more relevant (H11). Consistent with the result of information selection, people with a situational perspective also emphasized the relevance of dispositional information.

None of the AH components were related to the number of categories used in this study (H12). This is inconsistent with Markus and colleagues (2006) who found Japanese participants used more diverse categories for explanation of events. They used qualitative data to explore participants used of categories for explanation while I used a quantitative approach. A methodological difference may explain this deviation. Several participants appeared to have misunderstood the instructions and selected one information item from each category. This resulted in all categories being selected.

Attention was not related to information selection (H7) and information relevance (H8). Because participants were asked to read carefully all the information presented, this may have directed their attention and created an atypical attention focus. Previous research that found differences in attention used animated stimuli with short durations of presentation. This made attention more selective. Hence, the present scenarios or methods may not be good for eliciting differences in attention.

\section{How do personality differences relate to information use?}

The Need for Cognitive Closure was related to the selected dispositional information items in an opposite expected direction (H15). Winter and colleagues (1985) suggested that people with a higher need for cognitive closure make dispositional attributions as it is easier to reach a conclusion than it is to make situational attributions. The present study however suggests that this affinity towards attribution is not the result 
of selecting more dispositional information. Instead, people with higher need for cognitive closure selected less dispositional information and also less situational information. This is consistent with the findings of Webster and Kruglanski (1994). They found participants with a higher need for cognitive closure considered less information when making judgments. The present study confirms that, regardless of available information, people with a higher need for cognitive closure are less likely to use the information.

The need for cognition was not related to the number of information items selected (H17). It was also unrelated to specific types of items - dispositional, situational, confirming, and disconfirming information (See Table 13). Perhaps the need for cognition is important for other processes during sensemaking as suggested in the information recall section below. Is memory recall related to information use?

I looked at the items selection and relevance to information recall. I found three patterns for the link between items selections and recall. First, people who selected more dispositional confirming items also remembered more dispositional confirming information. Second, those who selected more dispositional disconfirming items recalled more dispositional disconfirming information. Those who selected more situational disconfirming items recalled more situational disconfirming information. The two disconfirming types of items selection were related only to their respective types of memory recall. These two patterns support earlier research that found that people are likely to select and remember information they judge as important (Wiley, 2004). Finally, situational confirming items selection showed a broader overlap with other information 
recall. Not only is it positively related to both confirming and disconfirming situation information recall, it is also positively related to dispositional confirmation information recall. These findings provided a better understanding of the effect that information selection has on information recall.

The above patterns of memory recall with information selection were similar to those for information relevance. The patterns of relationships suggest that people with a situational frame consider situational information but also dispositional information during sensemaking, whereas people with dispositional frame emphasize dispositional information to the exclusion of situational information. These patterns seem to be consistent with the finding that holistic thinkers include both context and focal objects during sensemaking and with earlier research on free memory recall of visual animation images (Masuda \& Nisbett, 2001).

In summary, I found situational attributors focused on situational information. They selected and rated situational items to be more useful. However, dispositional information was also important for situational attributors. The memory recall data supported the idea that they also consider disposition information during sensemaking. Participants' selection and ratings of situational confirming items and memory recall patterns suggest broader types of information were considered. While other components of $\mathrm{AH}$ thinking and the need for cognition were not related to information use, people with high need for cognitive closure selected less information items.

Do individual differences affect types of items recalled?

The results showed that holistic thinking was positively related to situational confirming and dispositional disconfirming recall of information. Both types of 
information are types of information that suggest the context is the problem. Situational confirming information indicates the context is the problem while dispositional disconfirming information suggests the person is not the problem. This is consistent with Wiley's (2004) findings that people often experience memory bias in favor of the information with which they agree.

The Need for Cognition was positively related to the number of dispositional confirming information recalled, and both situational confirming and disconfirming information recalled, while the Need for Cognitive Closure was negatively related to these types of information. These results supported previous findings of the willingness of people with higher need for cognition to deal with information (Berzonsky \& Sullivan, 1992) and people with higher need for cognitive closure to consider less information (Webster \& Kruglanski, 1994). Additionally, the present study looked at the different types of information. These two personality variables were found to play a role in memory recall.

\section{Limitations}

The first four limitations are related to the study's scenarios while the last two are related to the generalizability of results. First, while the feedback from participants in the pilot studies suggested the equivalence of the scenarios, the scenarios comparison reported here indicated they were not equivalent. The content differences may have influenced the results. The roles of the target person in the scenarios were different, a director versus a line worker. Undergraduate participants appeared to identify more with the line worker. They may also attribute more responsibility to the director because he is a person of authority. While differences in scenarios may add complications to 
interpretations of results they also add richness to different representations of the work environment. The differences suggest a variety of scenarios may be crucial to represent the complexity of sensemaking. This has implications for the need to generate different scenarios that represent the complexity in organizations as people encounter different problems in their work.

The second limitation of the material is that the scenarios provided both dispositional information and situational information equated for amount and strength. While this is a good experimental control, it does not represent how people with different analytic and holistic tendencies search for information in a non-experimental setting. In natural environments, they are likely to focus on their preferred kind of information. Future research can assess how participants choose the information they view instead of presenting all kinds of information. This would better reflect natural information management.

The third limitation is that the order of information presentation may affect sensemaking. In this study, dispositional information was presented first and then situation information or vice versa. This presentation may have a canceling effect and led to judgments being less polarized between dispositional and situational judgments at Time 3. Future research may present information differently. Information in the scenarios could be presented to be progressively more dispositional or progressively more situational. This extends the understanding of effects of AH thinking and information presentation on sensemaking.

The fourth limitation is also related to the scenarios. The scenarios in this study were designed to tap causal attribution. Thus, Attribution, a component of AH thinking 
may have matched the content of the sensemaking scenarios while other components of AH thinking may not. This may have contributed to their non-significant relationships. Using content related to the other components may have yielded different results. Hence, we should not be quick to conclude that other components were less important for information use. For example, using visual/video presentation may be more related to the Attention component and may result in a stronger relationship as shown in previous research by Masuda and Nisbett $(2001 ; 2006)$. This method may make background information more salient for people with broader attention.

The fifth limitation is related to the sensemaking processes in the study. Sensemaking is a complex phenomenon. The design of this study assumed that the information presented influenced PI and decision judgments. However, in reality, the relationship between judgments and information use is probably reciprocal and ongoing until an action has to be taken. In other words, judgments or current sense of the situation may also drive information gathering, which in turn may influence the perception of information relevance. To understand the casual effects of this relationship requires additional analyses (i.e. a cross-panel analysis).

The final limitation is related to generalizability of the study to cross-cultural interaction. With the importance of international exchanges in the military, transportation, commerce, and humanitarian domains, it is important to understand the present study in a cross-cultural context. The AH thinking concept is borrowed from cultural psychology. While the results presented here suggest a difference between analytic and holistic thinkers, we need to be cautious if we wish to generalize these 
results to national group differences. The present study needs to be replicated using national groups comparison.

$$
\text { Implications }
$$

\section{Theoretical Implications}

The findings of this study demonstrate the complexity of sensemaking. This study is an initial look at the complexity of sensemaking and information management for analytic and holistic thinkers. In order to represent the complex processes of sensemaking, information presented over time and the 'sense' at each of those times was assessed. Because our understanding of a situation can be a dynamic process, it is crucial for understanding how $\mathrm{AH}$ cognition interacts with the information presented. We need to make sense of information that is both consistent with and contradicts our view. The results confirmed the importance of using scenarios that represent the processes involved. For example, with only two measurement points, we would have concluded that changes in sensemaking were due to varying use of information by analytic and holistic thinkers. However, by including addition measurement points, we saw a bigger picture.

Subsequent sensemaking no longer differed by how analytic and holistic thinkers use information. The information content alone drove sensemaking. A different conclusion would have been reached without the additional measurement times.

I attempted to link quantitative and qualitative sensemaking data to individual differences. The qualitative data shows individuals use different forms of sensemaking when presented with the same scenario. This study supports the Data/Frame model in an experimental setting. In some cases, participants changed their sensemaking even when information presented was consistent with their frame. This suggests that while 
elaborating their frames, participants were able to directly reframe their understanding of the situation. The presence of inconsistent information might not be needed for them to question their frame. This suggests there might be idiosyncratic patterns that may not be represented by the model. Further research is needed.

The results support that analytic and holistic thinkers may bring with them different frameworks of causal attribution and that their frameworks guide the selection of information during sensemaking. First, people higher in holistic thinking were more likely to identify situational problems and adopt situational-based solutions even with limited information. Second, their cognition coupled with the types of information presented changed their judgments. Nevertheless, this effect did not last long. Third, holistic thinkers' focus on situational items supports differences in the information management process. Lastly, the patterns of recall show simultaneous focus on both situational and dispositional information while situational items were selected. However, no relationship was found for dispositional items selection and situational information recalled. These patterns of recall further emphasize the different information management processes. The different information needs of analytic and holistic thinkers support the idea that people bring with them past experiences and knowledge that may bias their information search processes.

Practical Implications

The AH thinking dimension was borrowed from cross-cultural literature. This may suggest that sensemaking and information use differences may be important during cross-cultural interactions. If holistic people need more information, this can limit their sensemaking when information is limited. Similarly, if analytic people are given more 
information than they would normally seek, it may alter their sensemaking. This study used U.S. participants who in cross-cultural literature typically make dispositional attribution. However, in the present study they also could make situational attributions. They might not have made situational attributions as strongly as dispositional attributions if they selected their own information. This study suggests that multinational teams may need to learn how to channel information appropriately to arrive at a common understanding.

Differing use of information has implications for information sharing in teams (Lin, Klein, Radford, Choi, \& Lien, 2007). In multinational organizations, multidisciplinary and multinational teams often carry out much of the work. While national differences can enrich the team's capacity, they can also complicate the teamwork and coordination. One critical task facing multinational teams is information management: making sense and using a myriad of complex information to achieve team goals and tasks. To do this, each team member must seek, select, organize, interpret, and share information. Each team member has his or her own knowledge base, mental models, and dynamic representations of problems. People are continually adding to their knowledge base, redefining their mental models, and reinterpreting their dynamic representations of problems using both existing and new information (Hinsz, 1995). When people work on teams, information and knowledge is exchanged so that a shared sense of the situation can emerge. With incongruent perceptions of information needs, information exchange may be limited or overflowed, thereby distorting sensemaking. Analytic and holistic people may identify cause differently as a result of exposure to an unfamiliar set of information. The sharing of unaccustomed amounts of information may 
also have a positive effect in providing focus to holistic thinkers and breadth to analytic thinkers. When there are differences in the selection of information during sensemaking, the outcome might be compromised or enhanced. Instead of assuming people use information the same way, understanding the cognitive differences of people from other nations can further predict communication conflict in multinational teams.

\section{Future Directions}

While this study investigated aspects of sensemaking and information use, the complexity of these processes provided opportunities to explore dynamics beyond the initial effort. First, I suggested improving the current measure of AH thinking. Then, I suggested several additional information characteristics and cultural dimensions yet to be explored in the context of sensemaking. Next, I discussed how contextual factors can be included to represent the complexity of information use and sensemaking in real world settings. Lastly, I presented several ideas for naturalistic investigations of sensemaking and information management.

\section{Analytic-Holistic Thinking Construct}

In the present study and in the literature, $\mathrm{AH}$ thinking is assumed to be a single dimension. The Analytic-Holism Scale (Choi et al., 2007) reflects this. However, all items in this scale tap holistic thinking and none tap analytic thinking. Future research should include items that tap analytic thinking to explore if a person could be high on both analytic and holistic thinking. This may extend further understanding of this construct.

\section{Additional Information Characteristics}

Choo (1998a) and O'Reilly (1983) listed many characteristics of information that 
organizations consider when making decisions. This study looked at three: amount, type, and relevance. Other characteristics of information that still need to be investigated in the context of sensemaking include saliency, ambiguity, forms, credibility of sources, accessibility and valence. Using the current paradigm, information presented can be manipulated in terms of the ambiguity of the content, the sources of information, and different formats of information presentation (i.e. text, pictorial, base rates, etc.). For example, presenting information from different sources, such as formal versus informal sources, replicates information gathering in the real world. Including these characteristics would give a more comprehensive view of information use that mirrors the complexity of sensemaking.

\section{Additional Cultural Dimensions}

Besides AH thinking, other cultural dimensions, including Tolerance of Uncertainty and Hypothetical-Concrete reasoning, may influence the way we manage information and make sense. Tolerance of Uncertainty (Hofstede, 1980), describes how people function in the face of uncertainty. Uncertainty is stressful for those with low tolerance and they work to avoid it. They prefer specifics, consider details, abhor incomplete information, resist plan changes, and feel unsettled until there is a final decision (Helmreich \& Merritt, 1998). They prefer formal rules and ritualistic behaviors to enhance stability (Lane, DiStefano, \& Maznevski, 1996). Consensus is valued because disagreement causes stress when it generates questions and uncertainty (Lane \& DiStefano, 1992). In contrast, those who are high in Tolerance of Uncertainty are comfortable with ambiguity and incomplete information (Hofstede, 1980). They adapt readily to change and act with limited information (Hall \& Hall, 1990). Rules and rituals 
may be ignored or treated flexibly because they are viewed as ineffectual (Helmreich \& Merritt, 1998). People high in Tolerance of Uncertainty accept dissent and are less threatened by deviant ideas.

During sensemaking, information is processed to reduce ambiguity (Weick, 1995). People who are low in tolerance for uncertainty may not be comfortable with frequent changes during sensemaking. Because they prefer certainty to changing plans, they may not seek information that showed a contradictory view in order to maintain stability in the process of sensemaking. People who are high in tolerance for uncertainty may be comfortable when information shifts, resulting in view changes. They are more likely to take action even with limited information, facilitating the process of sensemaking. In order to study Tolerance for Uncertainty in the current research paradigm, information would be manipulated to introduce ambiguity into the situation to test the effect on sensemaking. Time pressures and overload of information can also be introduced to increase uncertainty.

Hypothetical-Concrete reasoning may also influence sensemaking. Hypothetical thinkers use mental playing out of alternative strategies to consider different outcomes (Markus \& Kitayama, 1991). They separate reasoning from reality to consider options in an abstract, hypothesis-driven manner using "what if" questions. Concrete thinkers respect the constraints imposed by context and carefully integrate these constraints into their thinking (Markus \& Kitayama, 1991). Reasoning is grounded in past personal and national experience in similar contexts. Hypothetical thinking uses abstract speculation while concrete thinking analyzes events in grounded reality. 
As hypothetical thinkers play out scenarios, the sensemaking process is more flexible and varied and they may generate more hypotheses. These people may have several frames and eliminate each in a hypothesis driven manner. Concrete thinkers may be more constrained but more precise in their sensemaking because they may fit information to previous experiences. While precise, concrete thinkers are highly committed to a particular course of action based on one interpretation of the information, they may lack flexibility and the ability to change strategies in light of new information. Concrete thinkers may use fewer but more elaborate frames during sensemaking. However, concrete thinkers may view hypothetical thinkers' sensemaking as groundless. Hypothetical-Concrete thinkers can be compared in the qualitative forms of sensemaking they adopt. Different types of information such as if-then kind of reasoning versus base rates information can be presented to examine if hypothetical and concrete thinkers use them differently.

\section{Contextual Factors}

The selection and relevance of information may not only be biased by individual differences but also by situational constraints such as goals, decision purposes, time pressures, and sources of information (O'Reilly, 1983). To investigate the impact of these constraints, future research might include other aspects of situational constraints beyond information presentation. Again, these factors would extend the understanding of how people use information. In addition, we could observe the interplay of individual differences and the suggested situational constraints on sensemaking. For example, the scenarios could be augmented by including time pressure and changing goals. In the present study, individual personality differences did not affect the evaluation of 
information characteristics or sensemaking. Perhaps including time pressure in the scenarios would enhance individual differences effects. Including a changing and conflicting goals environment may relate better to Tolerance for Contradiction as it provides a situation where participants have to make decisions about conflicting goals. They may differentiate or synthesize goals based on their tolerance for contradiction.

\section{Naturalistic Investigation}

Finally, the real test of laboratory outcomes is their ability to predict real world behaviors (Dobbins, Lane \& Steiner, 1988). Hence, future research should investigate these processes in a naturalistic environment. Choo (1998b) and Bhagat and colleagues (2002) emphasized the importance of information sharing for organizations to be effective. Specifically, Bhagat and colleagues (2002) suggested that transfer of tacit knowledge between organizations may be easier for organizations with higher holistic thinking employees. The use of technology allows the tracking of information. For example, with information gathering and sharing over e-mail, transactions can be tracked objectively in organizations willing to participate in such research. Understanding how individuals share information and how this affects decisions and organization functioning would be important for understanding organizational effectiveness. Hence, future research needs to not only investigate the sensemaking processes at the individual level but also at the team and organizational level. 


\section{CONCLUSION}

Often in an organizational context, goals may be ill-defined or lack consensus, information may be incomplete and ambiguous, decision makers may be pursuing multiple or competing objectives, and time constraints may be undermining the adequate use of available information. This study investigated how AH thinking is related to information management and sensemaking, two processes that are crucial for decision making and organizational action. When individuals experience high pressure and complexity they are likely to fall back on cognitive scripts for how to behave. Under these circumstances, individuals and more importantly, multinational teams, can make different plans, have different goal priorities, and draw different conclusions. When teams have different interpretations they differ in sensemaking. Although differences can lead to difficulties in establishing shared understanding, they can also provide different views and diverse solutions (Klimoski \& Mohammed, 1994; Orasanu \& Salas, 1993; Triandis, Hall, \& Ewen, 1965). Understanding AH thinking differences and their effects is a first step to understanding how multinational teams and organizations might channel information to arrive at a common understanding, shape communication based on a group's information needs, and manage the additional demands for consensus building. 


\section{TABLES}

Table 1. Differences between Analytic and Holistic Thinking (Nisbett, 2003)

Analytic Thinking

Holistic Thinking

\begin{tabular}{ll}
\hline - Individualism & - Collectivism \\
- Westerners & - East Asians \\
- Detach from context & - Orient to whole context \\
- Attention: A focus on attributes & - Attention to relationships between \\
& categories
\end{tabular}


Table 2. Design of Scenarios

\begin{tabular}{|c|c|c|}
\hline $\begin{array}{c}\text { Scenario } \\
\text { Order }\end{array}$ & Information Presentation: D-S & Information Presentation: S-D \\
\hline $\begin{array}{l}\text { Scenario 1- } \\
\text { Scenario } 2\end{array}$ & $\begin{array}{l}\text { Booklet 1: } \\
\text { Scenario } 1^{\text {D-S }} \text { Scenario } 2^{\text {D-S }}\end{array}$ & $\begin{array}{l}\text { Booklet 2: } \\
\text { Scenario } 1{ }^{\text {S-D }} \text { Scenario } 2^{\text {S-D }}\end{array}$ \\
\hline $\begin{array}{l}\text { Scenario 2- } \\
\text { Scenario } 1\end{array}$ & $\begin{array}{l}\text { Booklet 3: } \\
\text { Scenario } 2^{\text {D-S }} \text { Scenario } 1^{\text {D-S }}\end{array}$ & $\begin{array}{l}\text { Booklet 4: } \\
\text { Scenario } 2^{\text {S-D }} \text { Scenario } 1^{\text {S-D }}\end{array}$ \\
\hline
\end{tabular}

$\mathrm{D}-\mathrm{S}=$ Dispositional first, Situation second

$\mathrm{S}-\mathrm{D}=$ Situational first, Dispositional second 


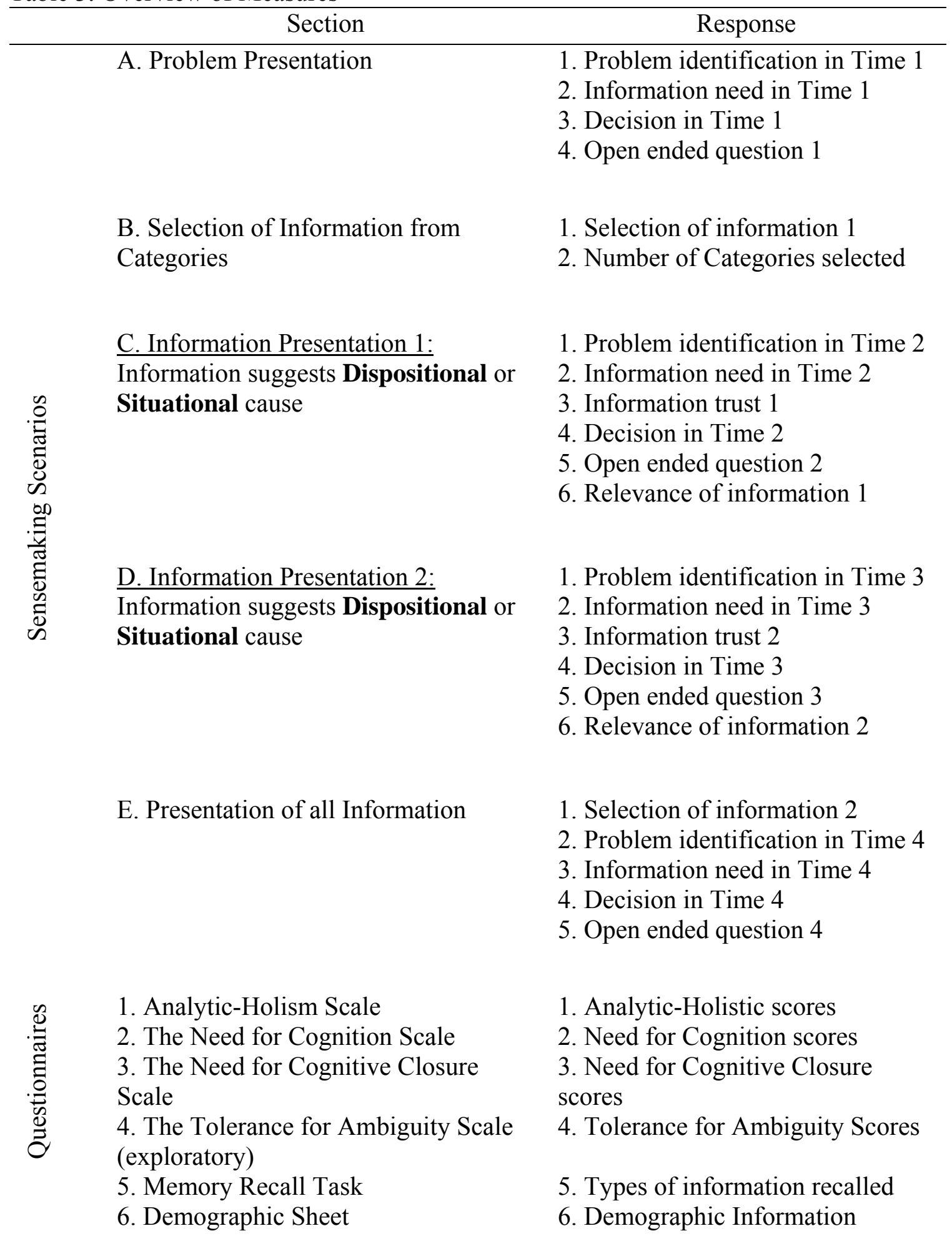


Reliability

\begin{tabular}{|c|c|c|c|c|c|c|}
\hline Outcome Variables & $\mathrm{n}$ & Overall & Time 1 & Time 2 & Time 3 & Time 4 \\
\hline \multicolumn{7}{|l|}{ Situational PI } \\
\hline Combined & 6 & & .63 & .72 & .65 & .74 \\
\hline Production Dilemma & 3 & & .74 & .81 & .79 & .84 \\
\hline Westerly Foundation & 3 & & .67 & .60 & .64 & .62 \\
\hline \multicolumn{7}{|l|}{ Dispositional PI } \\
\hline Combined & 6 & & .79 & .88 & .83 & .81 \\
\hline Production Dilemma & 3 & & .89 & .93 & .93 & .93 \\
\hline Westerly Foundation & 3 & & .84 & .89 & .86 & .84 \\
\hline \multicolumn{7}{|l|}{ Situational Decision } \\
\hline Combined & 6 & & .69 & .75 & .71 & .73 \\
\hline Production Dilemma & 3 & & .81 & .76 & .72 & .79 \\
\hline Westerly Foundation & 3 & & .73 & .74 & .67 & .66 \\
\hline \multicolumn{7}{|l|}{ Dispositional Decision } \\
\hline Combined & 6 & & .71 & .75 & .67 & .66 \\
\hline Production Dilemma & 3 & & .78 & .73 & .67 & .66 \\
\hline Westerly Foundation & 3 & & .73 & .74 & .67 & .66 \\
\hline \multicolumn{7}{|l|}{ Information Selection 1} \\
\hline Combined & 72 & .92 & & & & \\
\hline Production Dilemma & 36 & .87 & & & & \\
\hline Westerly Foundation & 36 & .87 & & & & \\
\hline \multicolumn{7}{|l|}{ Information Selection 2} \\
\hline Combined & 52 & .84 & & & & \\
\hline Production Dilemma & 26 & .73 & & & & \\
\hline Westerly Foundation & 26 & .74 & & & & \\
\hline \multicolumn{7}{|l|}{ Categories Selection } \\
\hline Combined & 18 & .89 & & & & \\
\hline Production Dilemma & 9 & .84 & & & & \\
\hline Westerly Foundation & 9 & .82 & & & & \\
\hline \multicolumn{7}{|c|}{ Situational Info Relevance } \\
\hline Combined & 26 & .86 & & & & \\
\hline Production Dilemma & 13 & .80 & & & & \\
\hline Westerly Foundation & 13 & .76 & & & & \\
\hline \multicolumn{7}{|c|}{ Dispositional Info Relevance } \\
\hline Combined & 26 & .86 & & & & \\
\hline Production Dilemma & 13 & .84 & & & & \\
\hline Westerly Foundation & 13 & .78 & & & & \\
\hline
\end{tabular}


Table 5. Participant's Demographics

\begin{tabular}{|c|c|c|c|}
\hline \multirow{2}{*}{ Variables } & & \multicolumn{2}{|c|}{$\mathrm{N}=312$} \\
\hline & & Frequency & Percentage \\
\hline \multirow[t]{2}{*}{ Gender } & Male & 83 & 26.6 \\
\hline & Female & 229 & 73.4 \\
\hline \multirow{3}{*}{ Age } & $18-21$ & 281 & 90.1 \\
\hline & $22-25$ & 20 & 6.4 \\
\hline & $>25$ & 11 & 3.5 \\
\hline \multirow[t]{5}{*}{ Ethnic } & Caucasian & 202 & 64.7 \\
\hline & African & 83 & 26.6 \\
\hline & Asian & 2 & .6 \\
\hline & Hispanic & 8 & 2.6 \\
\hline & Other & 17 & 5.4 \\
\hline \multirow{4}{*}{$\begin{array}{l}\text { Childhood } \\
\text { Background }\end{array}$} & Urban & 96 & 30.8 \\
\hline & Suburban & 134 & 42.9 \\
\hline & Rural & 74 & 23.7 \\
\hline & Other & 5 & 1.6 \\
\hline \multirow{4}{*}{$\begin{array}{l}\text { Year in } \\
\text { School }\end{array}$} & Freshman & 226 & 72.4 \\
\hline & Sophomore & 57 & 18.3 \\
\hline & Junior & 12 & 3.8 \\
\hline & Senior & 14 & 4.5 \\
\hline \multirow[t]{9}{*}{ Major } & Engineering & 24 & 7.7 \\
\hline & Social/Behavioral Science & 47 & 15.1 \\
\hline & Natural Science & 32 & 10.3 \\
\hline & Business & 36 & 11.5 \\
\hline & Humanities/Fine Arts & 23 & 7.4 \\
\hline & Education & 17 & 5.4 \\
\hline & Health Sciences & 106 & 34.0 \\
\hline & Law & 7 & 2.2 \\
\hline & Undecided & 16 & 5.1 \\
\hline \multirow[t]{4}{*}{ College GPA } & $3.0-4.0$ & 174 & 88.1 \\
\hline & $2.0-2.99$ & 89 & 28.5 \\
\hline & $1.0-1.99$ & 11 & 3.5 \\
\hline & $0-.99$ & 1 & .3 \\
\hline \multirow[t]{5}{*}{ Work Hours } & $<10$ hours & 15 & 4.8 \\
\hline & $<20$ hours & 62 & 19.9 \\
\hline & $<30$ hours & 97 & 31.1 \\
\hline & $<40$ hours & 61 & 19.6 \\
\hline & $>40$ hours & 45 & 14.4 \\
\hline
\end{tabular}


Table 6. Scenarios Comparison on Outcome Scores

\begin{tabular}{|c|c|c|c|c|c|c|c|}
\hline & & & & & & & \\
\hline Variables & $M$ & $S D$ & $M$ & $S D$ & $\begin{array}{l}\text { Pillai's } \\
\text { Trace }\end{array}$ & $\Lambda$ & $F$ \\
\hline Category Selection & 5.81 & 2.69 & 5.92 & 2.58 & .00 & 1.00 & .77 \\
\hline $\begin{array}{l}\text { \% Situational Info } \\
\text { Selected } 2\end{array}$ & 64.65 & 20.51 & 64.15 & 18.51 & .00 & 1.00 & .19 \\
\hline $\begin{array}{l}\text { \% Dispositional Info } \\
\text { Selected } 2\end{array}$ & 56.78 & 24.30 & 56.39 & 20.30 & .00 & 1.00 & .09 \\
\hline $\begin{array}{l}\% \text { Overall Info } \\
\text { Selected } 1 \& 2\end{array}$ & 56.29 & 15.60 & 56.21 & 15.37 & .00 & 1.00 & .02 \\
\hline $\begin{array}{l}\text { Situational Info } \\
\text { Relevance }\end{array}$ & 5.10 & .96 & 5.39 & .81 & .11 & .89 & $39.18 * *$ \\
\hline $\begin{array}{l}\text { Dispositional Info } \\
\text { Relevance }\end{array}$ & 4.91 & 1.10 & 4.79 & 1.01 & .01 & .99 & $3.91 *$ \\
\hline $\begin{array}{l}\text { Overall Info } \\
\text { Relevance }\end{array}$ & 5.09 & .82 & 5.19 & .75 & .02 & .98 & $6.54 *$ \\
\hline $\begin{array}{l}\text { Difference in Final PI } \\
\text { Judgments }\end{array}$ & -1.62 & 2.53 & -.67 & 1.86 & .10 & .90 & $36.02 * *$ \\
\hline $\begin{array}{l}\text { Difference in Final } \\
\text { Decision Judgments }\end{array}$ & -.97 & 2.50 & -.95 & 2.03 & .00 & 1.00 & .02 \\
\hline
\end{tabular}

Note: $* p<.05, * * p<.01$ 
Table 7. Individual Differences, Problem Identification, and Decision Judgments for Combined Scenarios

\begin{tabular}{|c|c|c|c|c|c|c|c|c|c|c|c|c|c|c|c|c|c|c|c|c|c|c|c|c|}
\hline & 1 & 2 & 3 & 4 & 5 & 6 & 7 & 8 & 9 & 10 & 11 & 12 & 13 & 14 & 15 & 16 & 17 & 18 & 19 & 20 & 21 & 22 & 23 & 24 \\
\hline 1 & 1 & & & & & & & & & & & & & & & & & & & & & & & \\
\hline 2 & $.57 * *$ & 1 & & & & & & & & & & & & & & & & & & & & & & \\
\hline 3 & $.72 * *$ & $.20 * *$ & 1 & & & & & & & & & & & & & & & & & & & & & \\
\hline 4 & $.59 * *$ & $.19 * *$ & $.21 * *$ & 1 & & & & & & & & & & & & & & & & & & & & \\
\hline 5 & $.26^{* *}$ & $-.25 * *$ & .06 & -.11 & 1 & & & & & & & & & & & & & & & & & & & \\
\hline 6 & -.05 & $.12 *$ & -.10 & -.01 & $-.12 *$ & 1 & & & & & & & & & & & & & & & & & & \\
\hline 7 & .03 & -.02 & $.18^{* *}$ & -.04 & -.09 & $-.49 * *$ & 1 & & & & & & & & & & & & & & & & & \\
\hline 8 & -.01 & .00 & .01 & -.11 & .08 & $-.39 * *$ & $.34 * *$ & 1 & & & & & & & & & & & & & & & & \\
\hline 9 & $.13^{*}$ & .01 & $.15^{* *}$ & .09 & .02 & .06 & .08 & $-.14 *$ & 1 & & & & & & & & & & & & & & & \\
\hline 10 & -.04 & .05 & -.01 & -.08 & -.06 & .00 & -.02 & -.08 & .05 & 1 & & & & & & & & & & & & & & \\
\hline 11 & $.12 *$ & .03 & $.12 *$ & .06 & .05 & -.04 & .06 & -.10 & $.43 * *$ & .08 & 1 & & & & & & & & & & & & & \\
\hline 12 & .10 & .03 & .08 & .06 & .04 & .00 & -.08 & .01 & -.03 & $.29 * *$ & $-.36^{* *}$ & 1 & & & & & & & & & & & & \\
\hline 13 & $.17 * *$ & .03 & $.20 * *$ & $.12 *$ & .00 & .05 & .01 & -.09 & $.35 * *$ & .01 & $.42 * *$ & $.12 *$ & 1 & & & & & & & & & & & \\
\hline 14 & .00 & .07 & -.04 & .01 & -.06 & -.08 & .03 & -.06 & .03 & $.40 * *$ & $.21^{* *}$ & .04 & -.05 & 1 & & & & & & & & & & \\
\hline 15 & $.20 * *$ & .02 & $.23 * *$ & .08 & .10 & .01 & .00 & -.10 & $.38 * *$ & -.04 & $.45^{* *}$ & .04 & $.71^{* *}$ & -.08 & 1 & & & & & & & & & \\
\hline 16 & -.07 & .06 & $-.12 *$ & -.02 & -.08 & -.10 & .00 & .01 & .00 & $.43 * *$ & $.14 *$ & .10 & -.02 & $.80 * *$ & $-.15 * *$ & 1 & & & & & & & & \\
\hline 17 & $.17^{* *}$ & .07 & $.17^{* *}$ & $.12 *$ & .00 & .02 & $.12 *$ & $-.14^{*}$ & $.64 * *$ & -.07 & $.43 * *$ & -.01 & $.37 * *$ & -.02 & $.41^{* *}$ & -.05 & 1 & & & & & & & \\
\hline 18 & -.02 & .08 & -.03 & .03 & $-.14^{*}$ & .10 & -.05 & -.10 & -.07 & $.62 * *$ & .03 & $.28 * *$ & .01 & $.28 * *$ & -.07 & $.32 * *$ & -.05 & 1 & & & & & & \\
\hline 19 & .00 & .00 & .02 & .04 & -.07 & -.04 & .09 & -.07 & $.34 * *$ & .07 & $.74 * *$ & $-.45^{* *}$ & $.34 * *$ & $.20 *$ & $.36^{* *}$ & $.17^{* *}$ & $.44 * *$ & .06 & 1 & & & & & \\
\hline 20 & .11 & .02 & .10 & .11 & .01 & .05 & $-.13 *$ & -.10 & .04 & $.20 * *$ & $-.28 * *$ & $.81 * *$ & .10 & .01 & .02 & .04 & .01 & $.38 * *$ & $-.39 * *$ & 1 & & & & \\
\hline 21 & .08 & .02 & $.12 *$ & .06 & -.03 & .06 & .02 & -.04 & $.27 * *$ & -.05 & $.36^{* *}$ & .06 & $.63 * *$ & -.07 & $.65^{* *}$ & -.03 & $.46^{* *}$ & -.05 & $.47 * *$ & .02 & 1 & & & \\
\hline 22 & -.04 & .11 & -.08 & .01 & $-.15^{* *}$ & .04 & -.02 & -.10 & .07 & $.36^{* *}$ & $.13^{* *}$ & .11 & -.06 & $.67^{* *}$ & -.07 & $.66^{* *}$ & -.01 & $.42 * *$ & .11 & $.21^{* *}$ & -.06 & 1 & & \\
\hline 23 & $.14^{*}$ & .05 & $.19 * *$ & .05 & -.02 & .01 & .05 & -.03 & $.27 * *$ & -.11 & $.29 * *$ & .06 & $.50 * *$ & $-.17 * *$ & $.67 * *$ & $-.18 * *$ & $.43^{* *}$ & -.05 & $.41 * *$ & .05 & $.77 * *$ & -.10 & 1 & \\
\hline 24 & .02 & .09 & -.03 & .10 & $-.14 *$ & -.06 & .02 & -.06 & .07 & $.35^{* *}$ & $.12 *$ & .09 & -.04 & $.62 * *$ & $-.12 * *$ & $.67 * *$ & -.01 & $.37 * *$ & $.14 * *$ & $.19^{* *}$ & -.09 & $.82 * *$ & $-.16 * *$ & \\
\hline
\end{tabular}

\begin{tabular}{|c|c|c|c|}
\hline 1. Overall AH Score & 7. The Need for Cognition & 13. Combined: Problem Identification Sit T3 & 19. Combined: Decision Sit T2 \\
\hline 2. Attention & 8. Tolerance for Ambiguity & 14. Combined: Problem Identification Dis T3 & 20. Combined: Decision Dis T2 \\
\hline 3. Causal Attribution & 9. Combined: Problem Identification Sit T1 & 15. Combined: Problem Identification Sit T4 & 21. Combined: Decision Sit T3 \\
\hline 4. Contradiction & 10. Combined: Problem Identification Dis T1 & 16. Combined: Problem Identification Dis T4 & 22. Combined: Decision Dis T3 \\
\hline 5. Perception of Change & 11. Combined: Problem Identification Sit T2 & 17. Combined: Decision Sit T1 & 23. Combined: Decision Sit T4 \\
\hline 6. The Need for Cognitive Closure & 12. Combined: Problem Identification Dis T2 & 18. Combined: Decision Dis T1 & 24. Combined: Decision Dis T4 \\
\hline
\end{tabular}


Table 8. Hypotheses 2 and 3: Predicting Problem Identification (PI) Judgment at Time 2 and Time 3

\begin{tabular}{|c|c|c|c|c|c|c|c|c|c|c|c|c|}
\hline \multirow[t]{2}{*}{ Predictor Variables } & \multicolumn{6}{|c|}{ Situational PI Time 2} & \multicolumn{6}{|c|}{ Dispositional PI Time 2} \\
\hline & $R$ & $R^{2}$ & $R^{2} \Delta$ & $F \Delta$ & $B$ & $S E$ & $R$ & $R^{2}$ & $R^{2} \Delta$ & $F \Delta$ & $B$ & $S E$ \\
\hline \multicolumn{13}{|l|}{ Step 1} \\
\hline Sit/Dis PI (T1) & .43 & .19 & .19 & $71.15 * *$ & $.51 * *$ & .06 & .29 & .08 & .08 & $28.02 * *$ & $.38 * *$ & .07 \\
\hline \multicolumn{13}{|l|}{ Step 2} \\
\hline Sit/Dis PI (T1) & .57 & .32 & .14 & $30.73 * *$ & $.49 * *$ & .06 & .77 & .60 & .51 & $196.14 * *$ & $.44 * *$ & .05 \\
\hline Info Presentation 1 (IP1) & & & & & $.75 * *$ & .10 & & & & & $-2.14 * *$ & .11 \\
\hline AH Scores & & & & & $.22 *$ & .10 & & & & & .13 & .11 \\
\hline \multicolumn{13}{|l|}{ Step 3} \\
\hline Sit/Dis PI (T1) & .58 & .33 & .01 & $5.13 *$ & $.49 *$ & .06 & .78 & .61 & .01 & $9.25 * *$ & $.44 * *$ & .05 \\
\hline Info Presentation 1 & & & & & -1.33 & .92 & & & & & .99 & 1.03 \\
\hline AH Scores & & & & & -.01 & .14 & & & & & $.47 * *$ & .16 \\
\hline AH Scores X IP1 & & & & & $.45^{*}$ & .20 & & & & & $-.67 * *$ & .22 \\
\hline \multirow[t]{2}{*}{ Predictor Variables } & \multicolumn{6}{|c|}{ Situational PI Time 3} & \multicolumn{6}{|c|}{ Dispositional PI Time 3} \\
\hline & $R$ & $R^{2}$ & $R^{2} \Delta$ & $F \Delta$ & $B$ & $S E$ & $R$ & $R^{2}$ & $R^{2} \Delta$ & $F \Delta$ & $B$ & $S E$ \\
\hline Step 1 & & & & & & & & & & & & \\
\hline Sit/Dis PI (T2) & .42 & .18 & .18 & $66.50 * *$ & $.33 * *$ & .04 & .04 & .001 & .001 & .39 & .03 & .05 \\
\hline \multicolumn{13}{|l|}{ Step 2} \\
\hline Sit/Dis PI (T2) & .51 & .26 & .09 & $17.62 * *$ & $.41 * *$ & .04 & .53 & .28 & .28 & $60.70 * *$ & $.46 * *$ & .06 \\
\hline Info Presentation 2 (IP2) & & & & & $.47 * *$ & .09 & & & & & $-1.88 * *$ & .17 \\
\hline AH Scores & & & & & .13 & .08 & & & & & .04 & .13 \\
\hline \multicolumn{13}{|l|}{ Step 3} \\
\hline Sit/Dis PI (T2) & .52 & .26 & .00 & 1.73 & $.42 * *$ & .04 & .53 & .29 & .01 & .77 & $.47 * *$ & .06 \\
\hline Info Presentation 2 & & & & & -.53 & .77 & & & & & -.85 & 1.18 \\
\hline AH Scores & & & & & .02 & .11 & & & & & .15 & .18 \\
\hline AH Scores X IP2 & & & & & .22 & .17 & & & & & -.22 & .26 \\
\hline
\end{tabular}


Table 9. Hypotheses 5 and 6: Predicting Decision Judgment at Time 2 and Time 3

\begin{tabular}{|c|c|c|c|c|c|c|c|c|c|c|c|c|}
\hline \multirow[t]{2}{*}{ Predictor Variables } & \multicolumn{6}{|c|}{ Situational Decision Time 2} & \multicolumn{6}{|c|}{ Dispositional Decision Time 2} \\
\hline & $R$ & $R^{2}$ & $R^{2} \Delta$ & $F \Delta$ & $B$ & $S E$ & $R$ & $R^{2}$ & $R^{2} \Delta$ & $F \Delta$ & $B$ & $S E$ \\
\hline \multicolumn{13}{|l|}{ Step 1} \\
\hline Sit/Dis Decision (T1) & .41 & .19 & .19 & $74.78 * *$ & $.50 * *$ & .06 & .38 & .15 & .15 & $53.06 * *$ & $.47 * *$ & .07 \\
\hline \multicolumn{13}{|l|}{ Step 2} \\
\hline Sit/Dis Decision (T1) & .66 & .43 & .24 & $64.29 * *$ & $.48 * *$ & .05 & .75 & .56 & .42 & $146.81 * *$ & $.47 * *$ & .05 \\
\hline Info Presentation 1 (IP1) & & & & & $1.11 * *$ & .10 & & & & & $-1.71 * *$ & .10 \\
\hline AH Scores & & & & & -.06 & .10 & & & & & .15 & .10 \\
\hline \multicolumn{13}{|l|}{ Step 3} \\
\hline Sit/Dis Decision (T1) & .66 & .44 & .01 & $4.89 *$ & $.48^{*}$ & .05 & .76 & .57 & .01 & $6.20 *$ & $.47 * *$ & .05 \\
\hline Info Presentation 1 & & & & & -.96 & .94 & & & & & .69 & .97 \\
\hline AH Scores & & & & & $-.29 *$ & .14 & & & & & $.41 * *$ & .15 \\
\hline AH Scores X IP1 & & & & & $.45 *$ & .20 & & & & & $-.52 *$ & .21 \\
\hline \multirow[t]{2}{*}{ Predictor Variables } & \multicolumn{6}{|c|}{ Situational Decision Time 3} & \multicolumn{6}{|c|}{ Dispositional Decision Time 3} \\
\hline & $R$ & $R^{2}$ & $R^{2} \Delta$ & $F \Delta$ & $B$ & $S E$ & $R$ & $R^{2}$ & $R^{2} \Delta$ & $F \Delta$ & $B$ & $S E$ \\
\hline \multicolumn{13}{|l|}{ Step 1} \\
\hline Sit/Dis Decision (T2) & .47 & .22 & .22 & $87.62 * *$ & $.41 * *$ & .04 & .21 & .05 & .05 & $14.58 * *$ & $.19 * *$ & .05 \\
\hline \multicolumn{13}{|l|}{ Step 2} \\
\hline Sit/Dis Decision (T2) & .57 & .33 & .11 & $24.81 * *$ & $.57 * *$ & .50 & .50 & .25 & .20 & $41.50 * *$ & $.52 * *$ & .57 \\
\hline Info Presentation 2 (IP2) & & & & & $.74 * *$ & .11 & & & & & $-1.37 * *$ & .15 \\
\hline AH Scores & & & & & .09 & .10 & & & & & -.13 & .12 \\
\hline \multicolumn{13}{|l|}{ Step 3} \\
\hline Sit/Dis Decision (T2) & .58 & .33 & .01 & 2.36 & $.58 * *$ & .05 & .51 & .26 & .01 & 3.87 & $.53 * *$ & .06 \\
\hline Info Presentation 2 & & & & & -.62 & .89 & & & & & .79 & 1.11 \\
\hline AH Scores & & & & & -.06 & .14 & & & & & .11 & .17 \\
\hline AH Scores X IP2 & & & & & .29 & .19 & & & & & -.47 & .24 \\
\hline
\end{tabular}


Table 10. Hypotheses 5 and 6: Predicting Decision Judgment at Time 2 and Time 3 for Individual Scenario

\begin{tabular}{|c|c|c|c|c|c|c|c|c|c|c|c|c|}
\hline \multirow[t]{2}{*}{ Predictor Variables } & \multicolumn{6}{|c|}{ Dispositional Decision Time 2 (WF) } & \multicolumn{6}{|c|}{ Dispositional Decision Time 2 (PD) } \\
\hline & $R$ & $R^{2}$ & $R^{2} \Delta$ & $F \Delta$ & B & $S E$ & $R$ & $R^{2}$ & $R^{2} \Delta$ & $F \Delta$ & $B$ & $S E$ \\
\hline \multicolumn{13}{|l|}{ Step 1} \\
\hline Dis Decision (T1) & .43 & .18 & .18 & $69.62 * *$ & $.51 * *$ & .06 & .34 & .11 & .11 & $39.23 * *$ & $.37 * *$ & .06 \\
\hline \multicolumn{13}{|l|}{ Step 2} \\
\hline Dis Decision $(\mathrm{T} 1)$ & .67 & .45 & .27 & $74.57 * *$ & $.51 * *$ & .05 & .50 & .25 & .14 & $27.80 * *$ & $.35 * *$ & .05 \\
\hline Info Presentation 1 (IP1) & & & & & $-1.58 * *$ & .14 & & & & & $1.11 * *$ & .15 \\
\hline AH Scores & & & & & $.36^{*}$ & .14 & & & & & .08 & .15 \\
\hline \multicolumn{13}{|l|}{ Step 3} \\
\hline Dis Decision (T1) & .68 & .46 & .01 & $3.97 *$ & $.51 * *$ & .05 & .50 & .25 & .00 & .30 & $.35^{* *}$ & .05 \\
\hline Info Presentation 1 & & & & & $.99 * *$ & 1.29 & & & & & .34 & 1.42 \\
\hline AH Scores & & & & & $.64 * *$ & .20 & & & & & -.002 & .22 \\
\hline AH Scores X IP1 & & & & & $-.55^{*}$ & .28 & & & & & .17 & .31 \\
\hline \multirow[t]{2}{*}{ Predictor Variables } & \multicolumn{6}{|c|}{ Situational Decision Time 3 (WF) } & \multicolumn{6}{|c|}{ Dispositional Decision Time 3 (PD) } \\
\hline & $R$ & $R^{2}$ & $R^{2} \Delta$ & $F \Delta$ & $B$ & $S E$ & $R$ & $R^{2}$ & $R^{2} \Delta$ & $F \Delta$ & $B$ & $S E$ \\
\hline \multicolumn{13}{|l|}{ Step 1} \\
\hline Dis Decision (T2) & .36 & .13 & .13 & $44.67 * *$ & $.33 * *$ & .05 & .15 & .02 & .02 & $6.65^{*}$ & $.14^{*}$ & .05 \\
\hline \multicolumn{13}{|l|}{ Step 2} \\
\hline Dis Decision (T2) & .50 & .25 & .13 & $24.95 * *$ & $.52 * *$ & .05 & .37 & .14 & .17 & $20.70 * *$ & $.35 * *$ & .06 \\
\hline Info Presentation 2 (IP2) & & & & & $-1.17 * *$ & .17 & & & & & $-1.24 * *$ & .20 \\
\hline AH Scores & & & & & -.17 & .15 & & & & & -.09 & .17 \\
\hline \multicolumn{13}{|l|}{ Step 3} \\
\hline Dis Decision (T2) & .50 & .25 & .00 & .03 & $.52 * *$ & .05 & .40 & .16 & .02 & $6.79 *$ & $.35 * *$ & .06 \\
\hline Info Presentation 2 & & & & & -.95 & 1.40 & & & & & 2.76 & 1.55 \\
\hline AH Scores & & & & & -.14 & .21 & & & & & .34 & .23 \\
\hline AH Scores X IP2 & & & & & -.05 & .30 & & & & & $-.86^{*}$ & .33 \\
\hline
\end{tabular}


Table 11. Individual Differences, Problem Identification, and Decision Judgments for Production Dilemma

\begin{tabular}{|c|c|c|c|c|c|c|c|c|c|c|c|c|c|c|c|c|c|c|c|c|c|c|c|c|}
\hline & 1 & 2 & 3 & 4 & 5 & 6 & 7 & 8 & 9 & 10 & 11 & 12 & 13 & 14 & 15 & 16 & 17 & 18 & 19 & 20 & 21 & 22 & 23 & 24 \\
\hline 1 & 1 & & & & & & & & & & & & & & & & & & & & & & & \\
\hline 2 & $.57 * *$ & 1 & & & & & & & & & & & & & & & & & & & & & & \\
\hline 3 & $.72 * *$ & $.20 * *$ & 1 & & & & & & & & & & & & & & & & & & & & & \\
\hline 4 & $.59 * *$ & $.19 * *$ & $.21 * *$ & 1 & & & & & & & & & & & & & & & & & & & & \\
\hline 5 & $.26 * *$ & $-.25 * *$ & .06 & -.11 & 1 & & & & & & & & & & & & & & & & & & & \\
\hline 6 & -.05 & $.12 *$ & -.10 & -.01 & $-.12 *$ & 1 & & & & & & & & & & & & & & & & & & \\
\hline 7 & .03 & -.02 & $.18^{* *}$ & -.04 & -.09 & $-.49 * *$ & 1 & & & & & & & & & & & & & & & & & \\
\hline 8 & -.01 & .00 & .01 & -.11 & .08 & $-.39 * *$ & $.34 * *$ & 1 & & & & & & & & & & & & & & & & \\
\hline 9 & .11 & .00 & $.16^{* *}$ & .07 & -.01 & .02 & .04 & -.10 & 1 & & & & & & & & & & & & & & & \\
\hline 10 & .01 & $.13^{*}$ & .01 & -.05 & -.09 & -.01 & -.05 & -.06 & $-.23 * *$ & 1 & & & & & & & & & & & & & & \\
\hline 11 & .11 & -.03 & $.12 *$ & .07 & .08 & -.01 & .04 & -.09 & $.32 * *$ & -.08 & 1 & & & & & & & & & & & & & \\
\hline 12 & .04 & .03 & .02 & -.01 & .04 & -.02 & -.06 & .00 & $-.13 *$ & $.36^{* *}$ & $-.45^{* *}$ & 1 & & & & & & & & & & & & \\
\hline 13 & $.16^{* *}$ & -.01 & $.16^{* *}$ & .09 & .09 & .03 & -.06 & -.07 & $.35 * *$ & $-.11^{*}$ & $.36 * *$ & -.02 & 1 & & & & & & & & & & & \\
\hline 14 & -.03 & .08 & -.06 & -.02 & -.07 & -.08 & .08 & -.05 & $-.15^{* *}$ & $.34 * *$ & .00 & $.14 *$ & $-.35^{* *}$ & 1 & & & & & & & & & & \\
\hline 15 & $.21 * *$ & .02 & $.21^{* *}$ & .09 & $.14 *$ & .03 & -.04 & $-.12 *$ & $.40^{* *}$ & $-.14^{*}$ & $.40^{* *}$ & $-.13^{*}$ & $.66^{* *}$ & $-.31 * *$ & 1 & & & & & & & & & \\
\hline 16 & -.08 & .07 & $-.15^{*}$ & -.03 & -.07 & -.05 & -.01 & -.03 & $-.19 * *$ & $.36 * *$ & -.05 & $.22 * *$ & $-.27 * *$ & $.76^{* *}$ & $-.39 * *$ & 1 & & & & & & & & \\
\hline 17 & .10 & .03 & .10 & .08 & .00 & .03 & .02 & -.09 & $.66^{* *}$ & $-.20^{* *}$ & $.31^{* *}$ & -.08 & $.39 * *$ & -.10 & $.34 * *$ & $-.14^{*}$ & 1 & & & & & & & \\
\hline 18 & .01 & $.11^{*}$ & -.02 & .03 & $-.13 *$ & .09 & -.02 & $-.13^{*}$ & $-.22 * *$ & $.51 * *$ & -.02 & $.23 * *$ & -.10 & $.19^{* *}$ & $-.13^{*}$ & $.23 * *$ & $-.16^{* *}$ & 1 & & & & & & \\
\hline 19 & .02 & -.04 & .03 & .08 & -.02 & .00 & -.02 & -.04 & $.26 * *$ & -.08 & $.67 * *$ & $-.43 * *$ & $.27 * *$ & .00 & $.24 * *$ & -.03 & $.34 * *$ & -.06 & 1 & & & & & \\
\hline 20 & .04 & -.01 & .05 & .05 & .00 & .03 & -.10 & -.08 & -.07 & $.23 * *$ & $-.30 * *$ & $.71^{* *}$ & -.03 & .02 & -.05 & .11 & -.09 & $.36^{* *}$ & $-.40 * *$ & 1 & & & & \\
\hline 21 & .08 & .00 & .10 & .05 & .01 & .05 & -.06 & -.04 & $.29 * *$ & -.06 & $.31^{* *}$ & -.07 & $.59 * *$ & $-.27 * *$ & $.52 * *$ & $-.20 * *$ & $.39 * *$ & $-.11 *$ & $.47 * *$ & $-.13^{*}$ & 1 & & & \\
\hline 22 & -.05 & $.14 *$ & -.09 & -.01 & $-.18 * *$ & .03 & .07 & -.07 & -.11 & $.25 * *$ & -.04 & .11 & $-.29 * *$ & $.59 * *$ & $-.24 * *$ & $.57 * *$ & $-.11^{*}$ & $.29 * *$ & -.10 & $.15^{*}$ & $-.26 * *$ & 1 & & \\
\hline 23 & $.13^{*}$ & .06 & $.15^{* *}$ & .04 & .01 & .04 & -.05 & -.03 & $.30^{* *}$ & $-.13^{*}$ & $.26^{* *}$ & -.10 & $.44 * *$ & $-.29 * *$ & $.57 * *$ & $-.30 * *$ & $.34 * *$ & $-.17 * *$ & $.41^{* *}$ & $-.12 *$ & $.73 * *$ & $-.25 * *$ & 1 & \\
\hline 24 & .03 & $.12 *$ & -.02 & .06 & $-.12 *$ & -.04 & .04 & -.07 & $-.13^{*}$ & $.23 * *$ & -.03 & $.15^{* *}$ & $-.30 * *$ & $.53 * *$ & $-.26 * *$ & $.58 * *$ & $-.15 * *$ & $.32 * *$ & -.07 & $.23 * *$ & $-.26 * *$ & $.79 * *$ & $-.29 * *$ & 1 \\
\hline
\end{tabular}

Note: $* p<.05, * * p<.01$

1. Overall AH Score

2. Attention

3. Causal Attribution

4. Contradiction

5. Perception of Change

6. The Need for Cognitive Closure
7. The Need for Cognition

8. Tolerance for Ambiguity

9. PD: Problem Identification Sit T1

10. PD: Problem Identification Dis T1

11. PD: Problem Identification Sit T2

12. PD: Problem Identification Dis T2
13. PD: Problem Identification Sit T3

14. PD: Problem Identification Dis T3

15. PD: Problem Identification Sit T4

16. PD: Problem Identification Dis T4

17. PD: Decision Sit T1

18. PD: Decision Dis T
19. PD: Decision Sit T2

20. PD: Decision Dis T2

21. PD: Decision Sit T3

22. PD: Decision Dis T3

23. PD: Decision Sit T4

24. PD: Decision Dis T4 
Table 12. Individual Differences, Problem Identification, and Decision Judgments for Westerly Foundation

\begin{tabular}{|c|c|c|c|c|c|c|c|c|c|c|c|c|c|c|c|c|c|c|c|c|c|c|c|c|}
\hline & 1 & 2 & 3 & 4 & 5 & 6 & 7 & 8 & 9 & 10 & 11 & 12 & $\begin{array}{ll}13 \\
\end{array}$ & 14 & 15 & 16 & 17 & 18 & 19 & 20 & 21 & 22 & 23 & 24 \\
\hline 1 & 1 & & & & & & & & & & & & & & & & & & & & & & & \\
\hline 2 & $.57 * *$ & 1 & & & & & & & & & & & & & & & & & & & & & & \\
\hline 3 & $.72 * *$ & $.20 * *$ & 1 & & & & & & & & & & & & & & & & & & & & & \\
\hline 5 & $.26 * *$ & $-.25 * *$ & .06 & -.11 & 1 & & & & & & & & & & & & & & & & & & & \\
\hline 6 & -.05 & $.12 *$ & -.10 & -.01 & $-.12 *$ & 1 & & & & & & & & & & & & & & & & & & \\
\hline 7 & .03 & -.02 & $.18^{* *}$ & -.04 & -.09 & $-.49 * *$ & 1 & & & & & & & & & & & & & & & & & \\
\hline 9 & .09 & .02 & .06 & .06 & .04 & .06 & .08 & -.11 & 1 & & & & & & & & & & & & & & & \\
\hline 10 & -.08 & -.07 & -.03 & -.07 & -.01 & .01 & .02 & -.07 & $.20 * *$ & 1 & & & & & & & & & & & & & & \\
\hline 11 & .08 & .09 & .07 & .03 & -.02 & -.07 & .07 & -.07 & $.31 * *$ & $.19 * *$ & 1 & & & & & & & & & & & & & \\
\hline 12 & $.14 *$ & .02 & $.12^{*}$ & $.12^{*}$ & .03 & .02 & -.08 & .01 & -.02 & $.23 * *$ & $-.21 * *$ & 1 & & & & & & & & & & & & \\
\hline 13 & .10 & .06 & $.13 *$ & .09 & -.10 & .04 & .08 & -.06 & $.19 * *$ & .09 & $.40 * *$ & .02 & 1 & & & & & & & & & & & \\
\hline 14 & .03 & .03 & .01 & .04 & -.02 & -.05 & -.05 & -.04 & $.12 *$ & $.34 * *$ & $.21 * *$ & $.16^{* *}$ & .07 & 1 & & & & & & & & & & \\
\hline 15 & .11 & .02 & $.16^{* *}$ & .04 & .01 & -.02 & .04 & -.05 & $.22 * *$ & .00 & $.40 * *$ & .05 & $.68^{* *}$ & .05 & 1 & & & & & & & & & \\
\hline 17 & $.16^{* *}$ & .08 & $.17 * *$ & .10 & .00 & .00 & $.16^{* *}$ & $-.13 *$ & $.54 * *$ & -.03 & $.33 * *$ & -.02 & $.28^{* *}$ & -.01 & $.37 * *$ & -.02 & 1 & & & & & & & \\
\hline 18 & -.05 & .01 & -.03 & .01 & -.10 & .07 & -.06 & -.03 & .03 & $.58 * *$ & .01 & $.31^{* *}$ & .02 & .27 & -.03 & $.31^{* *}$ & -.06 & 1 & & & & & & \\
\hline 19 & -.03 & .04 & .00 & -.02 & -.09 & -.06 & $.17 * *$ & -.07 & $.28 * *$ & $.13^{*}$ & $.69 * *$ & $-.38 * *$ & $.41 * *$ & .19 & $.43^{* *}$ & $.18^{* *}$ & $.40 * *$ & .05 & 1 & & & & & \\
\hline 20 & $.14^{*}$ & .04 & $.12 *$ & $.13 *$ & .01 & .05 & $-.11^{*}$ & -.09 & .04 & $.20^{* *}$ & $-.20 * *$ & $.79 * *$ & -.01 & .17 & -.02 & $.17 * *$ & .01 & $.43^{* *}$ & $-.29 * *$ & 1 & & & & \\
\hline 21 & .05 & .03 & .09 & .04 & -.07 & .04 & .10 & -.03 & $.17 * *$ & -.05 & $.28 * *$ & .06 & $.55^{* *}$ & -.04 & $.64 * *$ & -.03 & $.37 * *$ & -.03 & $.38 * *$ & .03 & 1 & & & \\
\hline 22 & -.02 & .03 & -.04 & .03 & -.06 & .03 & $-.11^{*}$ & -.08 & $.16^{* *}$ & $.31 * *$ & $.16^{* *}$ & $.22 * *$ & .01 & .73 & .02 & $.69 * *$ & .07 & $.38 * *$ & $.13 *$ & $.36^{* *}$ & -.01 & 1 & & \\
\hline 23 & .09 & .02 & $.16^{* *}$ & .04 & -.05 & -.03 & $.15^{* *}$ & -.02 & $.12 *$ & -.07 & $.23 * *$ & .07 & $.48^{* *}$ & -.10 & $.69 * *$ & $-.12 *$ & $.39 * *$ & -.01 & $.37 * *$ & .04 & $.68^{* *}$ & -.10 & 1 & \\
\hline 24 & .00 & .02 & -.02 & .09 & -.09 & -.05 & -.01 & -.02 & $.17 * *$ & $.30 * *$ & $.14^{*}$ & .11 & .05 & .61 & .01 & $.71^{* *}$ & .05 & $.33 * *$ & $.16^{* *}$ & $.26^{* *}$ & -.02 & $.75^{* *}$ & $-.12 *$ & 1 \\
\hline
\end{tabular}

1. Overall AH Score

2. Attention

3. Causal Attribution

4. Contradiction

5. Perception of Change

6. The Need for Cognitive Closure
7. The Need for Cognition

8. Tolerance for Ambiguity

9. WF: Problem Identification Sit T1

10. WF: Problem Identification Dis T1

11. WF: Problem Identification Sit T2

12. WF: Problem Identification Dis T2
13. WF: Problem Identification Sit T3

14. WF: Problem Identification Dis T3

15. WF: Problem Identification Sit T4

16. WF: Problem Identification Dis T4

17. WF: Decision Sit T1

18. WF: Decision Dis T1
19. WF: Decision Sit T2

20. WF: Decision Dis T2

21. WF: Decision Sit T3

22. WF: Decision Dis T3

23. WF: Decision Sit T4

24. WF: Decision Dis T4 
Table 13. Individual Differences and Information Selection

\begin{tabular}{|c|c|c|c|c|c|c|c|c|c|c|c|c|c|c|c|c|c|c|c|c|c|c|c|c|c|c|}
\hline & 1 & 2 & 3 & 4 & 5 & 6 & 7 & 8 & 9 & 10 & 11 & 12 & 13 & 14 & 15 & 16 & 17 & 18 & 19 & 20 & 21 & 22 & 23 & 24 & 25 & 26 \\
\hline 1 & 1 & & & & & & & & & & & & & & & & & & & & & & & & & \\
\hline 2 & $.57 * *$ & & & & & & & & & & & & & & & & & & & & & & & & & \\
\hline 3 & $.72 * *$ & $.20 * *$ & 1 & & & & & & & & & & & & & & & & & & & & & & & \\
\hline 4 & $.59 * *$ & $.19 * *$ & $.21 * *$ & 1 & & & & & & & & & & & & & & & & & & & & & & \\
\hline 5 & $.26 * *$ & $-.25^{* *}$ & .06 & -.11 & 1 & & & & & & & & & & & & & & & & & & & & & \\
\hline 6 & -.05 & $.12 *$ & -.10 & -.01 & $-.12 *$ & 1 & & & & & & & & & & & & & & & & & & & & \\
\hline 7 & .03 & -.02 & $.18^{* *}$ & -.04 & -.09 & $-.49 * *$ & 1 & & & & & & & & & & & & & & & & & & & \\
\hline 8 & -.01 & .00 & .01 & -.11 & .08 & $-.39 * *$ & $.34 * *$ & 1 & & & & & & & & & & & & & & & & & & \\
\hline 9 & -.02 & -.07 & .04 & -.04 & .02 & -.08 & .03 & -.09 & 1 & & & & & & & & & & & & & & & & & \\
\hline 10 & .03 & -.01 & .06 & -.03 & .04 & -.03 & .03 & -.09 & $.90^{* *}$ & 1 & & & & & & & & & & & & & & & & \\
\hline 11 & -.07 & $-.12 *$ & .01 & -.04 & .00 & $-.12 *$ & .03 & -.06 & $.89 * *$ & $.61 * *$ & 1 & & & & & & & & & & & & & & & \\
\hline 12 & .02 & -.04 & .10 & -.01 & -.01 & $-.19 * *$ & .07 & -.07 & $.76^{* *}$ & $.70 * *$ & $.67 * *$ & 1 & & & & & & & & & & & & & & \\
\hline 13 & .08 & .02 & $.12 *$ & .00 & .02 & $-.16^{*}$ & .06 & -.08 & $.70 * *$ & $.74 * *$ & $.51 * *$ & $.93 * *$ & 1 & & & & & & & & & & & & & \\
\hline 14 & -.03 & -.09 & .07 & -.02 & -.04 & $-.19 * *$ & .06 & -.04 & $.72 * *$ & $.55^{* *}$ & $.74 * *$ & $.93 * *$ & $.72 * *$ & 1 & & & & & & & & & & & & \\
\hline 15 & .00 & -.05 & .08 & -.04 & .00 & $-.12 * *$ & .04 & -.07 & $.90^{* *}$ & $.83^{* *}$ & $.80^{* *}$ & $.89^{* *}$ & $.82 * *$ & $.83^{* *}$ & 1 & & & & & & & & & & & \\
\hline 16 & .07 & .00 & $.12 *$ & -.02 & .03 & -.08 & .02 & -.09 & $.82 * *$ & $.89 * *$ & $.58^{*}$ & $.82 * *$ & $.87 * *$ & $.64 * *$ & $.91 * *$ & 1 & & & & & & & & & & \\
\hline 17 & -.07 & -.10 & .03 & -.06 & -.03 & $-.15^{* *}$ & .05 & -.04 & $.83^{* *}$ & $.61 * *$ & $.88^{* *}$ & $.81 * *$ & $.62 * *$ & $.88^{* *}$ & $.91 * *$ & $.66^{* *}$ & 1 & & & & & & & & & \\
\hline 18 & .05 & -.01 & .09 & .02 & -.02 & $-.21 * *$ & .08 & -.04 & $.39 * *$ & $.36^{* *}$ & $.34 * *$ & $.85^{* *}$ & $.80 * *$ & $.78^{* *}$ & $.52 * *$ & $.48^{* *}$ & $.47 * *$ & 1 & & & & & & & & \\
\hline 19 & .06 & .04 & .08 & .02 & .00 & $-.19 * *$ & .08 & -.04 & $.34 * *$ & $.34 * *$ & $.28 * *$ & $.77^{* *}$ & $.83 * *$ & $.59 * *$ & $.45 * *$ & $.46^{* *}$ & $.37 * *$ & $.92 * *$ & 1 & & & & & & & \\
\hline 20 & .02 & -.06 & .10 & .02 & -.03 & $-.19 * *$ & .06 & -.03 & $.37 * *$ & $.31 * *$ & $.36^{* *}$ & $.79 * *$ & $.63 * *$ & $.84 * *$ & $.50^{* *}$ & $.42 * *$ & $.49 * *$ & $.91^{* *}$ & $.67^{* *}$ & 1 & & & & & & \\
\hline 21 & .08 & -.03 & $.18^{* *}$ & .05 & -.05 & $-.17 * *$ & .07 & -.05 & $.39 * *$ & $.36^{* *}$ & $.33 * *$ & $.75^{* *}$ & $.70 * *$ & $.69 * *$ & $.50 * *$ & $.48 * *$ & $.43 * *$ & $.83 * *$ & $.74 * *$ & $.79 * *$ & 1 & & & & & \\
\hline 22 & .00 & .01 & -.01 & -.01 & .02 & $-.19 * *$ & .06 & -.02 & $.29 * *$ & $.25 * *$ & $.27 * *$ & $.71 * *$ & $.67 * *$ & $.64 * *$ & $.39 * *$ & $.35 * *$ & $.37 * *$ & $.87 * *$ & $.82 * *$ & $.77 * *$ & $.46^{* *}$ & 1 & & & & \\
\hline 23 & $.12 *$ & .05 & $.17 * *$ & .06 & -.05 & $-.12 *$ & .02 & -.08 & $.33^{* *}$ & $.33 * *$ & $.26^{* *}$ & $.63 * *$ & $.66 * *$ & $.50^{* *}$ & $.43 * *$ & $.44 * *$ & $.34 * *$ & $.69 * *$ & $.71^{* *}$ & $.54 * *$ & $.88^{* *}$ & $.33^{* *}$ & 1 & & & \\
\hline 24 & -.01 & .01 & -.04 & -.03 & .04 & $-.17 * *$ & .10 & .01 & $.20^{* *}$ & $.19 * *$ & $.17^{* *}$ & $.55^{* *}$ & $.61 * *$ & $.41^{* *}$ & $.28 * *$ & $.27^{* *}$ & $.23 * *$ & $.71^{* *}$ & $.81^{* *}$ & $.49 * *$ & $.30^{* *}$ & $.88^{* *}$ & $.15^{* *}$ & 1 & & \\
\hline 25 & .01 & -.11 & $.13 *$ & .02 & -.04 & $-.18 * *$ & $.11^{*}$ & -.01 & $.33 * *$ & $.29 * *$ & $.31 * *$ & $.67 * *$ & $.54 * *$ & $.70^{* *}$ & $.43 * *$ & $.38^{* *}$ & $.41^{* *}$ & $.76^{* *}$ & $.56^{* *}$ & $.83 * *$ & $.85^{* *}$ & $.47 * *$ & $.48^{* *}$ & $.38 * *$ & 1 & \\
\hline 26 & .02 & .01 & .03 & .02 & -.02 & $-.15 * *$ & -.01 & -.05 & $.30 * *$ & $.24 * *$ & $.30 * *$ & $.67 * *$ & $.52 * *$ & $.72 * *$ & $.41 * *$ & $.33 * *$ & $.41 * *$ & $.79 * *$ & $.58^{* *}$ & $.86^{* *}$ & $.50 * *$ & $.82 * *$ & $.43 * *$ & $.45^{* *}$ & $.43 * *$ & 1 \\
\hline
\end{tabular}

1. Overall AH Score

2. Attention

3. Causal Attribution

4. Contradiction

5. Perception of Change

6. The Need for Cognitive Closure

7. The Need for Cognition
8. Tolerance for Ambiguity

9. Combined: Numbers of Category Selected

10. PD: Numbers of Category Selected

11. WF: Numbers of Category Selected

12. Combined: $\%$ of Information Selected (1\&2)

13. PD: $\%$ of Information Selected (1\&2)

14. WF: \% of Information Selected (1\&2)
15. Combined: \% of Information Selected 1

16. PD: $\%$ of Information Selected 1

17. WF: \% of Information Selected 1

8. Combined: $\%$ of Information Selected 2

19. PD: $\%$ of Information Selected 2

20. WF $\%$ of Information Selected 2

21. Combined: $\%$ of Sit Information Selected 2
22. Combined: \% of Dis Information Selected 2

23. PD: $\%$ of Sit Information Selected 2

24. PD: $\%$ of Dis Information Selected 2

WF: $\%$ of Sit Information Selected 2

26. WF: \% of Dis Information Selected 2 
Table 14. Individual Differences and Information Relevance

\begin{tabular}{|c|c|c|c|c|c|c|c|c|c|c|c|c|c|c|c|c|c|c|c|c|c|c|c|}
\hline & 1 & 2 & 3 & 4 & 5 & 6 & 7 & 8 & 9 & 10 & 11 & 12 & 13 & 14 & 15 & 16 & 17 & 18 & 19 & 20 & 21 & 22 & 23 \\
\hline 1 & 1 & & & & & & & & & & & & & & & & & & & & & & \\
\hline 2 & $.57^{* *}$ & 1 & & & & & & & & & & & & & & & & & & & & & \\
\hline 3 & $.72 * *$ & $.20 * *$ & 1 & & & & & & & & & & & & & & & & & & & & \\
\hline 4 & $.59 * *$ & $.19 * *$ & $.21^{* *}$ & 1 & & & & & & & & & & & & & & & & & & & \\
\hline 5 & $.26^{* *}$ & $-.25 * *$ & .06 & -.11 & 1 & & & & & & & & & & & & & & & & & & \\
\hline 6 & -.05 & $.12 *$ & -.10 & -.01 & $-.12 *$ & 1 & & & & & & & & & & & & & & & & & \\
\hline 7 & .03 & -.02 & $.18 * *$ & -.04 & -.09 & $-.49 * *$ & 1 & & & & & & & & & & & & & & & & \\
\hline 8 & -.01 & .00 & .01 & -.11 & .08 & $-.39 * *$ & $.34 * *$ & 1 & & & & & & & & & & & & & & & \\
\hline 9 & .10 & .06 & $.15^{* *}$ & .02 & -.02 & $-.11^{*}$ & .04 & -.09 & 1 & & & & & & & & & & & & & & \\
\hline 10 & $.12 *$ & .07 & $.16^{* *}$ & .02 & -.01 & $-.11^{*}$ & .05 & -.07 & $.92 * *$ & 1 & & & & & & & & & & & & & \\
\hline 11 & .06 & .03 & $.11 * *$ & .01 & -.04 & -.09 & .02 & -.09 & $.90 * *$ & $.65^{* *}$ & 1 & & & & & & & & & & & & \\
\hline 12 & $.13^{*}$ & .08 & $.18 * *$ & .03 & -.05 & $-.11 *$ & .05 & -.08 & $.88^{* *}$ & $.79 * *$ & $.81^{* *}$ & 1 & & & & & & & & & & & \\
\hline 13 & .04 & .06 & .08 & -.06 & -.02 & -.07 & -.03 & -.07 & $.87^{* *}$ & $.81 * *$ & $.77 * *$ & $.66^{* *}$ & 1 & & & & & & & & & & \\
\hline 14 & $.15^{* *}$ & .09 & $.22 * *$ & .02 & -.03 & -.09 & .05 & -.04 & $.77 * *$ & $.79 * *$ & $.59 * *$ & $.90 * *$ & $.56^{* *}$ & 1 & & & & & & & & & \\
\hline 15 & .05 & .01 & .09 & -.03 & .05 & -.10 & .03 & -.07 & $.73 * *$ & $.81 * *$ & $.49 * *$ & $.51 * *$ & $.86^{* *}$ & $.47 * *$ & 1 & & & & & & & & \\
\hline 16 & .06 & .04 & .09 & .04 & -.06 & -.10 & .03 & -.10 & $.79 * *$ & $.59 * *$ & $.86^{* *}$ & $.86^{* *}$ & $.61 * *$ & $.56^{* *}$ & $.43^{* *}$ & 1 & & & & & & & \\
\hline 17 & .01 & .10 & .04 & -.07 & -.08 & -.01 & -.10 & -.05 & $.76 * *$ & $.56^{* *}$ & $.83^{* *}$ & $.61^{* *}$ & $.83 * *$ & $.47 * *$ & $.44 * *$ & $.62 * *$ & 1 & & & & & & \\
\hline 18 & $.13 *$ & .03 & $.17 * *$ & .05 & .02 & -.11 & .06 & $-.11^{*}$ & $.98 * *$ & $.90 * *$ & $.87 * *$ & $.84 * *$ & $.83^{* *}$ & $.74 * *$ & $.71 * *$ & $.75^{* *}$ & $.69 * *$ & 1 & & & & & \\
\hline 19 & .02 & $.12^{*}$ & .08 & -.08 & $-.12 *$ & -.10 & -.03 & -.03 & $.84 * *$ & $.75^{* *}$ & $.78^{* *}$ & $.80 * *$ & $.79 * *$ & $.69 * *$ & $.60^{* *}$ & $.74 * *$ & $.75^{* *}$ & $.70 * *$ & 1 & & & & \\
\hline 20 & $.12 *$ & .06 & $.15^{* *}$ & .03 & .00 & -.11 & .07 & -.08 & $.88^{* *}$ & $.98^{* *}$ & $.61 * *$ & $.73 * *$ & $.78^{* *}$ & $.73 * *$ & $.80^{* *}$ & $.55^{* *}$ & $.52 * *$ & $.90^{* *}$ & $.64 * *$ & 1 & & & \\
\hline 21 & .10 & .10 & $.15^{* *}$ & -.03 & -.04 & -.08 & -.01 & -.03 & $.78 * *$ & $.82 * *$ & $.58 * *$ & $.76^{* *}$ & $.70^{* *}$ & $.77 * *$ & $.65^{* *}$ & $.56 * *$ & $.52 * *$ & $.68 * *$ & $.86 * *$ & $.67 * *$ & 1 & & \\
\hline 22 & .11 & -.01 & $.15^{* *}$ & .06 & .03 & -.08 & .04 & -.11 & $.85^{* *}$ & $.61 * *$ & $.95 * *$ & $.76^{* *}$ & $.69^{* *}$ & $.57 * *$ & $.45^{* *}$ & $.80 * *$ & $.73 * *$ & $.88^{* *}$ & $.61 * *$ & $.59 * *$ & $.52 * *$ & 1 & \\
\hline 23 & -.05 & $.12 *$ & .00 & -.10 & $-.16 * *$ & -.09 & -.04 & -.03 & $.70 * *$ & $.51 * *$ & $.77 * *$ & $.65^{* *}$ & $.68^{* *}$ & $.45^{* * *}$ & $.41^{* * *}$ & $.72 * *$ & $.77 * *$ & $.56^{* *}$ & $.89 * *$ & $.46^{* *}$ & $.52 * *$ & $.54 * *$ & 1 \\
\hline
\end{tabular}

1. Overall AH Score

2. Attention

3. Causal Attribution

4. Contradiction

5. Perception of Change

6. The Need for Cognitive Closure
7. The Need for Cognition

8. Tolerance for Ambiguity

9. Combined: Overall Info Relevance

10. PD: Overall Info Relevance

11. WF: Overall Info Relevance

12. Combined: Sit Info Relevance
13. Combined: Dis Info Relevance

14. PD: Sit Info Relevance

15. PD: Dis Info Relevance

16. WF: Sit Info Relevance

17. WF: Dis Info Relevance

18. Combined: Confirming Info Relevance
19. Combined: Disconfirming Info Relevance 20. PD: Confirming Info Relevance

21. PD: Disconfirming Info Relevance

22. WF: Confirming Info Relevance

23. WF: Disconfirming Info Relevance 
Table 15. Individual Differences and Difference in Final Problem Identification and Decision Judgments

\begin{tabular}{|c|c|c|c|c|c|c|c|c|c|c|c|c|c|c|c|c|c|c|c|c|}
\hline & 1 & 2 & 3 & 4 & 5 & 6 & 7 & 8 & 9 & 10 & 11 & 12 & 13 & 14 & 15 & 16 & 17 & 18 & 19 & 20 \\
\hline 1 & 1 & & & & & & & & & & & & & & & & & & & \\
\hline 2 & $.57 * *$ & 1 & & & & & & & & & & & & & & & & & & \\
\hline 3 & $.72 * *$ & $.20 * *$ & 1 & & & & & & & & & & & & & & & & & \\
\hline 4 & $.59 * *$ & $.19 * *$ & $.21^{* *}$ & 1 & & & & & & & & & & & & & & & & \\
\hline 5 & $.26 * *$ & $-.25^{* *}$ & .06 & -.11 & 1 & & & & & & & & & & & & & & & \\
\hline 6 & -.05 & $.12 *$ & -.10 & -.01 & $-.12 *$ & 1 & & & & & & & & & & & & & & \\
\hline 7 & .03 & -.02 & $.18^{* *}$ & -.04 & -.09 & $-.49 * *$ & 1 & & & & & & & & & & & & & \\
\hline 8 & -.01 & .00 & .01 & -.11 & .08 & $-.39 * *$ & $.34 * *$ & 1 & & & & & & & & & & & & \\
\hline 9 & $-.16^{* *}$ & .04 & $-.22 * *$ & -.06 & $-.11 *$ & -.08 & .00 & .07 & 1 & & & & & & & & & & & \\
\hline 10 & $-.16^{* *}$ & .04 & $-.21 * *$ & -.06 & $-.12 *$ & -.05 & .02 & .04 & $.85^{* *}$ & 1 & & & & & & & & & & \\
\hline 11 & -.08 & .01 & $-.12 * *$ & -.02 & -.05 & -.08 & -.02 & .08 & $.70 * *$ & $.22 * *$ & 1 & & & & & & & & & \\
\hline 12 & $.11 *$ & -.01 & $.14^{*}$ & .03 & .10 & .04 & .04 & -.01 & $-.52 * *$ & $-.38 * *$ & $-.45 * *$ & 1 & & & & & & & & \\
\hline 13 & .09 & -.03 & $.14^{*}$ & .01 & .07 & -.02 & .11 & .07 & $-.48 * *$ & $-.50 * *$ & $-.21 * *$ & $.84 * *$ & 1 & & & & & & & \\
\hline 14 & .09 & .01 & .07 & .03 & .08 & .10 & -.08 & -.10 & $-.32 * *$ & -.05 & $-.54 * *$ & $.71 * *$ & $.22 * *$ & 1 & & & & & & \\
\hline 15 & -.07 & .03 & $-.14^{*}$ & .03 & -.08 & -.05 & -.01 & -.02 & $.71 * *$ & $.57 * *$ & $.53 * *$ & $-.41 * *$ & $-.37 * *$ & $-.25 * *$ & 1 & & & & & \\
\hline 16 & -.06 & .04 & -.10 & .01 & -.08 & -.05 & .06 & -.03 & $.55^{* *}$ & $.64 * *$ & $.15^{* *}$ & $-.23 * *$ & $-.32 * *$ & .00 & $.82 * *$ & 1 & & & & \\
\hline 17 & -.05 & .01 & -.11 & .04 & -.04 & -.03 & -.09 & -.01 & $.54 * *$ & $.20 * *$ & $.72 * *$ & $-.42 * *$ & $-.25 * *$ & $-.44 * *$ & $.72 * *$ & $.19 * *$ & 1 & & & \\
\hline 18 & .11 & -.02 & $.16^{* *}$ & .03 & .06 & .03 & .09 & -.01 & $-.36^{* *}$ & $-.19 * *$ & $-.40 * *$ & $.64 * *$ & $.50 * *$ & $.50 * *$ & $-.48 * *$ & $-.28 * *$ & $-.49 * *$ & 1 & & \\
\hline 19 & .06 & -.06 & $.14^{*}$ & .01 & .03 & .01 & .11 & .01 & $-.26^{* *}$ & $-.22 * *$ & $-.19 * *$ & $.51^{* *}$ & $.58 * *$ & $.17^{* *}$ & $-.40 * *$ & $-.37 * *$ & $-.24 * *$ & $.82 * *$ & 1 & \\
\hline 20 & $.12 *$ & .04 & .10 & .03 & .07 & .04 & .02 & -.04 & $-.30 * *$ & -.07 & $-.46 * *$ & $.48 * *$ & $.17 * *$ & $.64 * *$ & $-.34 * *$ & -.05 & $-.54 * *$ & $.74 * *$ & $.21 * *$ & 1 \\
\hline
\end{tabular}

1. Overall AH Score

2. Attention

6. The Need for Cognitive Closure

7. The Need for Cognition

8. Tolerance for Ambiguity

. Causal Attribution

4. Contradiction

5. Perception of Change
11. WF: Difference in PI T4

12. Combined: Abs Difference in PI T4

3. PD: Abs Difference in PI T4

14. WF: Abs Difference in PI T4

15. Combined: Difference in Decision T4
16. PD: Difference in Decision T4 17. WF: Difference in Decision T4

18. Combined: Abs Difference in Decision T

19. PD: Abs Difference in Decision T4

20. WF: Abs Difference in Decision T4 
Table 16. Hypotheses 16 and 18: Predicting Fundamental Attribution Error

\begin{tabular}{|c|c|c|c|c|c|c|}
\hline \multirow[b]{2}{*}{ Predictor Variables } & \multicolumn{6}{|c|}{ Dispositional PI Time 4} \\
\hline & $R$ & $R^{2}$ & $R^{2} \Delta$ & $F \Delta$ & $B$ & $S E$ \\
\hline \multicolumn{7}{|l|}{ Step 1} \\
\hline Sit PI (T4) & .15 & .02 & .02 & $7.02 * *$ & $-.21 * *$ & .08 \\
\hline \multicolumn{7}{|l|}{ Step 2} \\
\hline Sit PI (T4) & .20 & .04 & .02 & $3.16^{*}$ & $-.17 *$ & .08 \\
\hline NFCC Score & & & & & -.20 & .11 \\
\hline Attribution Score & & & & & -.14 & .08 \\
\hline \multicolumn{7}{|l|}{ Step 3} \\
\hline Sit PI (T4) & .21 & .04 & .00 & .52 & $-.17 *$ & .08 \\
\hline NFCC Score & & & & & $-.24^{*}$ & .12 \\
\hline Attribution Score & & & & & -.07 & .12 \\
\hline \multirow[t]{2}{*}{ Attribution X NFCC } & & & & & -.02 & .03 \\
\hline & \multicolumn{6}{|c|}{ Dispositional PI Time 4} \\
\hline Predictor Variables & $R$ & $R^{2}$ & $R^{2} \Delta$ & $F \Delta$ & $B$ & $S E$ \\
\hline \multicolumn{7}{|l|}{ Step 1} \\
\hline Sit PI (T4) & .15 & .02 & .02 & $7.02 * *$ & $-.21 * *$ & .08 \\
\hline \multicolumn{7}{|l|}{ Step 2} \\
\hline Sit PI (T4) & .16 & .02 & .00 & .28 & $.08 *$ & .08 \\
\hline NfCog Score & & & & & -.01 & .11 \\
\hline AH Score & & & & & -.12 & .15 \\
\hline \multicolumn{7}{|l|}{ Step 3} \\
\hline Sit PI (T4) & .16 & .03 & .01 & .71 & $-.19 *$ & .08 \\
\hline NfCog Score & & & & & -.89 & 1.05 \\
\hline AH Score & & & & & -.74 & .75 \\
\hline AH Score X NfCog & & & & & .18 & .22 \\
\hline
\end{tabular}


Table 17. Individual Differences and Situational-Dispositional/Confirming-Disconfirming Selection and Relevance

\begin{tabular}{|c|c|c|c|c|c|c|c|c|c|c|c|c|c|c|c|c|}
\hline & 1 & 2 & 3 & 4 & 5 & 6 & 7 & 8 & 9 & 10 & 11 & 12 & 13 & 14 & 15 & 16 \\
\hline 1 & 1 & & & & & & & & & & & & & & & \\
\hline 2 & $.57^{* *}$ & 1 & & & & & & & & & & & & & & \\
\hline 3 & $.72 * *$ & $.20^{* *}$ & 1 & & & & & & & & & & & & & \\
\hline 4 & $.59 * *$ & $.19^{* *}$ & $.21^{* *}$ & 1 & & & & & & & & & & & & \\
\hline 5 & $.26 * *$ & $-.25 * *$ & .06 & -.11 & 1 & & & & & & & & & & & \\
\hline 6 & -.05 & $.12 *$ & -.10 & -.01 & $-.12 *$ & 1 & & & & & & & & & & \\
\hline 7 & .03 & -.02 & $.18^{* *}$ & -.04 & -.09 & $-.49 * *$ & 1 & & & & & & & & & \\
\hline 8 & -.01 & .00 & .01 & -.11 & .08 & $-.39^{* *}$ & $.34 * *$ & 1 & & & & & & & & \\
\hline 9 & .10 & -.02 & $.18^{* *}$ & .06 & -.02 & $-.12 *$ & .07 & -.06 & 1 & & & & & & & \\
\hline 10 & -.01 & -.03 & .11 & -.01 & -.11 & $-.20 * *$ & .04 & -.03 & $.42 * *$ & 1 & & & & & & \\
\hline 11 & -.01 & -.04 & -.03 & .00 & .05 & $-.20 * *$ & .08 & -.01 & $.35^{* *}$ & $.36^{* *}$ & 1 & & & & & \\
\hline 12 & .05 & $.13^{*}$ & .05 & -.02 & -.07 & -.10 & -.03 & -.04 & $.35^{* *}$ & $.36^{* *}$ & $.46^{* *}$ & 1 & & & & \\
\hline 13 & $.16^{* *}$ & .06 & $.24 * *$ & .05 & -.02 & -.07 & .05 & $-.11 *$ & $.47^{* *}$ & $.29 * *$ & $.26^{* *}$ & $.28^{* *}$ & 1 & & & \\
\hline 14 & .03 & .10 & $.11^{*}$ & -.04 & -.13 & -.08 & .00 & -.02 & $.28^{* *}$ & $.47 * *$ & $.21^{* *}$ & $.31^{* *}$ & $.64 * *$ & 1 & & \\
\hline 15 & .08 & .00 & .07 & .04 & .05 & $-.12 *$ & .06 & -.08 & $.24 * *$ & $.25^{* *}$ & $.52^{* *}$ & $.28^{* *}$ & $.65^{* *}$ & $.49^{* *}$ & 1 & \\
\hline 16 & .00 & $.12 *$ & .03 & -.09 & -.09 & -.09 & -.05 & -.03 & $.22 * *$ & $.23 * *$ & $.27 * *$ & $.53 * *$ & $.59 * *$ & $.60 * *$ & $.57 * *$ & 1 \\
\hline
\end{tabular}

1. Overall AH Score

2. Attention

3. Causal Attribution

4. Contradiction

5. Perception of Change

6. The Need for Cognitive Closure
7. The Need for Cognition

8. Tolerance for Ambiguity

9. Combined: \% Confirming Sit Info Selected

10. Combined: \% Disconfirming Sit Info Selected

11. Combined: \% Confirming Dis Info Selected

12. Combined: \% Disconfirming Dis Info Selected
13. Combined: Confirming Sit Info Relevance

14. Combined: Disconfirming Sit Info Relevance

15. Combined: Confirming Dis Info Relevance

16. Combined: Disconfirming Dis Info Relevance 
Table 18. Individual Differences and Information Recall

\begin{tabular}{|c|c|c|c|c|c|c|c|c|c|c|c|c|c|}
\hline & 1 & 2 & 3 & 4 & 5 & 6 & 7 & 8 & 9 & 10 & 11 & 12 & 13 \\
\hline 1 & 1 & & & & & & & & & & & & \\
\hline 2 & $.57 * *$ & 1 & & & & & & & & & & & \\
\hline 3 & $.72 * *$ & $.20 * *$ & 1 & & & & & & & & & & \\
\hline 4 & $.59 * *$ & $.19^{* *}$ & $.21^{* *}$ & 1 & & & & & & & & & \\
\hline 5 & $.26^{* *}$ & $-.25 * *$ & .06 & -.11 & 1 & & & & & & & & \\
\hline 6 & -.05 & $.12 *$ & -.10 & -.01 & $-.12 *$ & 1 & & & & & & & \\
\hline 7 & .03 & -.02 & $.18^{* *}$ & -.04 & -.09 & $-.49 * *$ & 1 & & & & & & \\
\hline 8 & -.01 & .00 & .01 & -.11 & .08 & $-.39 * *$ & $.34 * *$ & 1 & & & & & \\
\hline 9 & .00 & -.06 & .05 & .01 & .00 & $-.17 * *$ & $.17 * *$ & .04 & 1 & & & & \\
\hline 10 & $.11 *$ & .05 & .10 & .06 & .04 & -.06 & .02 & -.04 & $.18^{* *}$ & 1 & & & \\
\hline 11 & $.15^{*}$ & -.04 & $.20 * *$ & .10 & .05 & $-.16^{* *}$ & $.21 * *$ & -.09 & $.26^{* *}$ & $.13 *$ & 1 & & \\
\hline 12 & .00 & $-.12 *$ & .06 & .09 & -.02 & $-.14 *$ & $.14^{*}$ & .05 & $.15^{* *}$ & $.14^{*}$ & $.41 * *$ & 1 & \\
\hline 13 & .03 & -.05 & .10 & .06 & -.06 & -.11 & $.20 * *$ & -.04 & $.57 * *$ & $.32 * *$ & $.73^{* *}$ & $.51^{* *}$ & 1 \\
\hline \multicolumn{14}{|c|}{ Note: $* p<.05,{ }^{* *} p<.01$} \\
\hline \multicolumn{4}{|c|}{ 1. Overall AH Score } & \multicolumn{7}{|c|}{ 6. The Need for Cognitive Closure } & \multicolumn{3}{|c|}{ 11. Situational Confirming Items Recalled } \\
\hline \multicolumn{4}{|c|}{ 2. Attention } & \multicolumn{7}{|c|}{ 7. The Need for Cognition } & \multirow{2}{*}{\multicolumn{3}{|c|}{$\begin{array}{l}\text { 12. Situational Disconfirming Items Recalled } \\
\text { 13. Total Items Recalled }\end{array}$}} \\
\hline \multicolumn{4}{|c|}{ 3. Causal Attribution } & \multicolumn{7}{|c|}{ 8. Tolerance for Ambiguity } & & & \\
\hline \multirow{2}{*}{\multicolumn{4}{|c|}{ 4. Contradiction }} & \multicolumn{10}{|c|}{ 9. Dispositional Confirming Items Recalled } \\
\hline & & & 5. Perception of Change & \multicolumn{10}{|c|}{ 10. Dispositional Disconfirming Items Recalled } \\
\hline
\end{tabular}


Table 19. Information Recall, Information Selection, Information Relevance, Problem Identification, and Decision Judgments

\begin{tabular}{|c|c|c|c|c|c|c|c|c|c|c|c|c|c|c|c|c|c|c|c|c|c|}
\hline & 1 & 2 & 3 & 4 & 5 & 6 & 7 & 8 & 9 & 10 & 11 & 12 & 13 & 14 & 15 & 16 & 17 & 18 & 19 & 20 & 21 \\
\hline 1 & 1 & & & & & & & & & & & & & & & & & & & & \\
\hline 2 & $.18^{* *}$ & 1 & & & & & & & & & & & & & & & & & & & \\
\hline 3 & $.26^{* *}$ & $.13 *$ & 1 & & & & & & & & & & & & & & & & & & \\
\hline 4 & $.15^{* *}$ & $.14 *$ & $.41^{* *}$ & 1 & & & & & & & & & & & & & & & & & \\
\hline 5 & $.57 * *$ & $.32 * *$ & $.73^{* *}$ & $.51 * *$ & 1 & & & & & & & & & & & & & & & & \\
\hline 6 & $.12 *$ & .02 & $.24 * *$ & $.22 * *$ & $.24 * *$ & 1 & & & & & & & & & & & & & & & \\
\hline 7 & $.14 *$ & .10 & .02 & .06 & $.14 *$ & $.46^{* *}$ & 1 & & & & & & & & & & & & & & \\
\hline 8 & $.11^{*}$ & .00 & $.27 * *$ & $.19 * *$ & $.22 * *$ & $.95^{* *}$ & $.40 * *$ & 1 & & & & & & & & & & & & & \\
\hline 9 & .09 & .06 & .08 & $.19 * *$ & $.18^{* *}$ & $.68^{* *}$ & $.41 * *$ & $.42 * *$ & 1 & & & & & & & & & & & & \\
\hline 10 & $.17 *$ & .08 & .02 & .06 & $.13 *$ & $.41^{* *}$ & $.96^{* *}$ & $.35^{* *}$ & $.36^{* *}$ & 1 & & & & & & & & & & & \\
\hline 11 & .01 & $.11 *$ & .03 & .03 & $.12 *$ & $.41 * *$ & $.69 * *$ & $.35^{* *}$ & $.36 * *$ & $.46^{* *}$ & 1 & & & & & & & & & & \\
\hline 12 & $.17 * *$ & $.13^{*}$ & $.14 *$ & .10 & $.24 * *$ & $.47 * *$ & $.32 * *$ & $.42 * *$ & $.39 * *$ & $.27^{* *}$ & $.31^{* *}$ & 1 & & & & & & & & & \\
\hline 13 & $.13^{*}$ & $.11 *$ & .00 & -.01 & $.11 *$ & $.28^{* *}$ & $.49 * *$ & $.24 * *$ & $.26^{* *}$ & $.43 * *$ & $.42 * *$ & $.66^{* *}$ & 1 & & & & & & & & \\
\hline 14 & $.20 * *$ & $.13^{*}$ & $.17^{* *}$ & .08 & $.26^{* *}$ & $.46^{* *}$ & $.30^{* *}$ & $.47 * *$ & $.29^{* *}$ & $.26^{* *}$ & $.28 * *$ & $.89^{* *}$ & $.66^{* *}$ & 1 & & & & & & & \\
\hline 15 & .10 & .07 & .00 & .06 & $.17 * *$ & $.39 * *$ & $.27 * *$ & $.28 * *$ & $.47 * *$ & $.21^{* *}$ & $.31^{* *}$ & $.82 * *$ & $.58 * *$ & $.64^{* *}$ & 1 & & & & & & \\
\hline 16 & $.20 * *$ & $.13^{* *}$ & .04 & .02 & $.15^{* *}$ & $.28^{* *}$ & $.51 * *$ & $.24 * *$ & $.25^{* *}$ & $.52 * *$ & $.28^{* *}$ & $.64 * *$ & $.84 * *$ & $.65^{* *}$ & $.49^{* *}$ & 1 & & & & & \\
\hline 17 & .09 & $.13^{* *}$ & -.03 & -.03 & .09 & $.26 * *$ & $.39 * *$ & $.22 * *$ & $.23 * *$ & $.27 * *$ & $.53 * *$ & $.61 * *$ & $.82 * *$ & $.59 * *$ & $.60^{* *}$ & $.57 * *$ & 1 & & & & \\
\hline 18 & -.05 & .02 & $.16^{* *}$ & .07 & .06 & $.24 * *$ & -.02 & $.24 * *$ & $.14^{*}$ & -.05 & .05 & $.29 * *$ & .08 & $.30^{* *}$ & $.19^{* *}$ & $.11 *$ & .10 & 1 & & & \\
\hline 19 & $.18^{* *}$ & .05 & -.06 & -.01 & .09 & -.09 & $.35^{* *}$ & -.11 & -.02 & $.36^{* *}$ & $.17 * *$ & .05 & $.29 * *$ & .06 & .08 & $.31 * *$ & $.18^{* *}$ & $-.39 * *$ & 1 & & \\
\hline 20 & -.10 & -.04 & -.03 & -.06 & -.10 & .16 & -.05 & $.16^{* *}$ & .10 & -.08 & .05 & $.22 * *$ & .01 & $.20 * *$ & $.16^{* *}$ & .09 & .05 & $.57^{* *}$ & $-.30 * *$ & 1 & \\
\hline 21 & .11 & .04 & .08 & -.01 & $.11^{*}$ & -.03 & $.24 * *$ & -.04 & -.01 & $.26^{* *}$ & .09 & .08 & $.22 * *$ & .11 & .08 & $.23 * *$ & .11 & $-.26^{* *}$ & $.58 * *$ & $-.29 * *$ & 1 \\
\hline
\end{tabular}

1. Dispositional Confirming Items Recalled

2. Dispositional Disconfirming Items Recalled

3. Situational Confirming Items Recalled

4. Situational Disconfirming Items Recalled

5. Total Items Recalled

6. Combined: $\%$ of Sit Information Selected 2

7. Combined: $\%$ of Dis Information Selected 2
8. Combined: \% Confirming Sit Info Selected

9. Combined: \% Disconfirming Sit Info Selected

10. Combined: \% Confirming Dis Info Selected

11. Combined: \% Disconfirming Dis Info Selected

12. Combined: Sit Info Relevance

13. Combined: Dis Info Relevance

14. Combined: Confirming Sit Info Relevance
15. Combined: Disconfirming Sit Info Relevance 16. Combined: Confirming Dis Info Relevance

17. Combined: Disconfirming Dis Info Relevance

18. Combined: Problem Identification Sit T4

19. Combined: Problem Identification Dis T4

20. Combined: Decision Sit T4

21. Combined: Decision Dis T4 
Table 20. Forms of Sensemaking

\begin{tabular}{lccc}
\hline Codes & $\begin{array}{c}\text { Combined } \\
\%\end{array}$ & $\begin{array}{c}\text { Westerly Foundation } \\
\%\end{array}$ & $\begin{array}{c}\text { Production Dilemma } \\
\%\end{array}$ \\
\hline Code 1 & 14.3 & 10.3 & 18.3 \\
Code 2 & 5.7 & 3.8 & 7.7 \\
Code 3 & 3.8 & 2.9 & 4.8 \\
Code 4 & 42.0 & 51.3 & 32.7 \\
Code 5 & 16.3 & 16.7 & 16.0 \\
Code 6 & 3.2 & 1.9 & 4.5 \\
Code 7 & 1.3 & .6 & 1.9 \\
Code 8 & 5.3 & 4.8 & 5.8 \\
Code 9 & .8 & .3 & 1.3 \\
Not Coded & 6.6 & 6.4 & 6.7 \\
Withholding & .6 & 1.0 & .3 \\
\hline
\end{tabular}


Table 21. Means and Standard Deviations

\begin{tabular}{|c|c|c|c|}
\hline Variables & $N$ & $M$ & $S D$ \\
\hline Age & 312 & 19.61 & 3.66 \\
\hline High School GPA & 305 & 3.32 & .54 \\
\hline College GPA & 276 & 3.04 & .71 \\
\hline Overall AH Score & 312 & 4.64 & .49 \\
\hline Attention & 312 & 4.43 & .94 \\
\hline Attribution & 312 & 4.80 & .99 \\
\hline Tolerance for Contradiction & 312 & 4.70 & .85 \\
\hline Perception of Change & 312 & 4.65 & .78 \\
\hline The Need for Cognitive Closure & 312 & 3.30 & .69 \\
\hline The Need for Cognition & 312 & 3.31 & .65 \\
\hline Tolerance for Ambiguity & 312 & 8.24 & 2.86 \\
\hline Combined: Problem Identification Sit T1 & 312 & 4.86 & .86 \\
\hline Combined: Problem Identification Dis T1 & 312 & 3.95 & 1.14 \\
\hline Combined: Problem Identification Sit T2 & 312 & 5.11 & 1.03 \\
\hline Combined: Problem Identification Dis T2 & 312 & 4.26 & 1.50 \\
\hline Combined: Problem Identification Sit T3 & 312 & 5.49 & .81 \\
\hline Combined: Problem Identification Dis T3 & 312 & 4.50 & 1.27 \\
\hline Combined: Problem Identification Sit T4 & 312 & 5.53 & .95 \\
\hline Combined: Problem Identification Dis T4 & 312 & 4.39 & 1.31 \\
\hline Combined: Decision Sit T1 & 312 & 4.82 & 1.02 \\
\hline Combined: Decision Dis T1 & 312 & 3.80 & 1.08 \\
\hline Combined: Decision Sit T2 & 312 & 4.75 & 1.15 \\
\hline Combined: Decision Dis T2 & 312 & 4.04 & 1.34 \\
\hline Combined: Decision Sit T3 & 312 & 5.15 & .99 \\
\hline Combined: Decision Dis T3 & 312 & 4.31 & 1.17 \\
\hline Combined: Decision Sit T4 & 312 & 5.24 & 1.08 \\
\hline Combined: Decision Dis T4 & 312 & 4.27 & 1.22 \\
\hline PD: Problem Identification Sit T1 & 312 & 4.94 & 1.15 \\
\hline PD: Problem Identification Dis T1 & 312 & 3.72 & 1.50 \\
\hline PD: Problem Identification Sit T2 & 312 & 5.22 & 1.34 \\
\hline PD: Problem Identification Dis T2 & 312 & 3.99 & 1.83 \\
\hline PD: Problem Identification Sit T3 & 312 & 5.63 & 1.11 \\
\hline PD: Problem Identification Dis T3 & 312 & 4.25 & 1.72 \\
\hline PD: Problem Identification Sit T4 & 312 & 5.68 & 1.24 \\
\hline PD: Problem Identification Dis T4 & 312 & 4.07 & 1.77 \\
\hline PD: Decision Sit T1 & 312 & 4.85 & 1.37 \\
\hline PD: Decision Dis T1 & 312 & 3.89 & 1.42 \\
\hline PD: Decision Sit T2 & 312 & 4.71 & 1.50 \\
\hline PD: Decision Dis T2 & 312 & 3.94 & 1.65 \\
\hline PD: Decision Sit T3 & 312 & 5.08 & 1.32 \\
\hline
\end{tabular}




\begin{tabular}{|c|c|c|c|}
\hline Variables & $N$ & $M$ & $S D$ \\
\hline PD: Decision Dis T3 & 312 & 4.29 & 1.53 \\
\hline PD: Decision Sit T4 & 312 & 5.13 & 1.50 \\
\hline PD: Decision Dis T4 & 312 & 4.15 & 1.62 \\
\hline WF: Problem Identification Sit T1 & 312 & 4.78 & 1.16 \\
\hline WF: Problem Identification Dis T1 & 312 & 4.19 & 1.40 \\
\hline WF: Problem Identification Sit T2 & 312 & 5.01 & 1.18 \\
\hline WF: Problem Identification Dis T2 & 312 & 4.53 & 1.67 \\
\hline WF: Problem Identification Sit T3 & 312 & 5.35 & 1.05 \\
\hline WF: Problem Identification Dis T3 & 312 & 4.74 & 1.44 \\
\hline WF: Problem Identification Sit T4 & 312 & 5.38 & 1.09 \\
\hline WF: Problem Identification Dis T4 & 312 & 4.71 & 1.52 \\
\hline WF: Decision Sit T1 & 312 & 4.80 & 1.28 \\
\hline WF: Decision Dis T1 & 312 & 3.70 & 1.34 \\
\hline WF: Decision Sit T2 & 312 & 4.79 & 1.36 \\
\hline WF: Decision Dis T2 & 312 & 4.15 & 1.60 \\
\hline WF: Decision Sit T3 & 312 & 5.22 & 1.14 \\
\hline WF: Decision Dis T3 & 312 & 4.33 & 1.47 \\
\hline WF: Decision Sit T4 & 312 & 5.34 & 1.19 \\
\hline WF: Decision Dis T4 & 312 & 4.40 & 1.51 \\
\hline Combined: Numbers of Category Selected & 312 & 5.87 & 2.37 \\
\hline PD: Numbers of Category Selected & 312 & 5.81 & 2.69 \\
\hline WF: Numbers of Category Selected & 312 & 5.92 & 2.58 \\
\hline Combined: $\%$ of Information Selected (1\&2) & 312 & 56.25 & 14.35 \\
\hline PD: \% of Information Selected (1\&2) & 312 & 56.29 & 15.60 \\
\hline WF: \% of Information Selected (1\&2) & 312 & 56.21 & 15.37 \\
\hline Combined: $\%$ of Information Selected 1 & 312 & 52.01 & 17.62 \\
\hline PD: \% of Information Selected 1 & 312 & 51.87 & 19.45 \\
\hline WF: \% of Information Selected 1 & 312 & 52.15 & 19.19 \\
\hline Combined: $\%$ of Information Selected 2 & 312 & 60.49 & 15.30 \\
\hline PD: \% of Information Selected 2 & 312 & 60.71 & 17.06 \\
\hline WF: \% of Information Selected 2 & 312 & 60.27 & 16.41 \\
\hline Combined: $\%$ of Sit Information Selected 2 & 312 & 64.40 & 16.79 \\
\hline Combined: $\%$ of Dis Information Selected 2 & 312 & 56.58 & 19.01 \\
\hline PD: \% of Sit Information Selected 2 & 312 & 64.64 & 20.51 \\
\hline PD: \% of Dis Information Selected 2 & 312 & 56.78 & 24.30 \\
\hline WF: $\%$ of Sit Information Selected 2 & 312 & 64.15 & 18.51 \\
\hline WF: \% of Dis Information Selected 2 & 312 & 56.39 & 20.30 \\
\hline Combined: Overall Info Relevance & 312 & 5.14 & .71 \\
\hline PD: Overall Info Relevance & 312 & 5.09 & .82 \\
\hline WF: Overall Info Relevance & 312 & 5.19 & .75 \\
\hline
\end{tabular}




\begin{tabular}{|c|c|c|c|}
\hline Variables & $N$ & $M$ & $S D$ \\
\hline Combined: Sit Info Relevance & 312 & 5.24 & .78 \\
\hline Combined: Dis Info Relevance & 312 & 4.85 & .90 \\
\hline PD: Sit Info Relevance & 312 & 5.10 & .96 \\
\hline PD: Dis Info Relevance & 312 & 4.91 & 1.10 \\
\hline WF: Sit Info Relevance & 312 & 5.39 & .81 \\
\hline WF: Dis Info Relevance & 312 & 4.79 & 1.01 \\
\hline Combined: Confirming Info Relevance & 312 & 5.26 & .70 \\
\hline Combined: Disconfirming Info Relevance & 312 & 4.74 & .96 \\
\hline PD: Confirming Info Relevance & 312 & 5.12 & .84 \\
\hline PD: Disconfirming Info Relevance & 312 & 5.01 & 1.04 \\
\hline WF: Confirming Info Relevance & 312 & 5.40 & .74 \\
\hline WF: Disconfirming Info Relevance & 312 & 4.48 & 1.17 \\
\hline Combined: Difference in PI T4 & 312 & -1.14 & 1.72 \\
\hline PD: Difference in PI T4 & 312 & -1.62 & 2.53 \\
\hline WF: Difference in PI T4 & 312 & -0.67 & 1.86 \\
\hline Combined: Abs Difference in PI T4 & 312 & 2.01 & 1.14 \\
\hline PD: Abs Difference in PI T4 & 312 & 2.51 & 1.63 \\
\hline WF: Abs Difference in PI T4 & 312 & 1.51 & 1.26 \\
\hline Combined: Difference in Decision T4 & 312 & -0.96 & 1.76 \\
\hline PD: Difference in Decision T4 & 312 & -0.97 & 2.50 \\
\hline WF: Difference in Decision T4 & 312 & -0.95 & 2.03 \\
\hline Combined: Abs Difference in Decision T4 & 312 & 1.96 & 1.16 \\
\hline PD: Abs Difference in Decision T4 & 312 & 2.15 & 1.60 \\
\hline WF: Abs Difference in Decision T4 & 312 & 1.77 & 1.37 \\
\hline Combined: \% Confirming Sit Info Selected & 312 & 66.99 & 17.68 \\
\hline Combined: \% Disconfirming Sit Info Selected & 312 & 55.77 & 24.76 \\
\hline Combined: \% Confirming Dis Info Selected & 312 & 59.98 & 20.11 \\
\hline Combined: \% Disconfirming Dis Info Selected & 312 & 45.25 & 26.25 \\
\hline Combined: Confirming Sit Info Relevance & 312 & 5.28 & .74 \\
\hline Combined: Disconfirming Sit Info Relevance & 312 & 4.93 & 1.05 \\
\hline Combined: Confirming Dis Info Relevance & 312 & 5.24 & .80 \\
\hline Combined: Disconfirming Dis Info Relevance & 312 & 4.56 & 1.10 \\
\hline Dispositional Confirming Items Recalled & 312 & 2.88 & 1.62 \\
\hline Dispositional Disconfirming Items Recalled & 312 & .80 & .75 \\
\hline Situational Confirming Items Recalled & 312 & 2.70 & 2.02 \\
\hline Situational Disconfirming Items Recalled & 312 & .53 & .75 \\
\hline Total Items Recalled & 312 & 8.53 & 3.75 \\
\hline
\end{tabular}




\section{FIGURES}

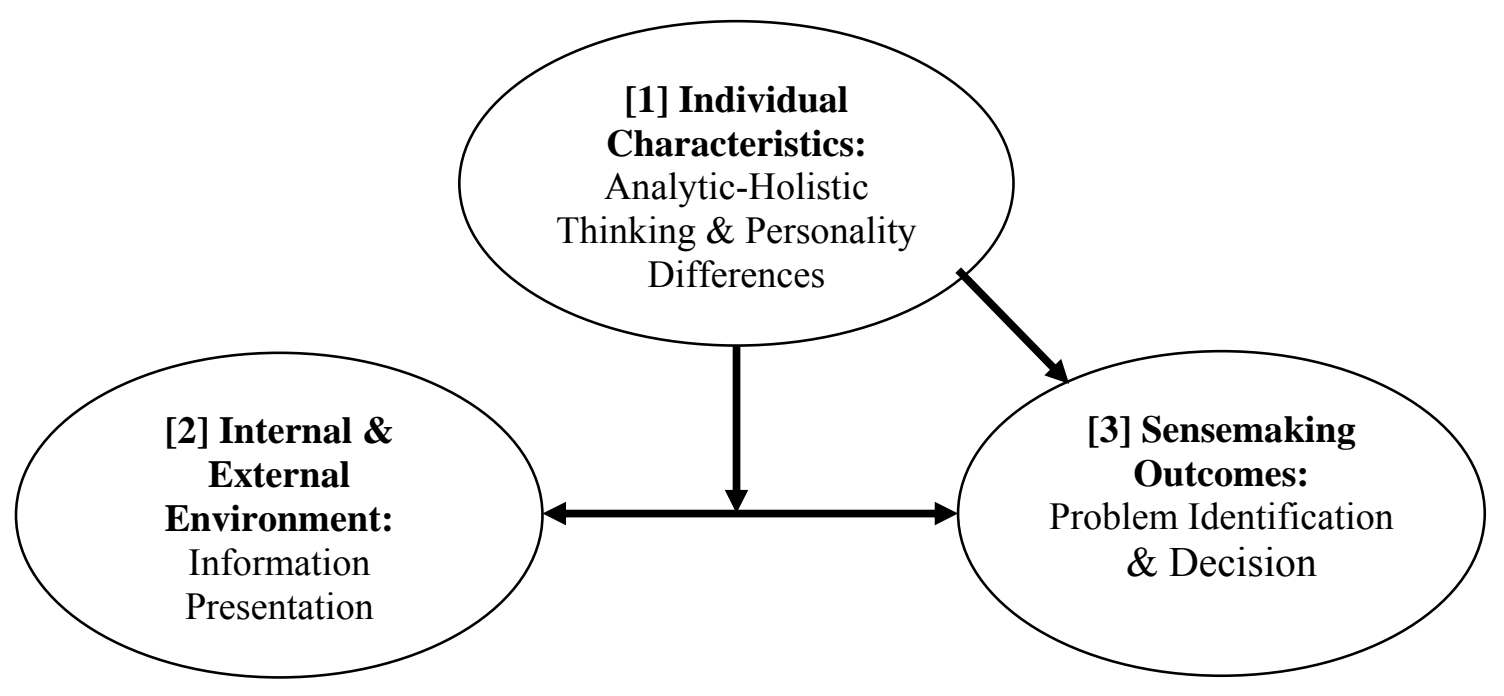

Figure 1. A Framework of Individual's Sensemaking Process

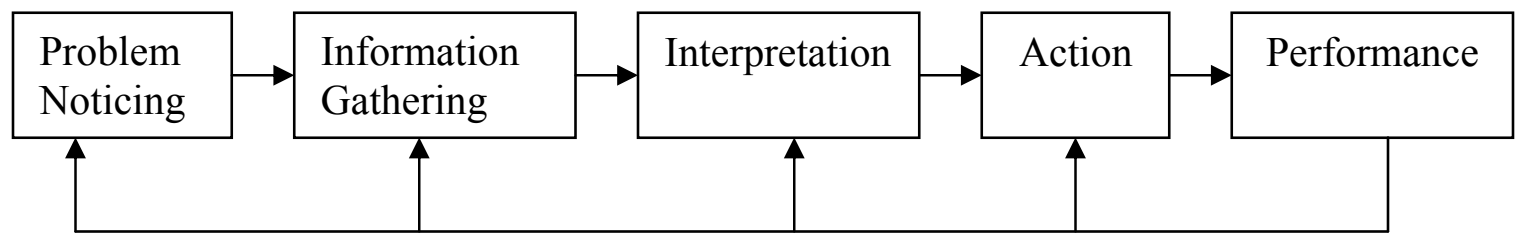

Figure 2. Weick's General Model of Sensemaking 


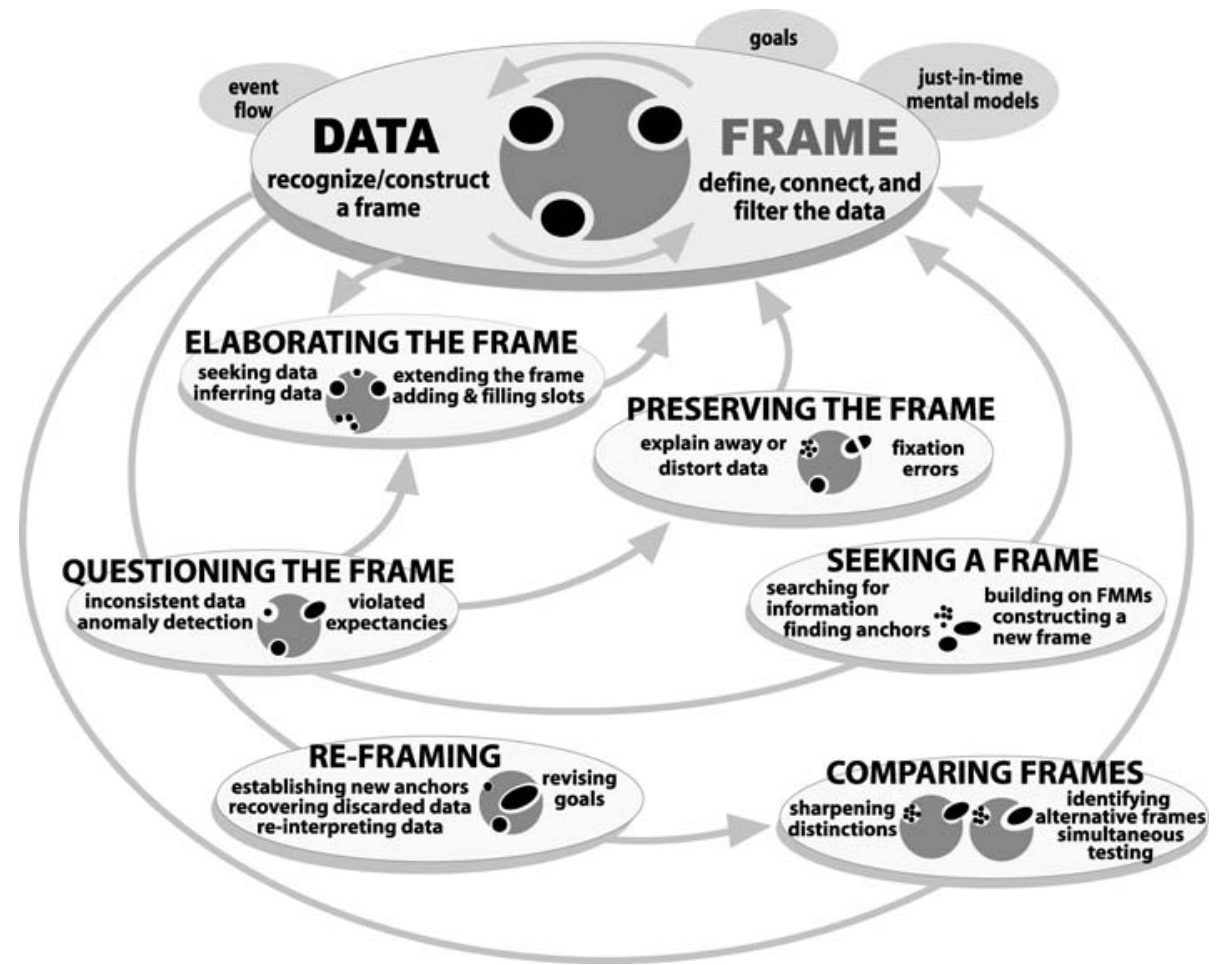

Figure 3. Sensemaking Activities represented in the Data Frame Model (Klein et al., 2007)

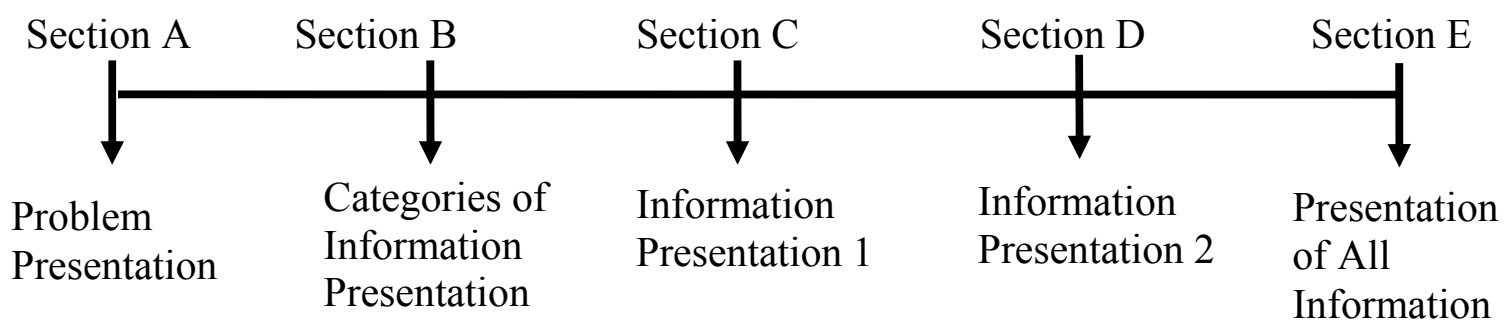

Figure 4. Sections in Each Sensemaking Scenario 
Situational PI Judgment at Different Level of AHS

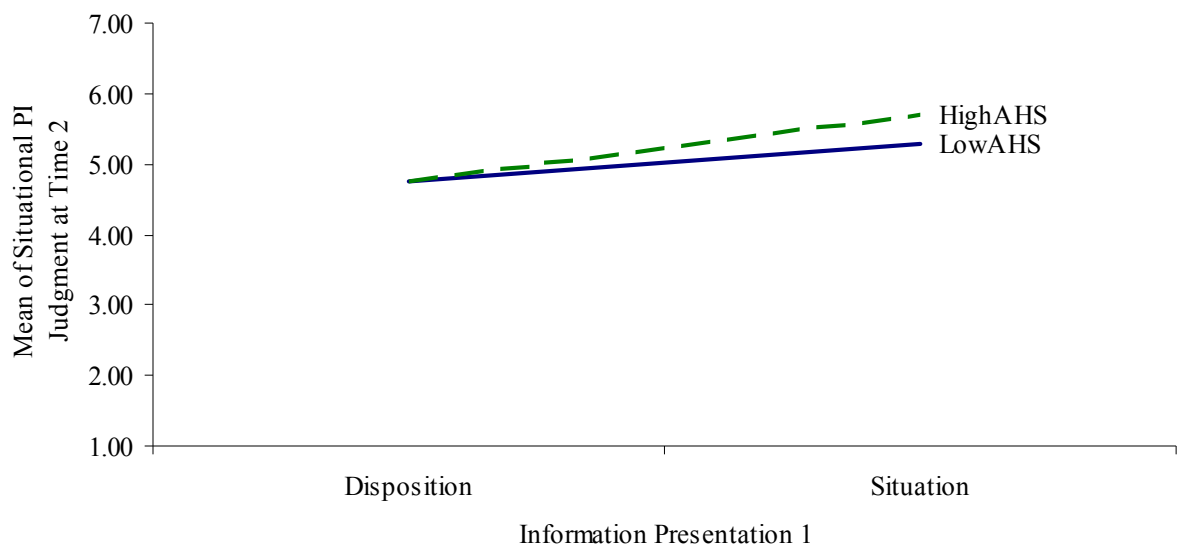

Figure 5. Simple slopes for high and low AH thinkers on Situational PI Judgment

Dispositional PI Judgment at Different Level of AHS

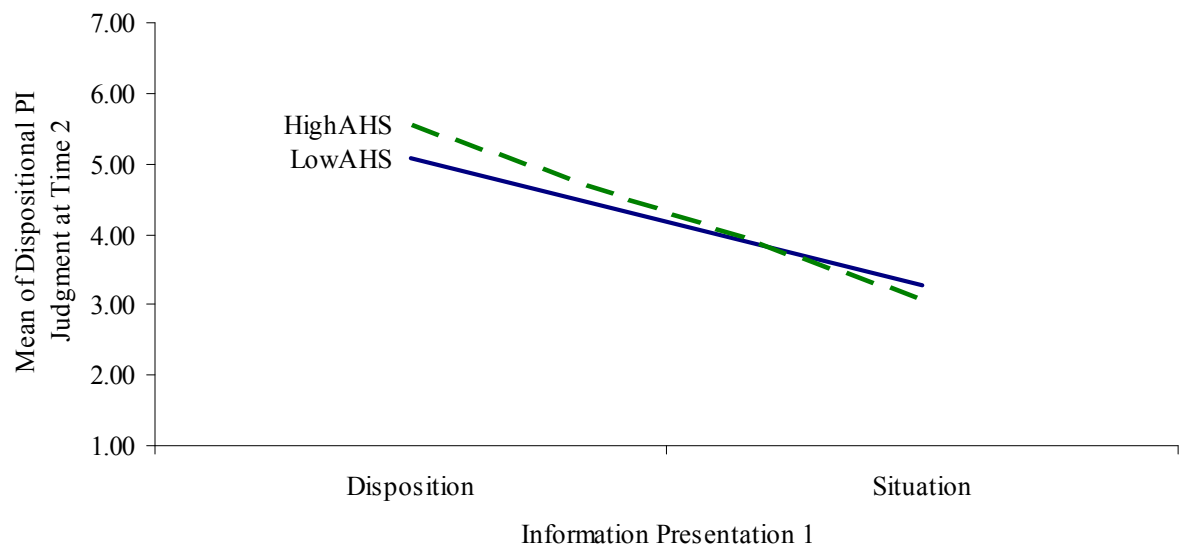

Figure 6. Simple slopes for high and low AH thinkers on Dispositional PI Judgment 
Situational DecisionJudgment at Different Level of AHS

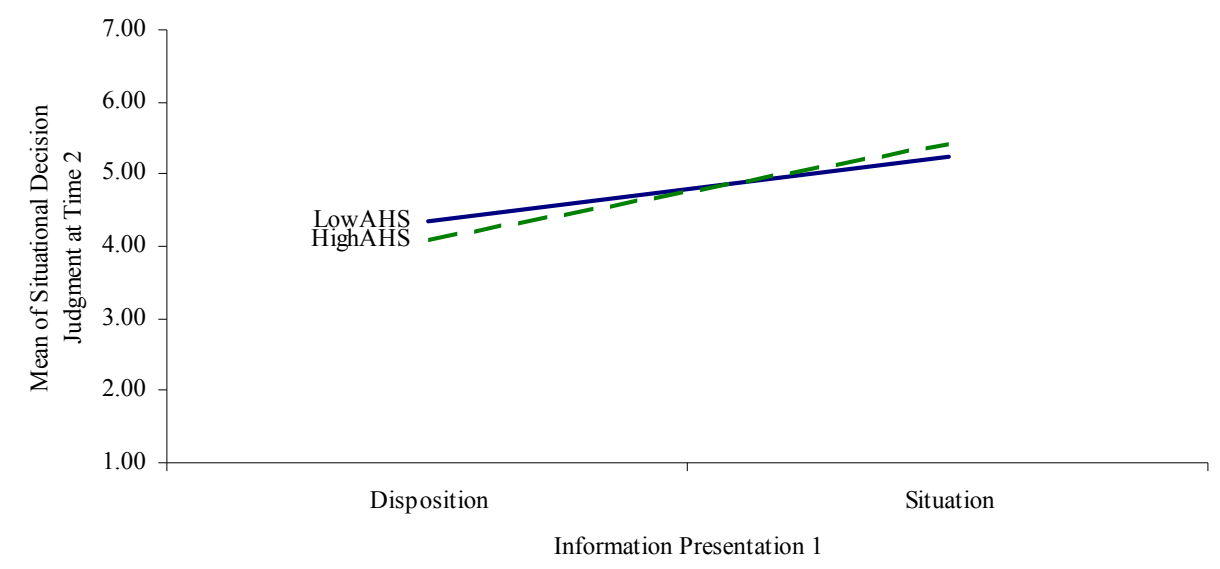

Figure 7. Simple slopes for high and low AH thinkers on Situational Decision Judgment

Disp ositional Decision Judgment at Different Level of AHS

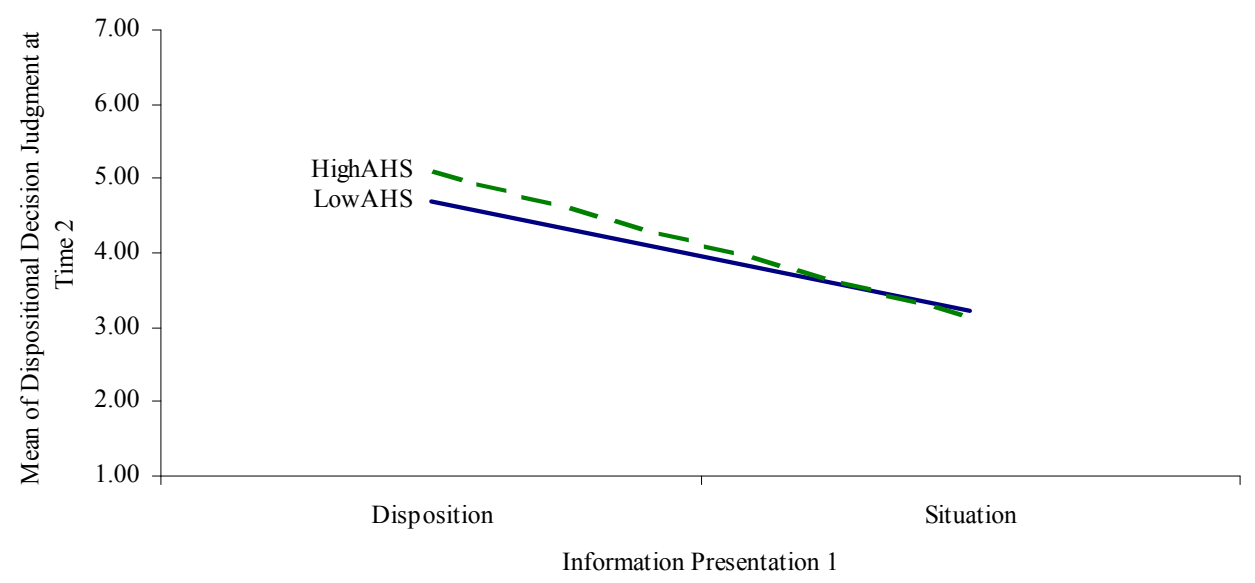

Figure 8. Simple slopes for high and low AH thinkers on Dispositional Decision Judgment 
Dispositional Decision Judgment at Different Level of AHS (WF)

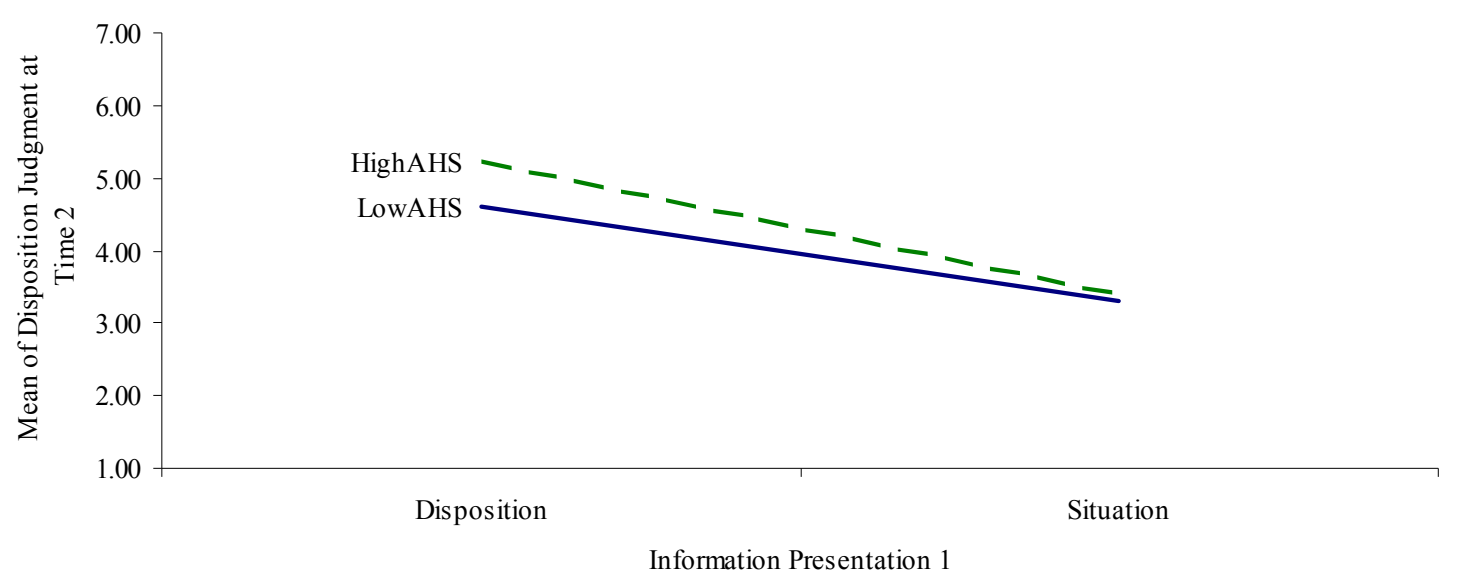

Figure 9. Simple slopes for high and low AH thinkers on Dispositional Decision Judgment (WF)

Dispositional Decision Judgment at Different Level of AHS (PD)

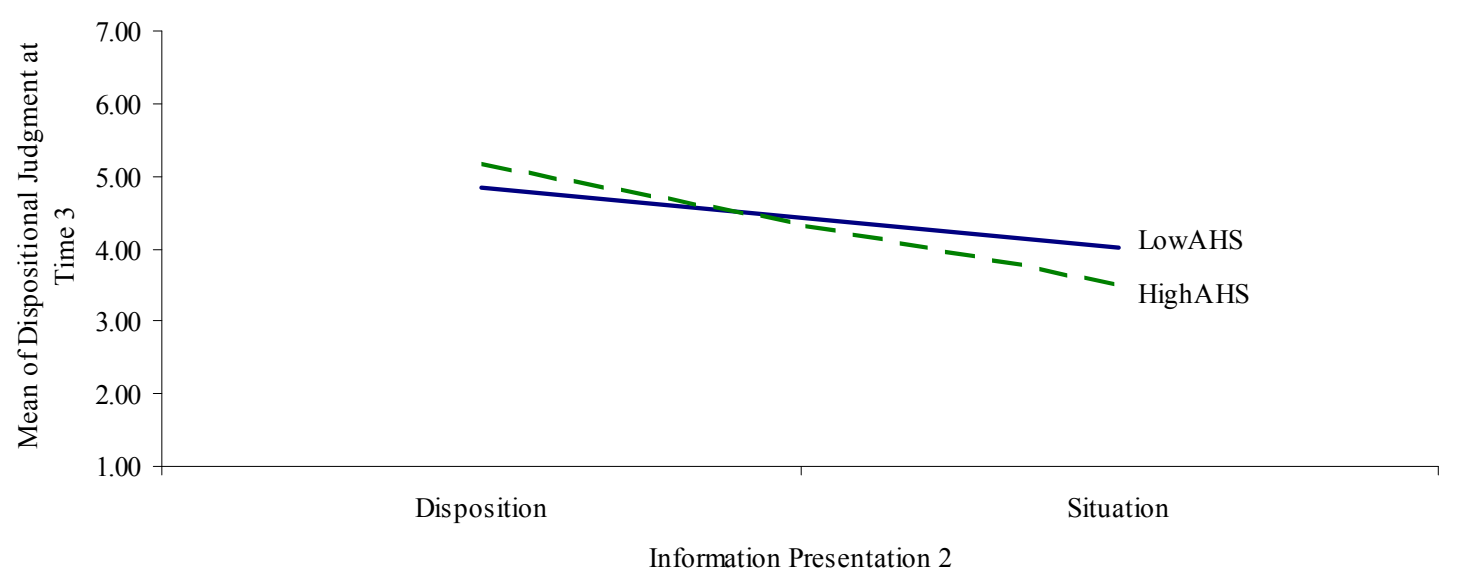

Figure 10. Simple slopes for high and low AH thinkers on Dispositional Decision Judgment (PD) 


\section{APPENDICES}

\section{Appendix A}

\section{Sensemaking Assessment Development}

1) Pilot Study 1: Interview with participants I first interviewed nine undergraduate participants. The goals of these interviews were to find relevant scenarios for undergraduates, to collect information that can be use in the scenarios, and to understand the use of information by participants. In each interview, participants were asked to recall a complex event in their life where they had to seek information and make sense of multiple perspectives to come to a conclusion about the event. During the interviews, participants were asked how the event unfolded, the strategies they used for searching information, the types of information that facilitated their understanding, how they acted at each decision points, and their final decision making.

When participants had difficulty in providing an event, hypothetical events were presented for exploratory discussion. These included conflict with a roommate, disputes in a working environment, job search after graduation, finding an apartment, and financial difficulty in an organization. I looked for events that have two contrasting options. For example, in the apartment search, participants were questioned on characteristics of an apartment versus attributes of a potential roommate. They were asked to provide both supporting and non-supporting information for picking the apartment based on its characteristics or attributes of the potential roommate.

While the interviews provided possible scenarios such as selecting a major, choosing between two colleges, and plans after high school, they lacked the contrast between dispositional versus situational factors (i.e. picking between two majors). 
However, some scenarios such as conflict at work, and conflict with roommates provided content useful for developing research scenarios.

2) Pilot Study 2: Information development In order to allow for the testing of the proposed hypotheses, several types of information were created iteratively for each scenario. The selection of information for the scenarios included both Situational and Dispositional information as explained below.

Three initial scenarios were developed to provide a contrast between dispositional and situational information. The scenarios titled, 'Financial Mess', 'Production Dilemma', and 'Westerly Foundation' all presented a problematic situation and contrasting perspectives that suggested both dispositional and situational causes. The situational causes included the dynamic changes in the organization and its external environment. 'Financial Mess' and 'Production Dilemma' were from previous research (Lin, 2004). These scenarios were modified for the purpose of the present study while 'Westerly Foundation' was created for this study.

To develop the scenarios, I developed information that suggested two opposing causes: dispositional and situational. Dispositional attribution was operationalized as finding causal factor(s) as internal to a person (i.e. personality, feelings, and values). Therefore, dispositional information was operationalized as information about an individual. For example, “Andy is a troublemaker.” Situational attribution was operationalized as finding causal factor(s) as external to a person (i.e. surrounding people and environment). Situational information was operationalized as information about the changing environment surrounding the person and the organization as a whole. For 
example, "The economy is facing a recession." The scenarios presented dilemmas and allowed participants to engage in sensemaking.

'Financial Mess' involved an organization facing financial problems. Some information focused dispositional concerns with a new, inexperienced young hire (i.e. Kevin does not like to take risks) while other information pinpointed the problem to the changing environment surrounding the person and the organization (i.e. the retirement of the Marketing Manager, the economy, the lack of leadership). 'Production Dilemma' involved a chaotic production department and a CEO who wanted a fair report on the activities of the department. Some information pinpointed the problem to a worker in the production department (i.e. Andy became less motivated to work) while others pointed to the changing situation surrounding the person and the organization (i.e. the changes that were being implemented, the economy, the lack of training). 'Westerly Foundation' involved a non-profit organization that was facing a shortage of funds. Some information located the problem with the current director (i.e. Michael does not have good social skills) while others pointed to the changing environment surrounding the person and the foundation (i.e. policy changes, the economy, history of the foundation).

In order to evaluate dispositional and situational information, 19 undergraduates were asked to rate how relevant each information item was in reference to dispositional cause and situational cause. Instructions asked participant to judge whether each information item support or refutes that the person is the cause or situation is the cause. Participants rated item from +3 (Strongly Support) to -3 (Strongly Refutes). If an information item was irrelevant to the cause, they were asked to mark ' $X$ ' and rate ' 0 ' if an information item was relevant but does not indicate whether it supported or refuted a 
cause. Participants first judged information items against one cause and then judged the same items against the other cause. Items rated high on one cause and low in another in support or refute were retained. These items were used in scenarios for information manipulation. Items that were rated non applicable or irrelevant were used as fillers (i.e. introduction and ending). Ambiguous items were rephrased for clarity.

\section{3) Pilot Study 3: Evaluation of scenarios and information Scenarios}

were revised after Pilot Study 2. They were balanced so that both situational and dispositional causes were reasonable. Several graduate students $(\mathrm{N}=5)$ reviewed the three scenarios. They also evaluated the information for each scenario as described above. They were asked about the balance and strength of information in each scenario, and their relevance for undergraduate students. This evaluation helped in refining the scenarios. Changes were made iteratively with the feedback of each graduate student.

The graduate students were also asked which two of the three scenarios, were most suitable for the study. 'Production Dilemma' and 'Westerly Foundation' were chosen while 'Financial Mess' was judged as too complicated as there were more individuals involved in the story. 'Production Dilemma' and 'Westerly Foundation' were also judged as more parallel, comparable in terms of format of story, length, and readability.

4) Pilot Study 4: Sensemaking Assessment Package development In order to test the hypotheses and answer research questions, the scenarios had to present information in an unfolding manner. The purpose of these scenarios was to tap the outcome measures: Problem identification, Information need, Decision, Information trust, Information selection, and Information relevance. The purpose of Pilot Study 4 was to 
test the sensemaking scenarios with Pilot Study 3 scenarios divided into sections and with response measures incorporated into these sections.

In Section A of each scenario (see Table 2 and Appendix B), a problem was presented (i.e. the Production Department is in trouble or Westerly Foundation is facing a shortage of funds). Two possible causes were presented, a person in the organization (i.e. Andy, or Michael) or situational changes surrounding the organization (i.e. the changes in the company). Participants responded to problem identification, decision, and information need questions. Hence, Section A measured these three outcome scores. There were two problem identification scores, one represented situational cause and the other represented dispositional cause. Participants were asked to rate independently the extent to which they thought that the person and the situational changes were the problems by rating ' 1 ' (Not at all) to '7' (Most Likely). There were also two decision scores for each scenario. One choice represented taking decision towards the individual and the other represented decision towards the situation. These were also rated independently. For example, participants rated how likely they would take each of these actions, 'To give warning to Andy' and 'To make changes in the company.' Information need in this study measured the extent participants still needed information to make sense and make decision. This section provided the baseline of problem identification, decision, and information need.

In Section B, participants chose information that they believed would help better understand the situation. This assessed the number of information items chosen. It also included the number of categories of information needed. There were nine categories with 2-5 information pieces in each category. Section B provided two outcome scores for 
information selected and number of categories used. This was the first time information selection was measured.

Section C provided the first information presentation manipulation. Information was presented to suggest one problem (disposition or situational). Participants then make judgments of problem identification, decision, information need, and information trust. They were also asked to judge the relevance of information presented by rating items from '1' (Not at all) to '7' (Very Relevant). Problem identification, decision, and information need were measured the second time. Two other outcomes measures, information trust and information relevance, were measured for the first time. Information trust measured the extent participants trusted the information presented to them. Information relevance measured the extent each information item was relevant.

In Section $\mathrm{D}$, the second information presentation was presented. When Section $\mathrm{C}$ presented dispositional cause, Section D presented situational cause and vice versa. This section provided the third measure of problem identification, decision, and information need, and the second measure of information trust and information relevance.

During Pilot Study 4, an additional condition provided a mixed set of information and asked participants to evaluate information. From this pilot testing, the third section of information presentation was incorporated in the second and third section of each scenario. This section was dropped from the final research tool.

In Section E, the last section, participants were presented all the information and were asked to select information they would use in their recommendation. Then they made the final judgment on problem identification and decision. Participants were asked to list additional information that they would like to receive. This gave the fourth 
measure of problem identification, decision, and information need. This section also gave the second measure of information selection.

In the sequential sections of the scenarios, Open Ended Questions queried what participants thought happened in the scenario. These questions tap the qualitative sensemaking, specifically by examining the different forms of sensemaking presented in the Data Frame Model (Klein et al. 2007). These open ended were asked four times in each scenario.

To evaluate this developed material in Pilot Study 4, 21 undergraduates from a senior level psychology class were observed and timed while completing the task. After completing the task, they were asked about the balance of information, redundancy of questions, the flow of scenarios, length and difficulty of the measure, and for improvements for the measure. Comparisons were also made between the two scenarios. Changes were made iteratively after feedbacks.

After Pilot Study 4, several changes were made. Redundant questions were removed from the original measure, while information need was asked for problem identification as well as action, $66.7 \%$ of the participants gave the same ratings for both. For this reason, these questions were asked once for problem identification in the final version.

After checking responses between problem identification and action for redundancy, it was found that most participants did not rate them the same. $55.6 \%$ gave different ratings between problem identification and decision judgments. Therefore, the original format of these questions was retained. The categories for information selection 
remained nine categories but the range of information item was changed to 3-5 pieces in each category.

5) Pilot Study 5: Testing of All Measures The revised sensemaking assessment scenarios, together with the other measures were given to undergraduate participants. Time of completion was recorded. A memory recall task was included in this study. This task was to measure the kind of information items participants recalled.

6) Pilot Study 6: Final Sensemaking Assessment Package After the Pilot Study 5, the third section of information presentation was incorporated in the second and third section of each. The final scenarios were as described in Pilot Study 4 with these exceptions: removal of redundant questions, the range of categories for information selection was changed to 3-5 pieces in each category, Section E was dropped, and a memory recall task was added. [Note: Original Section F is the new Section E]. Two items were added for each type of problem identification and decision, making three dispositional problem identification items, three situational problem identification items, three dispositional decision items, and three situational decision items.

The final experimental booklet each contained versions of the two scenarios with causal version counterbalanced for order and the memory recall task. The Dispositional version starts with the information presentation that indicates the cause to be an individual (i.e. Andy or Michael) and the other version indicates the changes that are happening in the organization to be the cause. In each scenario, there were thirteen items in each of the two information presentation manipulation, making it a total of 26 items. In the information presentation that suggested dispositional cause, there were eleven dispositional items and two situational items. In the information presentation that 
suggested a situational cause, there were eleven situational items and two dispositional items. The memory recall task a participant received was related to the first scenario the participant received. Hence, half the participant received the memory recall task for Westerly Foundation and half received Production Dilemma. See Appendix B for scenarios. See Appendix D for memory recall task. 


\section{“Production Dilemma”}

\section{Appendix B}

A. The CEO of your company, Brilliant Electronics Incorporated (BEI) recognizes that their Production Department is in trouble. Some people say that Andy Smith, a worker in the production, is disrupting work and others argued that the fault lies with the many changes underway in the company not with any one person. Your job is to investigate and report to the $\mathrm{CEO}$ so he can resolve the problem.

How likely do you think that each of this is the problem? Rate from 1 (Not likely) to 7 (Most likely).

\begin{tabular}{|l|l|rrrrrrr|}
\hline & \multicolumn{1}{|c}{ Not Likely } & \multicolumn{4}{c|}{ Most Likely } \\
\hline 1. & Changes in BEI & 1 & 2 & 3 & 4 & 5 & 6 & 7 \\
\hline 2. & Characteristics of Andy & 1 & 2 & 3 & 4 & 5 & 6 & 7 \\
\hline 3. & How the organization adjusted & 1 & 2 & 3 & 4 & 5 & 6 & 7 \\
\hline 4. & Andy, the employee & 1 & 2 & 3 & 4 & 5 & 6 & 7 \\
\hline 5. & Change in the company's situation & 1 & 2 & 3 & 4 & 5 & 6 & 7 \\
\hline 6. & Andy's traits & 1 & 2 & 3 & 4 & 5 & 6 & 7 \\
\hline
\end{tabular}

Rate from 1 (Not at all) to 7 (A lot) the extent you need more information to investigate the problem in the Production Department.

Not at all

1
2

3
4
5
6
A lot

7

What do you think happened?

How likely are you to recommend each of these actions? Rate from 1 (Not likely) to 7 (Most likely).

\begin{tabular}{|c|l|ccccccc|}
\hline & & \multicolumn{3}{|c}{ Not Likely } & \multicolumn{3}{c|}{ Most Likely } \\
\hline 1. & Makes changes in BEI & 1 & 2 & 3 & 4 & 5 & 6 & 7 \\
\hline 2. & Replace Andy with another worker & 1 & 2 & 3 & 4 & 5 & 6 & 7 \\
\hline 3. & Change organization to adjust & 1 & 2 & 3 & 4 & 5 & 6 & 7 \\
\hline 4. & Gives warning to Andy & 1 & 2 & 3 & 4 & 5 & 6 & 7 \\
\hline 5. & Adapt company to the situation & 1 & 2 & 3 & 4 & 5 & 6 & 7 \\
\hline 6. & Assigns Andy to another task & 1 & 2 & 3 & 4 & 5 & 6 & 7 \\
\hline
\end{tabular}


B. Mark ' $\mathbf{X}$ ' for items that will best help you understand the problem. Select from lists $\mathbf{A}$ through I or just a few; select any number of items or no items from each list. Remember, time is short.

\section{A. Company information:}

The financial status of the company

Organizational and physical structure of the company

The mission statement and goals of the company

Company's history

Current changes in the company

\section{B. Employees information:}

Employees' job satisfaction

Turnover rate

Pay and compensation

Employees' job performance

\section{Department information:}

The current orders that the department is handling

Department's history

The goal and vision of the department

\section{Andy Smith's information:}

Level of education

Past performance records

Evaluation by peers and subordinate

Personality \& background information

Andy's family background

\section{E. Supervisor's information:}

Level of education

Supervisors past performances

Evaluation by peers and subordinate

Personality \& background information

Supervisor's family background

\section{F. Competitor's information:}

The number of competitors

Current changes with the competitors

Market shares compared to BEI

Collaborations with BEI

\section{G. Market's information:}

General economy

Rules and regulations for the industry

Related industries

Price of the raw material

H. Customer's information:

Customers' product

Liaison from customer's company

Customer's satisfaction with BEI

\section{Work group information:}

Group composition

Competency of each group member

Group performance

C. First, you talked to some workers. You were not able to gather all the information you wanted. Only the information below is available:

BEI produces electronic components for car stereos. It has been in business in downtown Dayton, Ohio for over 20 years. The company started with about 30 employees. Today, there are over 100 employees, mostly in the Production Department. These employees are organized into small work groups. BEI has good market reputation and it has had great relations with its customers.

Recent implementation in the department was a big change for Andy Smith, the production line worker. At 46, Andy did not feel he should have to adapt to a new task assignment. He is a senior worker that had been in the company since the beginning. He knows a lot about the production process. Hence, he feels he can direct his coworkers. He felt that things were fine the way they were and that changing tasks were complicating things.

Andy became less motivated to work - he came later and later to work and took longer breaks. He became less efficient, barely meeting the minimum requirement. Andy felt his actions were justified as he was only reflecting his coworkers' feeling of being downgraded. His immediate supervisor, Chris Lester was very busy, therefore, did not give him specific feedback. The management felt that the new customer should help the company financially and that the changes were necessary. 
Chris is doing all he could. He feels Andy is not committed to the job and company. He had heard that Andy was looking for jobs with BEI's competitors. He sees Andy as hot headed and a troublemaker. To improve production changes were necessary. Chris does not understand the resentment.

Now that you have additional information, how likely do you think that each of this is the problem? Rate from 1 (Not likely) to 7 (Most likely).

\begin{tabular}{|l|l|rrrrrrr|}
\hline & \multicolumn{3}{|l}{ Not Likely } & \multicolumn{3}{c|}{ Most Likely } \\
\hline 1. & Changes in BEI & 1 & 2 & 3 & 4 & 5 & 6 & 7 \\
\hline 2. & Characteristics of Andy & 1 & 2 & 3 & 4 & 5 & 6 & 7 \\
\hline 3. & How the organization adjusted & 1 & 2 & 3 & 4 & 5 & 6 & 7 \\
\hline 4. & Andy, the employee & 1 & 2 & 3 & 4 & 5 & 6 & 7 \\
\hline 5. & Change in the company's situation & 1 & 2 & 3 & 4 & 5 & 6 & 7 \\
\hline 6. & Andy's traits & 1 & 2 & 3 & 4 & 5 & 6 & 7 \\
\hline
\end{tabular}

Rate from 1 (Not at all) to 7 (A lot) the extent you need more information to investigate the problem in the Production Department.

Not at all
1
2
3
4
5
6
7

A lot

How much do you trust the information that was presented to you?

Not at all

2

3

4

5

6

A lot

7

What do now you think happened?

Now that you have additional information, how likely are you to recommend each of these actions? Rate from 1 (Not likely) to 7 (Most likely).

\begin{tabular}{|c|l|rrrrrrr|}
\hline & & \multicolumn{3}{|c}{ Not Likely } & \multicolumn{3}{c|}{ Most Likely } \\
\hline 1. & Makes changes in BEI & 1 & 2 & 3 & 4 & 5 & 6 & 7 \\
\hline 2. & Replace Andy with another worker & 1 & 2 & 3 & 4 & 5 & 6 & 7 \\
\hline 3. & Change organization to adjust & 1 & 2 & 3 & 4 & 5 & 6 & 7 \\
\hline 4. & Gives warning to Andy & 1 & 2 & 3 & 4 & 5 & 6 & 7 \\
\hline 5. & Adapt company to the situation & 1 & 2 & 3 & 4 & 5 & 6 & 7 \\
\hline 6. & Assigns Andy to another task & 1 & 2 & 3 & 4 & 5 & 6 & 7 \\
\hline
\end{tabular}


Please rate from 1 (Not at all Relevant) to 7 (Very Relevant) how relevant is each item below.

\begin{tabular}{|c|c|c|c|c|c|c|c|c|}
\hline \multirow[b]{2}{*}{1.} & \multirow[b]{2}{*}{$\begin{array}{l}\text { At } 46 \text {, Andy did not feel he should have } \\
\text { to adapt to a new task assignment. }\end{array}$} & \multicolumn{5}{|c|}{$\begin{array}{l}\text { Not at all } \\
\text { Relevant }\end{array}$} & \multicolumn{2}{|c|}{$\begin{array}{c}\text { Very } \\
\text { Relevant }\end{array}$} \\
\hline & & 1 & 2 & 3 & 4 & 5 & 6 & 7 \\
\hline 2. & $\begin{array}{l}\text { Andy is a senior worker that had been in } \\
\text { the company since the beginning. }\end{array}$ & 1 & 2 & 3 & 4 & 5 & 6 & 7 \\
\hline 3. & $\begin{array}{l}\text { The new implementation was a big } \\
\text { change for Andy Smith, a production } \\
\text { line worker. }\end{array}$ & 1 & 2 & 3 & 4 & 5 & 6 & 7 \\
\hline 4. & $\begin{array}{l}\text { Andy's immediate supervisor, Chris was } \\
\text { very busy, therefore, did not give him } \\
\text { specific feedback. }\end{array}$ & 1 & 2 & 3 & 4 & 5 & 6 & 7 \\
\hline 5. & $\begin{array}{l}\text { Andy felt his actions were justified as he } \\
\text { was only reflecting his coworkers' } \\
\text { feeling of being downgraded. }\end{array}$ & 1 & 2 & 3 & 4 & 5 & 6 & 7 \\
\hline 6. & $\begin{array}{l}\text { Andy knows a lot about the production } \\
\text { process. }\end{array}$ & 1 & 2 & 3 & 4 & 5 & 6 & 7 \\
\hline 7. & $\begin{array}{l}\text { Andy felt that things were fine the way } \\
\text { they were and that changing tasks was } \\
\text { complicating things. }\end{array}$ & 1 & 2 & 3 & 4 & 5 & 6 & 7 \\
\hline 8. & $\begin{array}{l}\text { The management felt that the new } \\
\text { customer should help the company } \\
\text { financially and that the changes were } \\
\text { necessary. }\end{array}$ & 1 & 2 & 3 & 4 & 5 & 6 & 7 \\
\hline 9. & $\begin{array}{l}\text { Andy is perceived as a person who is } \\
\text { not committed to the job and company. }\end{array}$ & 1 & 2 & 3 & 4 & 5 & 6 & 7 \\
\hline 10. & $\begin{array}{l}\text { Andy became less motivated to work - } \\
\text { he came later and later to work and took } \\
\text { longer breaks. }\end{array}$ & 1 & 2 & 3 & 4 & 5 & 6 & 7 \\
\hline 11. & $\begin{array}{l}\text { Andy became less efficient, barely } \\
\text { meeting the minimum requirement. }\end{array}$ & 1 & 2 & 3 & 4 & 5 & 6 & 7 \\
\hline 12. & $\begin{array}{l}\text { It was mentioned that Andy was looking } \\
\text { for jobs with BEI's competitors. }\end{array}$ & 1 & 2 & 3 & 4 & 5 & 6 & 7 \\
\hline 13. & $\begin{array}{l}\text { Andy is perceived as hot headed and a } \\
\text { troublemaker. }\end{array}$ & 1 & 2 & 3 & 4 & 5 & 6 & 7 \\
\hline
\end{tabular}

D. You received additional from your conversation with Chris Lester, the Production Manager:

Six months ago the long-term supervisor of Production was assigned to a new position in management. The company replaced the supervisor with a young recent business graduate, Chris Lester. The management met with and explained the plan for changes to production workers. The more competent employees were selected and trained to operate the new machines. The company attracted a new customer with great potential for growth. Chris decided on changes to help keep customers happy. To speed up production, the department needed new machinery. Problems occurred after the implementation. Production was slower because the new machines were 
different and the trained employees were still getting used to them. Andy Smith was unhappy with these changes. He and other workers were reassigned with some training. Chris understood that change would take time but would be better for the company in the long run.

Chris was facing an overwhelming situation. He wished the employees were more patient and understanding with the changes. He was also under a lot of pressure from the top to layoff people because the recent recession had hurt the company. He wanted to succeed at his new job and he also hoped the company would be able to retain long-term employees.

The production department is in chaos and this worries the CEO. He is afraid that the employees will strike or slow down production. He fears these might interfere with keeping the new and long-term customers. He wants to know what is happening and he wants to resolve the problem.

Now that you have additional information, how likely do you think that each of this is the problem? Rate from 1 (Not likely) to 7 (Most likely).

\begin{tabular}{|l|l|rrrrrrr|}
\hline & & Not Likely & \multicolumn{4}{c|}{ Most Likely } \\
\hline 1. & Changes in BEI & 1 & 2 & 3 & 4 & 5 & 6 & 7 \\
\hline 2. & Characteristics of Andy & 1 & 2 & 3 & 4 & 5 & 6 & 7 \\
\hline 3. & How the organization adjusted & 1 & 2 & 3 & 4 & 5 & 6 & 7 \\
\hline 4. & Andy, the employee & 1 & 2 & 3 & 4 & 5 & 6 & 7 \\
\hline 5. & Change in the company's situation & 1 & 2 & 3 & 4 & 5 & 6 & 7 \\
\hline 6. & Andy's traits & 1 & 2 & 3 & 4 & 5 & 6 & 7 \\
\hline
\end{tabular}

Rate from 1 (Not at all) to 7 (A lot) the extent you need more information to investigate the problem in the Production Department.

\section{Not at all}

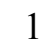

2

3

4

5

6

A lot

7

How much do you trust the information that was presented to you?

Not at all

1

2

3

4

5
6

A lot

7

What do you now think happened? 
Now that you have additional information, how likely are you to recommend each of these actions? Rate from 1 (Not likely) to 7 (Most likely).

\begin{tabular}{|l|l|rrrrrrrr|}
\hline & & Not Likely & & \multicolumn{3}{c|}{ Most Likely } \\
\hline 1. & Makes changes in BEI & 1 & 2 & 3 & 4 & 5 & 6 & 7 \\
\hline 2. & Replace Andy with another worker & 1 & 2 & 3 & 4 & 5 & 6 & 7 \\
\hline 3. & Change organization to adjust & 1 & 2 & 3 & 4 & 5 & 6 & 7 \\
\hline 4. & Gives warning to Andy & 1 & 2 & 3 & 4 & 5 & 6 & 7 \\
\hline 5. & Adapt company to the situation & 1 & 2 & 3 & 4 & 5 & 6 & 7 \\
\hline 6. & Assigns Andy to another task & 1 & 2 & 3 & 4 & 5 & 6 & 7 \\
\hline
\end{tabular}

Please rate from 1 (Not at all Relevant) to 7 (Very Relevant) how relevant is each item below.

\begin{tabular}{|c|c|c|c|c|c|c|c|c|}
\hline \multirow[b]{2}{*}{1.} & \multirow[b]{2}{*}{$\begin{array}{l}\text { Chris decided on changes to help keep } \\
\text { customers happy. }\end{array}$} & \multicolumn{5}{|c|}{$\begin{array}{l}\text { Not at all } \\
\text { Relevant }\end{array}$} & \multicolumn{2}{|c|}{$\begin{array}{r}\text { Very } \\
\text { Relevant }\end{array}$} \\
\hline & & 1 & 2 & 3 & 4 & 5 & 6 & 7 \\
\hline 2. & $\begin{array}{l}\text { The more competent employees were } \\
\text { selected and trained to operate the new } \\
\text { machines. }\end{array}$ & 1 & 2 & 3 & 4 & 5 & 6 & 7 \\
\hline 3. & $\begin{array}{l}\text { Six months ago the long-term supervisor } \\
\text { of Production was assigned to a new } \\
\text { position in management. }\end{array}$ & 1 & 2 & 3 & 4 & 5 & 6 & 7 \\
\hline 4. & $\begin{array}{l}\text { Andy Smith and other workers were } \\
\text { reassigned with some training. }\end{array}$ & 1 & 2 & 3 & 4 & 5 & 6 & 7 \\
\hline 5. & $\begin{array}{l}\text { To speed up production, the department } \\
\text { needed new machinery. }\end{array}$ & 1 & 2 & 3 & 4 & 5 & 6 & 7 \\
\hline 6. & $\begin{array}{l}\text { Production was slower because the new } \\
\text { machines were different and the trained } \\
\text { employees were still getting used to } \\
\text { them. }\end{array}$ & 1 & 2 & 3 & 4 & 5 & 6 & 7 \\
\hline 7. & $\begin{array}{l}\text { Chris wanted to succeed at his new job } \\
\text { and he also hoped the company would be } \\
\text { able to retain long-term employees. }\end{array}$ & 1 & 2 & 3 & 4 & 5 & 6 & 7 \\
\hline 8. & $\begin{array}{l}\text { The management met with and explained } \\
\text { the plan for changes to production } \\
\text { workers. }\end{array}$ & 1 & 2 & 3 & 4 & 5 & 6 & 7 \\
\hline 9. & $\begin{array}{l}\text { The company replaced the supervisor } \\
\text { with a young recent business graduate, } \\
\text { Chris Lester. }\end{array}$ & 1 & 2 & 3 & 4 & 5 & 6 & 7 \\
\hline 10. & $\begin{array}{l}\text { Andy Smith was unhappy with these } \\
\text { changes. }\end{array}$ & 1 & 2 & 3 & 4 & 5 & 6 & 7 \\
\hline 11. & $\begin{array}{l}\text { The company attracted a new customer } \\
\text { with great potential for growth. }\end{array}$ & 1 & 2 & 3 & 4 & 5 & 6 & 7 \\
\hline 12. & $\begin{array}{l}\text { Chris was facing an overwhelming } \\
\text { situation. }\end{array}$ & 1 & 2 & 3 & 4 & 5 & 6 & 7 \\
\hline
\end{tabular}




\begin{tabular}{|l|l|lllllllll|}
\hline 13. & $\begin{array}{l}\text { The management had pressured to layoff } \\
\text { people because the recent recession had } \\
\text { hurt the company. }\end{array}$ & 1 & 2 & 3 & 4 & 5 & 6 & 7 \\
\hline
\end{tabular}

E. The production department is in chaos and this is worrying the CEO. He is afraid that if this continues the company might lose its customers. He wants to know what happened and he wants to resolve the problem. Because figuring out the situation is important, you decide to review all the information in order to use them to support your recommendations. Please select information that is relevant for your report by marking ' $\mathrm{X}$ ' in the boxes below.

Chris wanted to succeed at his new job and he also hoped the company would be able to retain long-term employees.

Andy is a senior worker that had been in the company since the beginning.

Andy felt that things were fine the way they were and that changing tasks was complicating things.

Andy's immediate supervisor, Chris was busy, therefore, did not give him specific feedback.

The management felt that the new customer should help the company financially and that the changes were necessary.

Andy is perceived as hot headed and a troublemaker.

Andy knows a lot about the production process.

Andy became less efficient, barely meeting the minimum requirement.

Andy is perceived as a person who is not committed to his job and company.

The management had pressured to layoff people because the recent recession had hurt the company.

Changes were made in order to keep the new customer happy.

The more competent employees were selected and trained to operate the new machines. At 46, Andy did not feel he should have to adapt to the new task he was assigned.

The new implementation was a big change for Andy Smith, a production line worker.

A month ago the long-term supervisor of Production was assigned to a new position in management.

Chris was facing an overwhelming situation.

Andy became less motivated to work.

The company replaced the supervisor with a young recent business graduate, Chris Lester.

The company attracted a new customer with great growth potential.

Andy felt justified in the way he was acting as he was only reflecting his coworkers' feeling of being downgraded.

Production was slower because the new machines were different from the old ones and the trained employees needed to get used to them.

Plan for changes were explained to production workers.

It was mentioned that Andy was looking for other jobs with BEI's competitors.

Andy Smith and other workers were reassigned with some training.

Andy was unhappy with the changes.

The company had to speed up production and new machinery was needed to anticipate the customer's request. 
How likely do you think that each of this is the problem? Rate from 1 (Not likely) to 7 (Most likely).

\begin{tabular}{|l|l|rrrrrrr|}
\hline & \multicolumn{3}{|c}{ Not Likely } & \multicolumn{4}{c|}{ Most Likely } \\
\hline 1. & Changes in BEI & 1 & 2 & 3 & 4 & 5 & 6 & 7 \\
\hline 2. & Characteristics of Andy & 1 & 2 & 3 & 4 & 5 & 6 & 7 \\
\hline 3. & How the organization adjusted & 1 & 2 & 3 & 4 & 5 & 6 & 7 \\
\hline 4. & Andy, the employee & 1 & 2 & 3 & 4 & 5 & 6 & 7 \\
\hline 5. & Change in the company's situation & 1 & 2 & 3 & 4 & 5 & 6 & 7 \\
\hline 6. & Andy's traits & 1 & 2 & 3 & 4 & 5 & 6 & 7 \\
\hline
\end{tabular}

Rate from 1 (Not at all) to 7 (A lot) the extent you need more information to investigate the problem in the Production Department.

Not at all
1
2
3
4
5
6
7

A lot

How likely are you to recommend each of these actions? Rate from 1 (Not likely) to 7 (Most likely).

\begin{tabular}{|l|l|rrrrrrr|}
\hline & & \multicolumn{3}{|c}{ Not Likely } & \multicolumn{3}{c|}{ Most Likely } \\
\hline 1. & Makes changes in BEI & 1 & 2 & 3 & 4 & 5 & 6 & 7 \\
\hline 2. & Replace Andy with another worker & 1 & 2 & 3 & 4 & 5 & 6 & 7 \\
\hline 3. & Change organization to adjust & 1 & 2 & 3 & 4 & 5 & 6 & 7 \\
\hline 4. & Gives warning to Andy & 1 & 2 & 3 & 4 & 5 & 6 & 7 \\
\hline 5. & Adapt company to the situation & 1 & 2 & 3 & 4 & 5 & 6 & 7 \\
\hline 6. & Assigns Andy to another task & 1 & 2 & 3 & 4 & 5 & 6 & 7 \\
\hline
\end{tabular}

Summarize what you now think had happen with BEI's Production Department and what would you do if you were the CEO?

If any, what other information would you like to know? Please list them.

1.

2.

3.

4.

5. 
“Westerly Foundation”

A. You are an advisor for non-profit organizations. The Westerly Foundation is a non-profit organization that awards scholarships to college students. There is now a shortage of funding that might reduce next year's awards. Some people think the Director, Mr. Michael Smith, is not managing the funds well while others think that external factors and changes are the problem. Your job is to understand the situation and recommend actions.

How likely do you think that each of this is the problem? Rate from 1 (Not likely) to 7 (Most likely).

\begin{tabular}{|l|l|rrrrrrr|}
\hline & & Not Likely & & & Most Likely \\
\hline 1. & Changes in Westerly & 1 & 2 & 3 & 4 & 5 & 6 & 7 \\
\hline 2. & Characteristics of Michael & 1 & 2 & 3 & 4 & 5 & 6 & 7 \\
\hline 3. & How the organization has adjusted & 1 & 2 & 3 & 4 & 5 & 6 & 7 \\
\hline 4. & Michael, the director & 1 & 2 & 3 & 4 & 5 & 6 & 7 \\
\hline 5. & $\begin{array}{l}\text { Change in the foundation's } \\
\text { situation }\end{array}$ & 1 & 2 & 3 & 4 & 5 & 6 & 7 \\
\hline 6. & Michael's management skill & 1 & 2 & 3 & 4 & 5 & 6 & 7 \\
\hline
\end{tabular}

Rate from 1 (Not at all) to 7 (A lot) the extent you need more information to investigate the problem with the scholarship funding.

Not at all

1

2

3

4

5

6

A lot

7

What do you think happened?

How likely are you to recommend each of these actions? Rate from 1 (Not likely) to 7 (Most likely).

\begin{tabular}{|l|l|rrrrrrr|}
\hline & \multicolumn{3}{|l}{} & Not Likely & & & Most Likely \\
\hline 1. & Make changes in Westerly & 1 & 2 & 3 & 4 & 5 & 6 & 7 \\
\hline 2. & $\begin{array}{l}\text { Replace Michael with another } \\
\text { director }\end{array}$ & 1 & 2 & 3 & 4 & 5 & 6 & 7 \\
\hline 3. & Change organization to adjust & 1 & 2 & 3 & 4 & 5 & 6 & 7 \\
\hline 4. & $\begin{array}{l}\text { Assigns Michael to another } \\
\text { position }\end{array}$ & 1 & 2 & 3 & 4 & 5 & 6 & 7 \\
\hline
\end{tabular}




\begin{tabular}{|l|l|lllllll|}
\hline 5. & Adapt foundation to the situation & 1 & 2 & 3 & 4 & 5 & 6 & 7 \\
\hline 6. & Train Michael's management skill & 1 & 2 & 3 & 4 & 5 & 6 & 7 \\
\hline
\end{tabular}

B. Mark ' $\mathbf{X}$ ' for items that will best help you understand the problem. Select from lists $\mathbf{A}$ through I or just a few; select any number of items or no items from each list. Remember, time is short.

\section{A. Foundation information:}

The financial status of the foundation

Organizational and physical structure of the foundation

The mission statement and goals of the foundation

Foundation's history

Current changes in the foundation

\section{B. Employees information:}

Employees' job satisfaction

Turnover rate

Pay and compensation

Employees' job performance

\section{Hiring Process information:}

Candidate requirement

Interview committee

Number of applicants

\section{Michael Smith's information:}

Level of education

Past performance records

Evaluation by peers and subordinate

Personality \& background information

Michael's family background

\section{E. Previous Directors' information:}

Level of education
Previous directors' past performances

Evaluation by peers and subordinate

Personality \& background information

Previous directors' family background

F. Other Foundations' information:

Number of similar foundations

Current changes with the other

foundations

Funds of other foundations compared to

Westerly

Collaborations with Westerly

\section{G. External environment's information:}

General economy

Rules and regulations for charitable

organization

Taxation rules

University's policy on scholarships

\section{H. Donors' information:}

Donors' contribution

Other foundation(s) donors funded

Donors' satisfaction with Westerly

Foundation

\section{Work group information:}

Group composition

Competency of each group member

Group performance

C. First, you talked to Michael Smith, the present Director. You were not able to gather all the information you wanted. Only the information below is available:

Westerly Foundation was founded in 1983 to help students finance their college education. Each year the foundation receives many applicants for scholarships. Westerly awards a full year scholarship to applicants that best fulfill the academic and financial criteria. Recipients continue to receive the scholarship if they maintain the required GPA. In the past, many recipients benefited from this scholarship.

Michael Smith is currently the Director of Westerly Foundation. Three years ago, Michael was in between jobs when the foundation offered him the director's position. His expertise did not lie within non-profit organizations though he has a degree in Financial Management. Nevertheless, Michael seemed to be up to the challenge. 
For the past years, the foundation has had difficulty maintaining its scholarship program. When Michael took over he changed the strategy for getting funds. Instead of relying on a few big donors, he felt the foundation should approach moderate donors to increase funds. Many in the organization dislike that Michael was running the foundation like a business. The new strategy to approach moderate donors was risky, required more planning and coordinating, and took resources that could go to scholarships. It also cost money for brochures to attract donors. Although the foundation had relied on several big donations, many employees still think the old strategy works better.

An employee recalled a recent event that might have lowered the funds. Michael had a conflict with one of the foundation's biggest donors. She felt that Michael does not have the social skill needed to communicate with potential donors. Because of this, Michael had to change the fund raising strategy. She believes that Michael does not understand the foundation's goals and its philosophy.

Now that you have additional information, how likely do you think that each of this is the problem? Rate from 1 (Not likely) to 7 (Most likely).

\begin{tabular}{|l|l|rrrrrrr|}
\hline & & Not Likely & & & Most Likely \\
\hline 1. & Changes in Westerly & 1 & 2 & 3 & 4 & 5 & 6 & 7 \\
\hline 2. & Characteristics of Michael & 1 & 2 & 3 & 4 & 5 & 6 & 7 \\
\hline 3. & How the organization has adjusted & 1 & 2 & 3 & 4 & 5 & 6 & 7 \\
\hline 4. & Michael, the director & 1 & 2 & 3 & 4 & 5 & 6 & 7 \\
\hline 5. & $\begin{array}{l}\text { Change in the foundation's } \\
\text { situation }\end{array}$ & 1 & 2 & 3 & 4 & 5 & 6 & 7 \\
\hline 6. & Michael's management skill & 2 & 3 & 4 & 5 & 6 & 7 \\
\hline
\end{tabular}

Rate from 1 (Not at all) to 7 (A lot) the extent you need more information to investigate the problem with the scholarship funding.

Not at all

1
2
4
5
A lot 7

How much do you trust the information that was presented to you?

Not at all

1
2

3
4
5
6

What do you now think happened? 
Now that you have additional information, how likely are you to recommend each of these actions? Rate from 1 (Not likely) to 7 (Most likely).

\begin{tabular}{|l|l|ccccccc|}
\hline & & Not Likely & & \multicolumn{3}{c|}{ Most Likely } \\
\hline 1. & Make changes in Westerly & 1 & 2 & 3 & 4 & 5 & 6 & 7 \\
\hline 2. & $\begin{array}{l}\text { Replace Michael with another } \\
\text { director }\end{array}$ & 1 & 2 & 3 & 4 & 5 & 6 & 7 \\
\hline 3. & Change organization to adjust & 1 & 2 & 3 & 4 & 5 & 6 & 7 \\
\hline 4. & Assigns Michael to another position & 1 & 2 & 3 & 4 & 5 & 6 & 7 \\
\hline 5. & Adapt foundation to the situation & 1 & 2 & 3 & 4 & 5 & 6 & 7 \\
\hline 6. & Train Michael's management skill & 1 & 2 & 3 & 4 & 5 & 6 & 7 \\
\hline
\end{tabular}

Please rate from 1 (Not at all Relevant) to 7 (Very Relevant) how relevant is each item below.

\begin{tabular}{|c|c|c|c|c|c|c|c|c|}
\hline \multirow[b]{2}{*}{1.} & \multirow[b]{2}{*}{$\begin{array}{l}\text { Three years ago, Michael was in between } \\
\text { jobs when the foundation offered him the } \\
\text { director's position. }\end{array}$} & \multicolumn{5}{|c|}{$\begin{array}{l}\text { Not at all } \\
\text { Relevant }\end{array}$} & \multicolumn{2}{|c|}{$\begin{array}{c}\text { Very } \\
\text { Relevant }\end{array}$} \\
\hline & & 1 & 2 & 3 & 4 & 5 & 6 & 7 \\
\hline 2. & $\begin{array}{l}\text { Michael had a conflict with one of the } \\
\text { foundation's biggest donors. }\end{array}$ & 1 & 2 & 3 & 4 & 5 & 6 & 7 \\
\hline 3. & $\begin{array}{l}\text { Many in the organization dislike that } \\
\text { Michael was running the foundation like a } \\
\text { business. }\end{array}$ & 1 & 2 & 3 & 4 & 5 & 6 & 7 \\
\hline 4. & $\begin{array}{l}\text { Michael has a degree in Financial } \\
\text { Management. }\end{array}$ & 1 & 2 & 3 & 4 & 5 & 6 & 7 \\
\hline 5. & $\begin{array}{l}\text { Michael's expertise did not lie within non } \\
\text { profit organizations. }\end{array}$ & 1 & 2 & 3 & 4 & 5 & 6 & 7 \\
\hline 6. & $\begin{array}{l}\text { The new strategy to approach moderate } \\
\text { donors was risky, required more planning } \\
\text { and coordinating, and took resources that } \\
\text { could go to scholarships. }\end{array}$ & 1 & 2 & 3 & 4 & 5 & 6 & 7 \\
\hline 7. & $\begin{array}{l}\text { Many employees still think the old strategy } \\
\text { works better. }\end{array}$ & 1 & 2 & 3 & 4 & 5 & 6 & 7 \\
\hline 8. & Michael seemed to be up to a challenge. & 1 & 2 & 3 & 4 & 5 & 6 & 7 \\
\hline 9. & $\begin{array}{l}\text { It also cost money for brochures to attract } \\
\text { donors. }\end{array}$ & 1 & 2 & 3 & 4 & 5 & 6 & 7 \\
\hline 10. & $\begin{array}{l}\text { Michael felt the foundation should approach } \\
\text { moderate donors to increase funds. }\end{array}$ & 1 & 2 & 3 & 4 & 5 & 6 & 7 \\
\hline 11. & $\begin{array}{l}\text { The foundation relies on several big } \\
\text { donations. }\end{array}$ & 1 & 2 & 3 & 4 & 5 & 6 & 7 \\
\hline 12. & $\begin{array}{l}\text { Michael does not understand the } \\
\text { foundation's goals and its philosophy. }\end{array}$ & 1 & 2 & 3 & 4 & 5 & 6 & 7 \\
\hline 13. & $\begin{array}{l}\text { Michael does not have the social skill needed } \\
\text { to communicate with potential donors. }\end{array}$ & 1 & 2 & 3 & 4 & 5 & 6 & 7 \\
\hline
\end{tabular}


D. You received additional information from your conversation with some employees:

Before Michael took over the foundation, two previous directors faced many challenging situations associated with the scholarship funds. Organization policies were mostly set up by Mr. Spector, the first director. He decided to approach some key donors in supporting the foundations effort. Being very personable, he was successful in getting large donations. The key donors have high praise for Mr. Spector. Then, there were increases in universities tuition before Mr. Spector retired. Funding may have been affected by this increase. Mr. Tanner, the second director, continued the policy and effort of Mr. Spector. Due to recession the funds started dropping under Mr. Tanner's management. To solve the problem, some funds were put in a high-risk investment and this did not return a profit. Unable to change the situation, Mr. Tanner decided to resign. Mr. Tanner felt that Michael was a good candidate. His only concern is that Michael is new to fundraising.

Several employees speculated that two similar foundations established this past year affected the donation to their foundation. Since it was also an election year, some donors might have contributed less. Recent tax policy on charitable donations may have changed donation patterns of the key donors.

The shortage of funds worries the Board of Directors. They are concerned about the foundation's ability to provide scholarships. They feared that this might affect deserving students as well as the foundation's goals. They want to know what happened and how they should manage the problem.

Now that you have additional information, how likely do you think that each of this is the problem? Rate from 1 (Not likely) to 7 (Most likely).

\begin{tabular}{|l|l|crrrrrrc|}
\hline & & Not Likely & \multicolumn{5}{c|}{ Most Likely } \\
\hline 1. & Changes in Westerly & 1 & 2 & 3 & 4 & 5 & 6 & 7 \\
\hline 2. & Characteristics of Michael & 1 & 2 & 3 & 4 & 5 & 6 & 7 \\
\hline 3. & How the organization has adjusted & 1 & 2 & 3 & 4 & 5 & 6 & 7 \\
\hline 4. & Michael, the director & 1 & 2 & 3 & 4 & 5 & 6 & 7 \\
\hline 5. & $\begin{array}{l}\text { Change in the foundation's } \\
\text { situation }\end{array}$ & 1 & 2 & 3 & 4 & 5 & 6 & 7 \\
\hline 6. & Michael's management skill & 1 & 2 & 3 & 4 & 5 & 6 & 7 \\
\hline
\end{tabular}

Rate from 1 (Not at all) to 7 (A lot) the extent you need more information to investigate the problem with the scholarship funding.

Not at all

1
2

3
4
5
6

A lot

7

How much do you trust the information that was presented to you?

Not at all

2

3

4

5

6

A lot

7 
What do you now think happened?

Now that you have additional information, how likely are you to recommend each of these actions? Rate from 1 (Not likely) to 7 (Most likely).

\begin{tabular}{|c|l|rrrrrrr|}
\hline & & \multicolumn{3}{|l}{$\begin{array}{l}\text { Not Likely } \\
\text { Likely }\end{array}$} & & & & Most \\
\hline 1. & Make changes in Westerly & 1 & 2 & 3 & 4 & 5 & 6 & 7 \\
\hline 2. & Replace Michael with another director & 1 & 2 & 3 & 4 & 5 & 6 & 7 \\
\hline 3. & Change organization to adjust & 1 & 2 & 3 & 4 & 5 & 6 & 7 \\
\hline 4. & Assigns Michael to another position & 1 & 2 & 3 & 4 & 5 & 6 & 7 \\
\hline 5. & Adapt foundation to the situation & 1 & 2 & 3 & 4 & 5 & 6 & 7 \\
\hline 6. & Train Michael's management skill & 1 & 2 & 3 & 4 & 5 & 6 & 7 \\
\hline
\end{tabular}

Please rate from 1 (Not at all Relevant) to 7 (Very Relevant) how relevant is each item below.

\begin{tabular}{|c|c|c|c|c|c|c|c|c|}
\hline & & $\begin{array}{l}\text { Not a } \\
\text { Relev }\end{array}$ & & & & & & $\begin{array}{r}\text { Very } \\
\text { Relevant }\end{array}$ \\
\hline 1. & $\begin{array}{l}\text { Organization policies were mostly set } \\
\text { up by Mr. Spector, the first director. }\end{array}$ & 1 & 2 & 3 & 4 & 5 & 6 & 7 \\
\hline 2. & $\begin{array}{l}\text { Two similar foundations established } \\
\text { this past year affected the donation to } \\
\text { Westerly Foundation. }\end{array}$ & 1 & 2 & 3 & 4 & 5 & 6 & 7 \\
\hline 3. & $\begin{array}{l}\text { The key donors have high praise for } \mathrm{Mr} \text {. } \\
\text { Spector. }\end{array}$ & 1 & 2 & 3 & 4 & 5 & 6 & 7 \\
\hline 4. & $\begin{array}{l}\text { Before Mr. Smith took over the } \\
\text { foundation, two previous directors faced } \\
\text { many challenging situations associated } \\
\text { with the scholarship funds. }\end{array}$ & 1 & 2 & 3 & 4 & 5 & 6 & 7 \\
\hline 5. & $\begin{array}{l}\text { Mr. Tanner felt that Michael was a good } \\
\text { candidate. }\end{array}$ & 1 & $7^{2}$ & & & 4 & 5 & 6 \\
\hline 6. & $\begin{array}{l}\text { Mr. Tanner continued the policy and } \\
\text { effort of Mr. Spector. }\end{array}$ & 1 & 2 & 3 & 4 & 5 & 6 & 7 \\
\hline 7. & $\begin{array}{l}\text { Being very personable, Mr. Spector was } \\
\text { successful in getting large donations. }\end{array}$ & 1 & 2 & 3 & 4 & 5 & 6 & 7 \\
\hline 8. & $\begin{array}{l}\text { Due to recession the funds started } \\
\text { dropping under Mr. Tanner's } \\
\text { management. }\end{array}$ & 1 & 2 & 3 & 4 & 5 & 6 & 7 \\
\hline
\end{tabular}




\begin{tabular}{|c|l|rrrrrrr|}
\hline 9. & $\begin{array}{l}\text { Mr. Tanner only concern is that Michael } \\
\text { is new to fundraising. }\end{array}$ & 1 & 2 & 3 & 4 & 5 & 6 & 7 \\
\hline 10. & $\begin{array}{l}\text { There was an increase in university } \\
\text { tuitions. }\end{array}$ & 1 & 2 & 3 & 4 & 5 & 6 & 7 \\
\hline 11. & $\begin{array}{l}\text { Some funds were put in a high-risk } \\
\text { investment and this did not return a } \\
\text { profit. }\end{array}$ & 1 & 2 & 3 & 4 & 5 & 6 & 7 \\
\hline 12. & $\begin{array}{l}\text { Since it was also an election year, some } \\
\text { donors might have also contributed less. }\end{array}$ & 1 & 2 & 3 & 4 & 5 & 6 & 7 \\
\hline 13. & $\begin{array}{l}\text { Recent tax policy on charitable } \\
\text { donations may have changed donation } \\
\text { patterns of the key donors. }\end{array}$ & 1 & 2 & 3 & 4 & 5 & 6 & 7 \\
\hline
\end{tabular}

$E$. The funds for the foundation are low and this might affect the effort to provide next year's scholarships. As the foundation is for a good cause, many involved hope to solve the problem. Because figuring out the situation is important, you decide to review all the information in order to use them to support your recommendations. Please select information that is relevant for your report by marking ' $\boldsymbol{X}$ ' in the boxes below.

Organization policies were mostly set up by Mr. Spector, the first director.

Michael does not have the social skill needed to communicate with potential donors.

Mr. Tanner continued the policy and effort of Mr. Spector.

Being very personable, Mr. Spector was successful in getting large donations.

There was an increase in university tuitions.

Mr. Tanner felt that Michael was a good candidate.

Mr. Tanner only concern is that Michael is new to fundraising.

Recent tax policy on charitable donations may have changed donation patterns of the key donors.

Michael does not understand the foundation's goals and its philosophy.

Since it was also an election year, some donors might have also contributed less.

Some funds were put in a high-risk investment and this did not return a profit.

The key donors have high praise for Mr. Spector.

It also cost money for brochures to attract donors.

Michael seemed to be up to a challenge.

Michael's expertise did not lie within non profit organizations.

The foundation relies on several big donations.

Many employees still think the old strategy works better.

Many in the organization dislike that Michael was running the foundation like a business.

Two similar foundations established this past year affected the donation to Westerly Foundation.

The new strategy to approach moderate donors was risky, required more planning and coordinating, and took resources that could go to scholarships.

Michael has a degree in Financial Management.

Michael felt the foundation should approach moderate donors to increase funds.

Before Mr. Smith took over the foundation, two previous directors faced many challenging situations associated with the scholarship funds.

Michael had a conflict with one of the foundation's biggest donors.

Three years ago, Michael was in between jobs when the foundation offered him the director's position.

Due to recession the funds started dropping under Mr. Tanner's management. 
How likely do you think that each of this is the problem? Rate from 1 (Not likely) to 7 (Most likely).

\begin{tabular}{|r|l|rrrrrrr|}
\hline & & \multicolumn{3}{|l}{ Not Likely } & & & & Most \\
Likely & & & & & \\
\hline 1. & Changes in Westerly & 1 & 2 & 3 & 4 & 5 & 6 & 7 \\
\hline 2. & Characteristics of Michael & 1 & 2 & 3 & 4 & 5 & 6 & 7 \\
\hline 3. & How the organization has adjusted & 1 & 2 & 3 & 4 & 5 & 6 & 7 \\
\hline 4. & Michael, the director & 1 & 2 & 3 & 4 & 5 & 6 & 7 \\
\hline 5. & Change in the foundation's situation & 1 & 2 & 3 & 4 & 5 & 6 & 7 \\
\hline 6. & Michael's management skill & 1 & 2 & 3 & 4 & 5 & 6 & 7 \\
\hline
\end{tabular}

Rate from 1 (Not at all) to 7 (A lot) the extent you need more information to investigate the problem with the scholarship funding.

Not at all
1
2
3
4
5
6
7

A lot

How likely are you to recommend each of these actions? Rate from 1 (Not likely) to 7 (Most likely).

\begin{tabular}{|c|l|rrrrrrr|}
\hline & & \multicolumn{3}{|l}{ Not Likely } & \multicolumn{3}{c|}{ Most Likely } \\
\hline 1. & Make changes in Westerly & 1 & 2 & 3 & 4 & 5 & 6 & 7 \\
\hline 2. & Replace Michael with another director & 1 & 2 & 3 & 4 & 5 & 6 & 7 \\
\hline 3. & Change organization to adjust & 1 & 2 & 3 & 4 & 5 & 6 & 7 \\
\hline 4 & Assigns Michael to another position & 1 & 2 & 3 & 4 & 5 & 6 & 7 \\
\hline 5 & Adapt foundation to the situation & 1 & 2 & 3 & 4 & 5 & 6 & 7 \\
\hline 6. & Train Michael's management skill & 1 & 2 & 3 & 4 & 5 & 6 & 7 \\
\hline
\end{tabular}

Summarize what you now think had happen with Westerly's funding situation and what would you recommend as an advisor?

If any, what other information would you like to know? Please list them.

1.
2.
3.
4.
5. 
Appendix C

Qualitative Sensemaking Coding

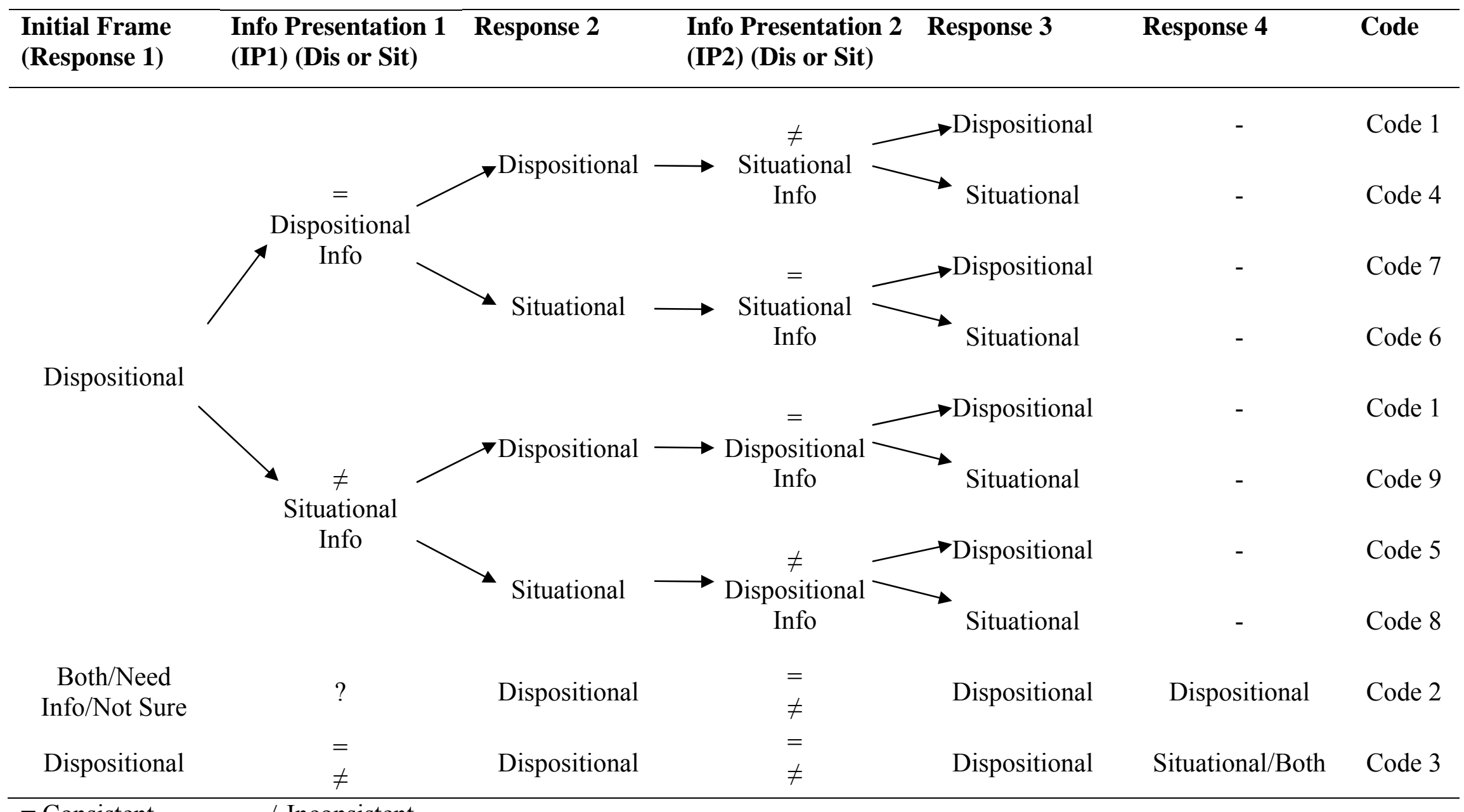




\section{Descriptions of Qualitative Sensemaking Codes}

Code 1: Consistent All the Way [R1=IP $1=\mathrm{R} 2 \neq \mathrm{IP} 2 \neq \mathrm{R} 3 ; \mathrm{R} 1 \neq \mathrm{IP} 1 \neq \mathrm{R} 2=\mathrm{IP} 2=\mathrm{R} 3]$

This code is given when participants did not change in their sense making. They remained with their initial frame from beginning to end even when information presented contradicted their view. These are people who explained away contradictory information or they kept elaborating their initial frame by seeking information consistent with their frame. For example, these participants would consistently identify the problem to be situational, dispositional/person, or both across all open ended responses.

Code 2: Open Then Consistent All the Way [R1?IP $1=\mathrm{R} 2 \neq \mathrm{IP} 2 \neq \mathrm{R} 3 ; \mathrm{R} 1$ ? IP $1 \neq \mathrm{R} 2=\mathrm{IP} 2=\mathrm{R} 3]$ This code is given when participants did not have an initial frame or respond to initial frame as both person and situation or either person or situation as the problem. Participants may indicate they need more information or just restate the problem when they do not have an initial frame; they want to remain open to changes in their sensemaking. Then participants changed or have a frame after the first information presentation and stayed with that frame throughout the remaining responses. For example, they may change from saying both were the problem to situation or dispositional being the problem for the rest of the scenario. They may not have a frame to begin with but then adopt one and stayed consistent with the frame the rest of the scenario.

Code 3: Consistent Then Change $[\mathrm{R} 1=\mathrm{IP} 1=\mathrm{R} 2 \neq \mathrm{IP} 2 \neq \mathrm{R} 3(\mathrm{R} 2 \neq \mathrm{R} 3) ; \mathrm{R} 1 \neq \mathrm{IP} 1 \neq \mathrm{R} 2=\mathrm{IP} 2=\mathrm{R} 3(\mathrm{R} 2 \neq \mathrm{R} 3)]$ This code is given when participants have an initial frame; did not change with both information presentations but changed at the last open ended response. For example, these participants would consistently identity the problem to be situational, dispositional, or both and then switched to dispositional/both, situational/both, or, situational/dispositional, respectively.

\section{Code 4 \& 5 changed with the direction of information presented}

Code 4: Consistent With Information Presentation (IP) 1 And Change With IP 2. [R $1=\mathrm{IP} 1=\mathrm{R} 2 \neq \mathrm{IP} 2=\mathrm{R} 3]$

This code is given when participant initial frame was same as the content of information presentation 1. For example, when a participant indicated the person to be the problem and received dispositional information in the first information presentation; the frame was consistent with information received. The second response given was also consistent with the first information given. Sensemaking did not change but frame is elaborated. Because the current frame was consistent with the previous information, the second information presentation would automatically be inconsistent with the current frame. Participants then changed their current frame to be consistent with the second information presentation. The current frame was questioned and a new frame was adopted. For example, before the second information was given, the problem was the person but now the problem is situational.

\section{Code 5: Inconsistent With IP 1, Changed with IP 1 And Changed With IP 2.}

$[\mathrm{R} 1 \neq \mathrm{IP} 1=\mathrm{R} 2 \neq \mathrm{IP} 2=\mathrm{R} 3]$

This code is given when a participant initial frame was different as the content of information presentation 1. For example, when a participant indicated the person to be the problem and received situational information in the first information presentation. The frame was inconsistent with information received. Upon receiving the inconsistent information, participants switched their frame/explanation to be consistent with the information received. For example, they switched from dispositional explanation to situational explanation upon receiving situational information. Hence, they adopted a new frame (re-framing). Because the current frame was consistent with the previous information, the second information presentation would automatically be inconsistent with the current frame. Again, participant would switch their 
frame/explanation to be consistent with the second information received. Again, they switched to adopt a new frame (re-framing). For example, participant would switch from situational explanation to dispositional explanation upon receiving dispositional information.

\section{Code 6 - 9 changed with the direction Opposite of information presented} Code 6: Consistent with IP 1, Changed Opposite of IP [R1=IP1 $\neq \mathrm{R} 2=\mathrm{IP} 2=\mathrm{R} 3$ ]

This code is given when a participant's initial frame was the same as the content of information presentation 1. For example, when a participant indicated the person to be the problem and received dispositional information in the first information presentation. The frame was consistent with information received. But frame was changed at the second open ended response. Here, the second information presented would be consistent with the current frame. Participants then remained with the same frame consistent with the second information presentation.

\section{Code 7: Consistent but Changed Opposite of IP at both Information Presentations} $[\mathrm{R} 1=\mathrm{IP} 1 \neq \mathrm{R} 2=\mathrm{IP} 2 \neq \mathrm{R} 3]$

This code is similar to participants who have a pattern of Form 6 but these participants changed their frame opposite to both the Information Presentation. For example, when information presentation was situational, participants switched frames to dispositional and vice versa. While participants with Form 6 went with one and opposed the other, participants with Form 7 opposed both information presentations.

Code 8: Inconsistent with IP 1 , Changed with IP 1 But Not IP 2. [R $1 \neq \mathrm{IP} 1=\mathrm{R} 2 \neq \mathrm{IP} 2 \neq \mathrm{R} 3]$

This code is similar to Form 5 where participants' initial frames were not consistent with the first information received but changed in the second response with the information presented. For example, they switched form dispositional explanation to situational explanation upon receiving situational information. Hence, they adopted a new frame (re-framing). Because the current frame was consistent with the previous information, the second information presentation would automatically be inconsistent with the current frame. Differ from Form 5, participants did not switch their frame/explanation to be consistent with the second information received. They remained the same as their second frame.

Code 9: Inconsistent with IP 1, Did Not Change with IP 1 But Changed With IP 2. $[\mathrm{R} 1 \neq \mathrm{IP} 1 \neq \mathrm{R} 2=\mathrm{IP} 2 \neq \mathrm{R} 3]$

This is similar to Form 8 with inconsistent initial frames compared to information received except that participants did not change in the second frame based in the information they received. For example, they begin with and stayed with dispositional explanation upon receiving situational information. Because the current frame is inconsistent with the previous information, the second information presentation would automatically be consistent with the current frame. Participants, however, changed their explanation on the third frame even when the information received was consistent with the second information presentation. For example, participants would switch from dispositional explanation to situational explanation upon receiving dispositional information. 


\section{Appendix D}

Earlier in this session, you were presented with the Production Dilemma scenario.

The CEO of your company, Brilliant Electronics Incorporated (BEI) recognizes that their Production Department is in trouble. Some people say that Andy Smith, a worker in the production department, is disrupting work and others argued that the fault lies with the many changes underway in the company not with any one person. Your job is to investigate and report to the CEO so he can resolve the problem.

\section{Instructions}

In the scenario, you were presented with information about Andy and about the changes in the Production Department. In the space provided below, write down as many pieces of information as you can remember. You can write them in any order with one piece of information on each line. If you need more lines use the back to continue.

1.

2.

3.

4.

5.

6.

7.

8.

9.

10.

11.

12.

13.

14.

15.

16.

17.

18.

19.

20. 
Earlier in this session, you were presented with the Westerly Foundation scenario.

You are an advisor for non-profit organizations. The Westerly Foundation is a non-profit organization that awards scholarships to college students. There is now a shortage of funding that might reduce next year's awards. Some people think the Director, Mr. Michael Smith, is not managing the funds well while others think that external factors and changes are the problem. Your job is to understand the situation and recommend actions.

\section{Instructions}

In the scenario, you were presented with information about Michael and about the external factors and changes in the foundation. In the space provided below, write down as many pieces of information as you can remember. You can write them in any order with one piece of information on each line. If you need more lines use the back to continue.

1.

2.

3.

4.

5.

6.

7.

8.

9.

10.

11.

12.

13.

14.

15.

16.

17.

18.

19.

20. 


\section{Appendix E}

\section{Coding System for Memory}

[If present, code ' 1 '; if absent, code ' 0 ']. Coding for this system is mutually exclusive for some codes, that is, an item that is coded ' 1 ' will have ' 0 ' for other codes. This is true within the Attributional codes and within the Confirming/Disconfirming codes. Coding between Attributional Codes and Confirming/Disconfirming codes are not mutually exclusive. That is for each statement you code for an Attributional code and a Confirming/Disconfirming code.

\section{Attributional Codes:}

Dispositional: Information that is related to internal attributes o a person such as personality, beliefs, feelings, physical attributes, etc.

- Dispositional [Target]: There is a target person in each story (WF: Michael Smith, PD: Andy Smith). This code is present when dispositional information is requested for the target person. [DT]

Example: "Michael did not have social skills," "Andy came late and took longer breaks," "Michael ran the company like business"

- Dispositional [Non-Target]: In each scenario there are other people that are non target person (WF: other directors and employees, PD: Chris and other employees). This code is present when dispositional information is requested for a non-target person. [DNT] Example: "The second director failed," "The old director was good with donors," "Some employees were not trained," "Chris was overwhelmed"

Situational: Information that is related to external factors of a person (i.e. events surrounding the person, industry and organizational information, economy, etc.). This code is present when situational information is requested. [S]

Example: "The change in economy," "The company hired a young business grad," "BEI took in new customer"

\section{Confirming/Disconfirming Codes:}

Confirming: Confirming information is information that is consistent and supports a current sense of a situation. This is operationalized as information that confirms a cause to be the problem.

Example: "Andy is a troublemaker" supports an individual to be the problem.

"The economy is facing a recession" supports the situation to be the problem.

Disconfirming: Disconfirming information is information that is inconsistent and can shift the current sense of a situation. This is operationalized as information that refutes a cause to be the problem.

Example: "Andy knows a lot about the production process" refutes an individual to be the problem.

"The management met with and explained the planned changes to production workers" refutes the situation to be the problem. 


\section{Appendix F}

Rate each item on the scale ranging from 1 to $7(1=$ strongly disagree, $7=$ strongly agree $)$.

\begin{tabular}{|ccccccc|}
\hline Strongly Disagree & & & \multicolumn{2}{c|}{ Strongly Agree } \\
1 & 2 & 3 & 4 & 5 & 6 & 7 \\
\hline
\end{tabular}

\begin{tabular}{|c|c|}
\hline 1. & An individual who is currently honest will stay honest in the future. \\
\hline 2. & $\begin{array}{l}\text { Any phenomenon has numerous numbers of causes, although some of the causes are } \\
\text { not known. }\end{array}$ \\
\hline 3. & Everything in the universe is somehow related to each other. \\
\hline 4. & $\begin{array}{l}\text { We should consider the situation a person is faced with, as well as his/her } \\
\text { personality, in order to understand one's behavior. }\end{array}$ \\
\hline 5. & Nothing is unrelated. \\
\hline 6. & A person who is currently living a successful life will continue to stay successful. \\
\hline 7. & $\begin{array}{l}\text { Any phenomenon entails a numerous number of consequences, although some of } \\
\text { them may not be known. }\end{array}$ \\
\hline 8. & $\begin{array}{l}\text { Even a small change in any element of the universe can lead to significant } \\
\text { alterations in other elements. }\end{array}$ \\
\hline 9. & The whole is greater than the sum of its parts. \\
\hline 10. & Future events are predictable based on present situations. \\
\hline 11. & $\begin{array}{l}\text { When disagreement exists among people, they should search for ways to } \\
\text { compromise and embrace everyone's opinions. }\end{array}$ \\
\hline 12. & Everything in the world is intertwined in a causal relationship. \\
\hline 13. & It is more desirable to take the middle ground than go to extremes. \\
\hline 14. & Current situations can change at any time. \\
\hline 15. & $\begin{array}{l}\text { The whole, rather than its parts, should be considered in order to understand a } \\
\text { phenomenon. }\end{array}$ \\
\hline 16. & It is not possible to understand the parts without considering the whole picture. \\
\hline 17. & $\begin{array}{l}\text { If an event is moving toward a certain direction, it will continue to move toward that } \\
\text { direction. }\end{array}$ \\
\hline 18. & Every phenomenon in the world moves in predictable directions. \\
\hline 19. & It is more important to pay attention to the whole than its parts. \\
\hline 20. & It is more important to pay attention to the whole context rather than the details. \\
\hline 21. & $\begin{array}{l}\text { It is desirable to be in harmony, rather than in discord, with others of different } \\
\text { opinions than one's own. }\end{array}$ \\
\hline 22. & Choosing a middle ground in an argument should be avoided. \\
\hline 23. & $\begin{array}{l}\text { It is important to find a point of compromise than to debate who is right/wrong, } \\
\text { when one's opinions conflict with other's opinions. }\end{array}$ \\
\hline 24. & We should avoid going to extremes. \\
\hline
\end{tabular}




\section{INSTRUCTIONS:}

\section{Appendix G}

For each of the statement below, please indicate to what extent the statement is characteristic of you by circling a number. If the statement is extremely uncharacteristics of you (not at all like you) please circle " 1 "; if the statement is extremely characteristics of you (very much like you) please circle " 5 ". Of course, a statement may be neither extremely uncharacteristics nor extremely characteristic of you; if so, please use the number in the middle of the scale that describes the best fit. Please keep the following scale in mind as you rate each of the statements below:

\begin{tabular}{|llccc}
\hline Extremely & Somewhat & Uncertain & Somewhat & Extremely \\
Uncharacteristics & Uncharacteristics & & Characteristic & Characteristic \\
1 & 2 & 3 & 4 & 5
\end{tabular}

1. I would prefer complex to simple problems.

$1 \quad 2 \quad 3 \quad 4 \quad 5$

2. I like to have the responsibility of handling a situation that requires a lot of thinking.
1
2
3
4

\section{5}

3. Thinking is not my idea of fun.

1

34

5

4. I would rather do something that requires little thought than something that is sure to challenge my thinking abilities.

$\begin{array}{lllll}1 & 2 & 3 & 4\end{array}$

5. I try to anticipate and avoid situations where there is likely a chance I will have to think in depth about something.

$\begin{array}{lllll}1 & 2 & 3 & 4 & 5\end{array}$

6. I find satisfaction in deliberating hard and for long hours.

7. I only think as hard as I have to.

$\begin{array}{ccccc}1 & 2 & 3 & 4 & 5\end{array}$

8. I prefer to think about small, daily projects to long-term ones.

$\begin{array}{ccccc}1 & 2 & 3 & 4\end{array}$

9. I like tasks that require little thought once I've heard them.

$\begin{array}{lllll}1 & 2 & 3 & 4 & 5\end{array}$

10. The idea of relying on thought to make my way to the top appeals to me.

11. I really enjoy a task that involves coming up with new solutions to problems.

$\begin{array}{lllll}1 & 2 & 3 & 4 & 5\end{array}$

12. Learning new ways to think doesn't excite me very much.

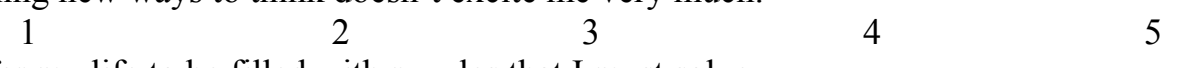

13. I prefer my life to be filled with puzzles that I must solve.

$1 \quad 203045$

14. The notion of thinking abstractly is appealing to me.
1
2
34
5

15. I would prefer a task that is intellectual, difficult, and important to one that is somewhat important but does not require much thought.
1
34
5

16. I feel relieve rather than satisfaction after completing a task that required a lot of mental effort.

$\begin{array}{llllll}1 & 2 & 3 & 4 & 5\end{array}$

17. It's enough for me that something gets the job done; I don't care how or why it works.

$\begin{array}{lllll}1 & 2 & 3 & 4 & 5\end{array}$

18. I usually end up deliberating about issues even when they do not affect me personally.

$\begin{array}{lllll}1 & 2 & 3 & 4 & 5\end{array}$ 


\section{Appendix $\mathrm{H}$}

Read each of the following statements and decide how much you would agree with each according to your attitudes, beliefs and experiences. Please respond according to the following scale, using only one number for each statement.

$1=$ Strongly disagree

$2=$ Moderately disagree

$3=$ Slightly disagree
$4=$ Slightly agree

$5=$ Moderately agree

$6=$ Strongly agree

\begin{tabular}{|c|c|c|c|c|c|c|c|}
\hline 1 & $\begin{array}{l}\text { In case of uncertainty, I prefer to make an immediate decision, } \\
\text { whatever it may be. }\end{array}$ & 1 & 2 & 3 & 4 & & \\
\hline 2 & $\begin{array}{l}\text { When I find myself facing various, potentially valid, alternatives, } \\
\text { I decide in favor of one of them quickly and without hesitation. }\end{array}$ & 1 & 2 & 3 & 4 & & 5 \\
\hline 3 & I never been late for work or for an appointment & 1 & 2 & 3 & 4 & & \\
\hline 4 & $\begin{array}{l}\text { I prefer to decide on the first available solution rather than to } \\
\text { ponder at length what decision I should make. }\end{array}$ & 1 & 2 & 3 & 4 & 5 & 5 \\
\hline 5 & I get very upset when things around me aren't in their place. & 1 & 2 & 3 & 4 & & \\
\hline 6 & $\begin{array}{l}\text { Generally, I avoid participating in discussions on ambiguous and } \\
\text { controversial problems. }\end{array}$ & 1 & 2 & 3 & 4 & & \\
\hline 7 & $\begin{array}{l}\text { When I need to confront a problem, I do not think about it too } \\
\text { much and I decide without hesitation }\end{array}$ & 1 & 2 & 3 & 4 & & 5 \\
\hline 8 & $\begin{array}{l}\text { When I need to solve a problem, I generally do not waste time in } \\
\text { considering diverse points of view about it. }\end{array}$ & 1 & 2 & 3 & 4 & & 5 \\
\hline 9 & $\begin{array}{l}\text { I prefer to be with people who have the same ideas and tastes as } \\
\text { myself. }\end{array}$ & 1 & 2 & 3 & 4 & & 5 \\
\hline 10 & $\begin{array}{l}\text { Generally, I do not search for alternative solutions to problems } \\
\text { for which I already have a solution available. }\end{array}$ & 1 & 2 & 3 & 4 & & \\
\hline 11 & $\begin{array}{l}\text { I feel uncomfortable when I do not manage to give a quick } \\
\text { response to problems that I face. }\end{array}$ & 1 & 2 & 3 & 4 & & 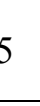 \\
\hline 12 & I have never hurt another person's feelings & 1 & 2 & 3 & 4 & & \\
\hline 13 & $\begin{array}{l}\text { Any solution to a problem is better than remaining in a state of } \\
\text { uncertainty. }\end{array}$ & 1 & 2 & 3 & 4 & & 5 \\
\hline 14 & $\begin{array}{l}\text { I prefer activities where it is always clear what is to be done and } \\
\text { how it need to be done. }\end{array}$ & 1 & 2 & 3 & 4 & & 5 \\
\hline 15 & $\begin{array}{l}\text { After having found a solution to a problem I believe that it is a } \\
\text { waste of time to take into account diverse possible solutions. }\end{array}$ & 1 & 2 & 3 & 4 & & 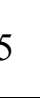 \\
\hline 16 & $\begin{array}{l}\text { I prefer things that I am used to over those I do not know, and } \\
\text { cannot predict. }\end{array}$ & 1 & 2 & 3 & 4 & & 5 \\
\hline
\end{tabular}




\section{Appendix I}

\section{INSTRUCTIONS:}

Please do not spend too much time on the following items. There are no right or wrong answers and therefore your first response is important. Circle your answers and please be sure to answer every question.

\begin{tabular}{|c|c|c|}
\hline 1. A problem has little attraction for me if I don't think it has a solution. & True & False \\
\hline $\begin{array}{l}\text { 2. I am just a little uncomfortable with people unless I feel that I can } \\
\text { understand their behavior. }\end{array}$ & True & False \\
\hline 3. There's a right way and a wrong way to do almost everything. & True & False \\
\hline 4. I would rather bet 1 to 6 on a long shot than 3 to 1 on a probable winner. & True & False \\
\hline $\begin{array}{l}\text { 5. The way to understand complex problems is to be concerned with their } \\
\text { larger aspects instead of breaking them into smaller pieces. }\end{array}$ & True & False \\
\hline $\begin{array}{l}\text { 6. I get pretty anxious when I'm in a social situation over which I have no } \\
\text { control. }\end{array}$ & True & False \\
\hline 7. Practically every problem has a solution. & True & False \\
\hline 8. It bothers me when I am unable to follow another person's train of thought. & True & False \\
\hline 9. I have always felt that there is a clear difference between right and wrong. & True & False \\
\hline 10. It bothers me when I don't know how other people react to me. & True & False \\
\hline $\begin{array}{l}\text { 11. Nothing gets accomplished in this world unless you stick to some basic } \\
\text { rules. }\end{array}$ & True & False \\
\hline $\begin{array}{l}\text { 12. If I were a doctor, I would prefer the uncertainties of a psychiatrist to the } \\
\text { clear and definite work of someone like a surgeon or X-ray specialist. }\end{array}$ & True & False \\
\hline 13. Vague and impressionistic pictures really have little appeal for me. & True & False \\
\hline $\begin{array}{l}\text { 14. If I were a scientist, it would bother me that my work would never be } \\
\text { completed (because science will always make new discoveries). }\end{array}$ & True & False \\
\hline $\begin{array}{l}\text { 15. Before an examination, I feel much less anxious if I know how many } \\
\text { questions there will be. }\end{array}$ & True & False \\
\hline 16. The best part of working a jigsaw puzzle is putting in the last piece. & True & False \\
\hline $\begin{array}{l}\text { 17. Sometimes I rather enjoy going against the rules and doing things I'm not } \\
\text { supposed to do. }\end{array}$ & True & False \\
\hline $\begin{array}{l}\text { 18. I don't like to work on a problem unless there is a possibility of coming } \\
\text { out with a clear-cut and unambiguous answers. }\end{array}$ & True & False \\
\hline $\begin{array}{l}\text { 19. I like to fool around with new ideas, even if they turn out later to be a total } \\
\text { waste of time. }\end{array}$ & True & False \\
\hline 20. Perfect balance is the essence of all good composition. & True & False \\
\hline
\end{tabular}


Appendix $\mathbf{J}$

\section{Information Sheet}
1. Age:
Years
2. Gender:
Male
Female
3. Place of Birth
4. Place of childhood (0-18 years old) years: Urban
Suburban
Other:
3. Academic major:
4. Grade point average (High School)
5. Grade point average (College)
6. Your year in school:
Year 1 (Freshman)
Year 2 (Sophomore)
Year 3 (Junior)
Year 4 (Senior)

(City, State, Country)

Rural

7. Nationality/Ethnic/Cultural background: Please circle

(1) African American (2) Caucasian American (3) Asian American (4) Native American

(5) Hispanic American (6) Other:

List the job(s) you previously and currently have, beginning with the most current.

\begin{tabular}{|l|l|l|l|}
\hline 1. & Job Title & Hours work per week & Duration \\
\hline 2. & & & \\
\hline 3. & & & \\
\hline 4. & & & \\
\hline 5. & & & \\
\hline
\end{tabular}

Thank you for your help 


\section{References}

Aiken, L. S., \& West, S. G. (1991). Multiple regression: Testing and interpreting interactions. Newbury Park, CA: Sage.

Anderson, M. H. (2002). The effects of individuals' social network characteristics and information processing characteristics on their sensemaking of complex, ambiguous issues. Dissertation Abstracts International Section A: Humanities and Social Sciences. Vol 62 (12-A), 4240.

Berry, J.W. (1986). The comparative study of cognitive abilities: A summary. In S. E. Newstead, S. H. Irvine \& P. L. Dann (Eds.), Human assessment: Cognition and motivation (pp. 57-74). Dordrecht, Netherlands: Martinus Nijholt.

Berry, J. W. (1976). Human ecology and cognitive style: Comparative studies in cultural and psychological adaptation. NY: Sage.

Berzonsky, M. D., \& Sullivan, C. (1992). Social-cognitive aspects of identity style: Need for cognition, experiential openness, and introspection. Journal of Adolescent Research, 7, 140-155.

Bhagat, R. S., Harveston, P. D., \& Triandis, H. C. (2002). Cultural variations in the crossborder transfer of organizational knowledge: An integrative framework. Academy of Management Review, 27, 204-221.

Bhawuk, D. P. S. (2001). Evolution of culture assimilators: Toward theory-based assimilators. International Journal of Intercultural Relations, 25, 141-163.

Bliese, P. D., \& Ployhart, E. (2002). Growth modeling using random coefficient models: Model building, testing, and illustration. Organizational Research Methods, 5, 362387. 
Cacioppo, J. T., \& Petty, R. E. (1982). The need for cognition. Journal of Personality and Social Psychology, 42, 116-131.

Cacioppo, J. T., Petty, R. E., Feinstein, J. A., \& Jarvis, W. B. G. (1996). Dispositional differences in cognitive motivation: The life and times of individuals varying in need for cognition. Psychological Bulletin, 119, 197-253.

Cacioppo, J. T., Petty, R. E., \& Kao, C. F. (1984). The efficient assessment of need for cognition. Journal of Personality Assessment, 48, 306-307.

Chiu, C., Morris, M., Hong, Y., \& Menon, T. (2000). Motivated cultural cognition: The impact of implicit cultural theories on dispositional attribution varies as a function of need for closure. Journal of Personality and Social Psychology, 78, 247-259.

Choo, C. W. (1998a). The Knowing Organization: How organizations use information to construct meaning, create knowledge, and make decisions. NY: Oxford University Press.

Choo, C. W. (1998b). Information management for the intelligent organization (2ed.). Medford, NJ: Information Today, Inc.

Choi, I., Choi, J. A., \& Norenzayan, A. (2004). Culture and decisions. In D.J. Koehler and N. Harvey (Eds.), Blackwell handbook of judgment and decision making (pp. 504-524). Malden, MA: Blackwell.

Choi, I., Dalal, R., Kim-Prieto, C., \& Park, H. (2003). Culture and judgment of causal relevance. Journal of Personality and Social Psychology, 84, 46-59.

Choi., I, Koo, M., \& Choi, J. (2007). Individual differences in analytic versus holistic thinking. Personality and Social Psychology Bulletin, 33, 691-705 
Choi, I., \& Nisbett, R. E. (2000). Cultural psychology of surprise: Holistic theories and recognition of contradiction. Journal of Personality and Social Psychology, 79, 890-905.

Choi, I., \& Nisbett, R. E. (1998). Situational salience and cultural differences in the correspondence bias and actor-observer bias. Personality and Social Psychology Bulletin, 24, 949-960.

Choi, I., Nisbett, R. E., \& Norenzayan, A. (1999). Causal attribution across cultures: Variation and universality. Psychological Bulletin, 125, 47-63.

Chu, P., Spires, E., \& Sueyoshi, T. (1999). Cross-cultural differences in choice behavior and use of decision aids: A comparison of Japan and the United States. Organizational Behavior and Human Decision Processes, 77, 147-170

Cohen, W. M., \& Levinthal, A. (1990). Absorptive capacity: A new perspective on learning and innovation. Administrative Science Quarterly, 35, 128-152.

Cromer, A. (1993). Uncommon sense: The heretical nature of science. NY: Oxford University Press.

Daft, R. L., \& Weick, K. E. (1984). Toward a model of organizations as interpretation systems. Academy of Management Review, 9, 284-295.

Davenport, T. H. \& Prusak, L. (1998). Working knowledge. Boston: Harvard Business School Press.

Dobbins, G. H., Lane, I. M., \& Steiner, D. D. (1988). A note on the role of laboratory methodologies in applied behavioural research: Don't throw out the baby with the bath water. Journal of Organizational Behavior, 9, 281-286. 
Fernald, A., \& Morikawa, H. (1993). Common themes and cultural variations in Japanese and Americans mother's speech to infants. Child Development, 64, 637 - 656.

Festinger, L. (1957). A theory of cognitive dissonance. Stanford University Press.

Fiske, S. T., \& Taylor, S. E. (1993). Social cognition. NY: McGraw-Hill.

Gelfand, M. J., Sputlock, D., Sniezek, J. A., \& Shao, L. (2000). Culture and social prediction: The role of information in enhancing confidence in social prediction in the United States and China. Journal of Cross-cultural Psychology, 31, 498-516.

Gilbert, D. T., \& Malone, P. S. (1995). The correspondence bias. Psychological Bulletin, 117, 21-38.

Gilbert, D. T., Pelham, B. W., \& Krull, D. S. (1988). On cognitive business: When person perceivers meet persons perceived. Journal of Personality and Social Psychology, 54, 733-740.

Hall, E. T., \& Hall, M. R. (1990). Understanding cultural differences. Yarmouth, ME: Intercultural Press.

Hambrick, D. C. (1981). Specialization of environmental scanning activities among upper level executives. Journal of Management Studies, 18, 299-320.

Hambrick, D. C. (1982). Environmental scanning and organizational strategy. Strategic Management Journal, 3, 159-174.

Hayes, J., \& Allinson, C. W. (1994). Cognitive style and its relevance for management practice. British journal of Management, 5, 53-71.

Hayes, J., \& Allinson, C. W. (1998). Cognitive style and the theory and practice of individual and collective learning in organizations. Human Relations, 51, 847-871. 
Heaton, A. W., \& Kruglanski, W. (1991). Person perception by introverts and extraverts under time pressure: Effects of need for closure. Personality and Social Psychology Bulletin, 17, 161-165.

Hedden, T., Ketay, S., Aron, A., Markus, H. R., \& Gabrieli, J. D. E. (2008). Cultural influences on neural substrates of attentional control. Psychological Science, 19, 1217.

Heider, F. (1958). The psychology of interpersonal relations. NY: Wiley.

Helmrich, R. L. \& Merritt, A. C. (1998). Culture at work in aviation and medicine. Aldershot, VT: Ashgate.

Hiniker, P. J. (1969). Chinese reactions to forced compliance: Dissonance reduction or national character. Journal of Social Psychology, 77, 157-176.

Hinsz, V. B. (1995). Mental models of groups as social systems: Considerations of specification and assessment. Small Group Research, 26, 200-233.

Hofstede, G. (1980). Culture's consequences: International differences in work-related values. Beverly Hills, CA: Sage

Hong, Y.-Y., Morris, M. W., Chiu, C.-Y., \& Veronica, B.,-M. (2000). Multicultural Minds: A dynamic constructivist approach to culture and cognition. American Psychologist, 55, 709-720.

Huber, G. P. (1991). Organizational learning: The contributing processes and the literatures. Organization Science, 2, 88-115.

Hutchins, E. (1995). Cognition in the wild. Cambridge, MA: The MIT Press. 
Jones, E. E., \& Davis, K. E. (1965). From acts to disposition: The attribution process in person perception. In Berkowitz (Ed.), Advances in experimental social psychology (Vol.2). NY: Academic Press.

Jones, J. W., \& MacLeod, R. (1986). The structure of executive information systems: An exploratory analysis. Decision Sciences, 17, 220-249.

Kagitcibasi, C. (1997). Individualism and collectivism. In J. W. Berry, M. H. Segall, \& C. Kagitcibasi (Eds.), Handbook of cross-cultural psychology, Vol. 3 (pp. 1-50). Needham Heights, MA: Allyn \& Bacon.

Kelley, H. H. (1967). Attribution theory in social psychology. Nebraska Symposium on Motivation, 15, 192-238.

Klein, G., Phillips, J. K., Rall, E. L., \& Peluso, D. A. (2007). A data/frame theory of sensemaking. In R.R. Hoffman (Ed.), Expertise out of context (pp. 113-155). Mahwah, NJ: Lawrence Erlbaum Associates.

Klein, H. A. (2004). Cognition in natural settings: The cultural lens model. In M. Kaplan (Ed.), Cultural ergonomics: Advances in human performance and cognitive engineering (pp. 249-280). Oxford: Elsevier.

Klein, H. A., Lin, M., Radford, M., Masuda, T., Choi, I., Lien, Y-W., Yeh, Y-Y., \& Chu, C. (2006). The Rosetta Project: Measuring national differences. Technical Report prepared for the Air Force Research Laboratory/Human Effectiveness, Dayton, Ohio and AOARD, Tokyo, Japan.

Kitayama, S., Duffy, S., Kawamura, T., \& Larsen, J. T. (2003). Perceiving an objects and its context in different cultures: A cultural look at New Look. Psychological Science, 14, 201-206. 
Klimoski, R., \& Mohammed, S. (1994). Team mental model: Construct or metaphor? Journal of Management, 20, 403-437.

Knowles, E. D., Morris, M. W., Chiu, C., \& Hong, Y. (2001). Culture and the process of person perception: Evidence for automaticity among East Asians in correcting for situational influences on behavior. Personality and Social Psychology Bulletin, 27, 1344-1356.

Koppes, L. L., \& Billings, R. S. (1988). A schematic perspective on problem identification. In R. L. Cardy, S. M. Puffer, \& J. M. Newman (Eds.), Advances in information processing in organizations (pp. 155-168). Greenwich, CT: JAI Press.

Kruglanski, A. W., \& Freund, T. (1983). The freezing and unfreezing of lay-inferences: Effects on impressional primacy, ethnic stereotyping, and numerical anchoring. Journal of Experimental Social Psychology, 19, 448-468.

Lane, H., DiStefano, J., \& Maznevski, M. (1996). International management behavior (3rd ed.). Cambridge, MA: Blackwell.

Lane, H., \& DiStefano, J. (1992). International management behavior: From policy to practice. Boston: PWS-Kent.

Lewin , K. (1935). Dynamic theory of personality. NY: McGraw Hill.

Lin, M. (2004). The role of analytic-holistic thinking on sensemaking. Unpublished master's thesis, Wright State University, Dayton, Ohio.

Lin, M. \& Klein, H. A. (2008). Athletes, murderers, and a Chinese farmer: Cultural perspectives on sensemaking. In J. M. C Schraagen, L. Militello, T. Ormerod, \& R. Lipshitz (Eds.), Naturalistic decision making and macrocognition (pp. 159-181). Aldershot, United Kingdom: Ashgate. 
Lin, M., Klein, H. A., Radford, M. H. B, Choi, I., \& Lien, Y-W. (April, 2007). Cultural differences in information relevance: Implications for multinational teamwork. Poster presented at the 22nd Annual Conference of The Society for Industrial and Organizational Psychology, New York, NY, April 2007.

Lloyd, G. E. R. (1991). The invention of nature. In G. E. R. Lloyd (Ed.), Methods and problems in Greek science (pp. 417-434). Cambridge, UK: Cambridge University Press.

MacDonald, A. P. (1970). Revised scale for ambiguity tolerance: Reliability and validity. Psychological Reports, Vol. 26, 791-798.

Markus, H. R., \& Kitayama, S. (1991). Culture and the self: Implications for cognition, emotion, and motivation. Psychological Review, 98, 224-253.

Markus, H. R., Kitayama, S., \& Heiman, R. J. (1996). Culture and basic psychological principles. In E. T. Higgins, \& A. W. Kruglanski (Eds.). Social psychology: Handbook of basic principles (pp. 857-915). NY: Guilford Press.

Markus, H. R., Uchida, Y., Omoregie, H., Townsend, S. S. M., \& Kitayama, S. (2006). Going for the gold. Psychological Science 17, 103-112.

Masuda, T., Ellsworth, P. C., Mesquita, B., Leu, J., Tanida, S., \& Van de Veerdonk, E. (2008). "Placing the face in context: Cultural differences in the perception of facial emotion." Journal of Personality and Social Psychology, 94: 365-381.

Masuda, T., \& Nisbett, R. E. (2001). Attending holistically versus analytically: Comparing the context sensitivity of Japanese and Americans. Journal of Personality and Social Psychology, 81, 922-934. 
Masuda, T., \& Nisbett, R. E. (2006). Culture and change blindness. Cognitive Science, 30, 381-399.

Miller, J. G. (1984). Culture and the development of everyday social explanation. Journal of Personality and Social Psychology, 46, 961-978.

Milliken, F. J. (1990). Perceiving and interpreting environmental change: An examination of college administrators' interpretation of changing demographics. Academy of Management Journal, 33, 42-63.

Minsky, M. (1975). A framework for representing knowledge. In P. Winston (Ed.), The psychology of computer vision (pp. 211-277). New York, NY: McGraw-Hill.

Miyamoto, Y., Nisbett, R. E., \& Masuda, T. (2006). Culture and the physical environment: Holistic versus analytic perceptual affordances. Psychological Science, 17, 113-119.

Morris, M., \& Peng, K. (1994). Culture and cause: American and Chinese attributions for social and physical events. Journal of Personality and Social Psychology, 67, 949971.

Nakamura, H. (1985). Ways of thinking of eastern people. Honolulu: University of Hawaii Press.

Nisbett, R. E. (2003). The geography of thought: How Asians and Westerners think differently... and why. NY: The Free Press.

Nisbett, R. E., Choi, I., Peng, K., \& Norenzayan, A. (2001). Culture and system of thoughts: Holistic versus analytic cognition. Psychological Review, 108, 291-310.

Norenzayan, A., Smith, E. E., Kim, B. J., \& Nisbett, R. E. (2002). Cultural preferences for formal versus intuitive reasoning. Cognitive Science, 26, 653-684. 
Orasanu, J., \& Salas, E. (1993). Team decision making in complex environment. In G. Klein, J. Orasanu, R. Calderwood, \& C. E. Zsambok (Eds.), Decision making in action: models and methods (pp. 327-346). Norwood, NJ: Ablex.

O'Reilly, C. A. (1980). Individuals and information overload in organizations: is more necessarily better? Academy of Management Journal. 23, 684-696.

O'Reilly, C. A. (1983). The use of information in organizational decision making: A model and some propositions. Research in Organizational Behavior, 5, 103-139.

Peng, K., \& Nisbett, R. E. (1999). Culture, dialectics, and reasoning about contradiction. American Psychologist, 54, 741-754.

Petty, R. E., \& Jarvis, W. B. G. (1996). An individual differences perspective on assessing cognitive processes. In N. Schwarz, \& S. Sudman (Eds.), Answering questions: Methodology for determining cognitive and communicative processes in survey research (pp. 221-257). San Francisco, CA: Jossey-Bass.

Pierro, A., \& Kruglanski, A. W. (2005). Revised Need for Cognitive Closure Scale. Unpublished manuscript. Università di Roma, "La Sapienza".

Ross, L. D., Amabile, T. M., \& Steinmetz, J. L. (1977). Social roles, social control, and biases in social-perception processes. Journal of Personality and Social Psychology, 35, 485-494.

Strohschneider, S., \& Guss, D. (1999). The fate of the MOROS: A cross-cultural exploration of strategies in complex and dynamic decision making. International Journal of Psychology, 34, 235-252. 
Tetlock, P. E. (1992). The impact of accountability on judgment and choice: Toward a social contingency model. M. P. Zanna (Ed.) Advances in experimental social psychology, Vol. 25 (pp. 331-376). San Diego, CA: Academic Press.

Thomas, J. B., Clarke, S. M., \& Gioia, D. A. (1993). Strategic sensemaking and organizational performance: Linkages among scanning, interpretation, action and outcomes. Academy of Management Journal, 36, 239-270.

Thomas, J. B., Gioia, D. A., \& Ketchen, D. J. (1997). Strategic sense-making: Learning through scanning, interpretation, action and performance. Advances in Strategic Management, 14, 299-329.

Thomas, J. B., Shankster, L. J., \& Mathieu, J. E. (1994). Antecedents to organizational issue interpretation: The roles of single-level, cross-level, and content cues. Academy of Management Journal, 37, 1252-1284.

Triandis, H. C. (1995). Individualism and collectivism. Boulder, CO: Westview.

Triandis, H. C., Hall, E. R., \& Ewan, R. B. (1965). Member heterogeneity and dyadic creativity. Human Relations, 18, 33-55.

Van Boven, L., Kamada, A., \& Gilovich, T. (1999). The perceiver as perceived: Everyday intuitions about the correspondence bias. Journal of Personality and Social Psychology, 77, 1188-1199.

Venkatraman, M. P., Marlino, D., Kardes, F. R., \& Sklar, K. B. (1990). The interactive effects of message appeal and individual differences on information processing and persuasion. Psychology \& Marketing, 7, 85-96.

Weary, G., \& Edwards, A. (1994). Individual differences in causal uncertainty. Journal of Personality and Social Psychology, 67, 308-318. 
Webster, D. M., (1993). Motivated augmentation and reduction of the overattribution bias. Journal of Personality and Social Psychology, 65, 261-271.

Webster, D. M., \& Kruglanski, W. (1994). Individual differences in need for cognitive closure. Journal of Personality and Social Psychology, 67, 1049-1062.

Weick, K. E. (1979). The social psychology of organizing ( $2^{\text {nd }}$ ed.). Reading, MA: Addison-Wesley.

Weick, K. E. (1995). Sensemaking in organizations. Thousand Oaks, CA: Sage Publications.

Weick, K. E., Sutcliffe, K. M., \& Obstfeld, D. (2005). Organizing and the process of sensemaking. Organization Science, 16, 409-421.

Wiley, J. (2004). A fair and balanced look at the news: What affects memory for controversial arguments? Journal of Memory and Language, 53, 95-109.

Winter, L., \& Uleman, J. S. (1984). When are social judgment made? Evidence for the spontaneousness of trait inference. Journal of Personality and Social Psychology, 47, 237-252.

Winter, L., \& Uleman, J. S., \& Cunniff, C. (1985). How automatic are social judgments? Journal of Personality and Social Psychology, 49, 904-917.

Witkin, H. A., Lewis, H. B., Hertzman, M., Machover, K., Meissner, P. B., \& Karp, S. A. (1954). Personality through perception. NY: Harper. 